\title{
ANÁLISE DO PERFIL DE AQUISIÇÃO DOMICILIAR DE MEDICAMENTOS NO BRASIL A PARTIR DOS DADOS DA PESQUISA DE ORÇAMENTOS FAMILIARES 2008-2009
}

Dissertação de Mestrado apresentada ao Programa de Pós-Graduação em Ciências Farmacêuticas da Faculdade de Ciências da Saúde, Universidade de Brasília, como requisito parcial à obtenção do Título de Mestre em Ciências Farmacêuticas.

Orientadora: Profa. Dra. Eloísa Dutra Caldas Co-orientador: Prof. Dr. Maurício Homem de Mello

\section{Brasília - DF}


Autorizo a reprodução e divulgação total ou parcial deste trabalho, por qualquer meio convencional ou eletrônico, para fins de ensino, estudo ou pesquisa, desde que citada a fonte.

Catalogação da Publicação

Ficha catalográfica elaborada pela Biblioteca Central da Universidade de Brasília. Acervo 1018308.

Goes, Fernanda Carol ine Silva.

G598a Análise do perfil de aquisição domiciliar de medicamentos no Brasil a partir dos dados da Pesquisa de Orçamentos Familiares 2008-2009 / Fernanda Carol ine Silva Goes. -- 2014. xi i, $108 \mathrm{f} .:$ il. ; $30 \mathrm{~cm}$.

Dissertação (mestrado) - Universidade de Brasília, Faculdade de Ciências da Saúde, Programa de Pós-Graduação em Ciências Farmacêuticas, 2014.

Inclui bibliografia.

Or ientação: Eloísa Dutra Caldas ; Coorientação: Mauricio Homem de Mel Io.

1. Medicamentos - Utilização - Brasil. 2. Consumidores. 3. Levantamentos domiciliares. I. Caldas, Eloísa Dutra. II. Mello, Mauricio Homem de. III. Título. 
FERNANDA CAROLINE SILVA GOES

\section{ANÁLISE DO PERFIL DE AQUISIÇÃO DOMICILIAR DE MEDICAMENTOS NO BRASIL A PARTIR DOS DADOS DA PESQUISA DE ORÇAMENTOS FAMILIARES 2008-2009}

Dissertação de Mestrado apresentada ao Programa de Pós-Graduação em Ciências Farmacêuticas da Faculdade de Ciências da Saúde, Universidade de Brasília, como requisito parcial à obtenção do Título de Mestre em Ciências Farmacêuticas.

Aprovada em 20 de outubro de 2014.

\section{BANCA EXAMINADORA}

PRESIDENTE

Profa. Dra. Eloísa Dutra Caldas

Membro Interno do Programa

Universidade de Brasília

MEMBROS:

Profa. Dra. Janeth de Oliveira Silva Naves

Membro Interno do Programa

Universidade de Brasília

Profa. Dra. Lia Lusitana Cardozo de Castro

Membro Externo do Programa

Universidade Federal do Mato Grosso do Sul

\section{SUPLENTE:}

Prof. Dr. Maria Inês de Toledo

Membro Externo do Programa

Universidade de Brasília 


\section{AGRADECIMENTOS}

À Deus, pela presença constante em minha vida e fonte de força em todos os momentos.

À minha família, especialmente aos meus pais Valéria e Gilson, ao meu irmão Fabrício e à minha tia Peta por todo amor, carinho e apoio incondicional.

Aos meus avós, em especial, Ritinha (in memoriam) e Aristides (in memoriam), minhas fontes de inspiração.

Ao meu marido Tiago, pelo amor, companheirismo, paciência, auxílio e conforto, em especial, nos momentos mais difíceis.

Aos meus sogros Tânia e Expedito pelo grande incentivo, carinho e amor.

À professora Eloísa, pela amizade, orientação, paciência e compreensão, por ter me proporcionado a realização desse projeto.

Ao professor Maurício pela orientação e confiança no meu trabalho.

À Universidade de Brasília e ao Programa de Pós-Graduação em Ciências Farmacêutica

À Coordenação de Aperfeiçoamento de Pessoal de Nível Superior (CAPES) pelo apoio recebido.

À equipe do Laboratório de Toxicologia da Universidade de Brasília pelo auxílio e companheirismo, em especial, à Patrícia, Mariana, Denise, Alessandra, Érica e Jéssica.

Aos colegas do LACEN/DF, em especial, Leonardo Machado e Analda Lima pelo apoio e amizade.

À todos os amigos e amigas que de alguma forma contribuíram para esse projeto. 
"Feliz o homem que acha sabedoria e o homem que adquire conhecimento". (Provérbios 3:13) 


\section{SUMÁRIO}

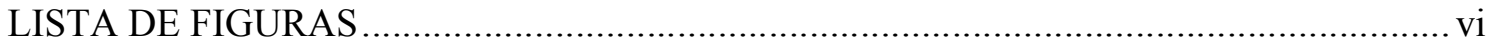

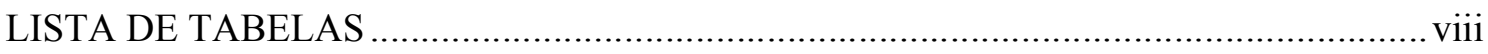

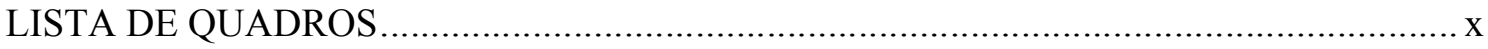

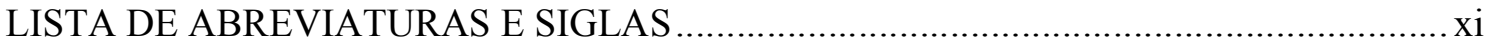

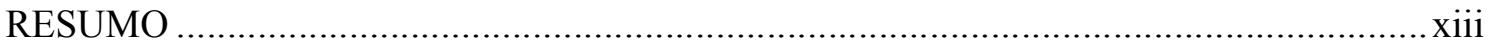

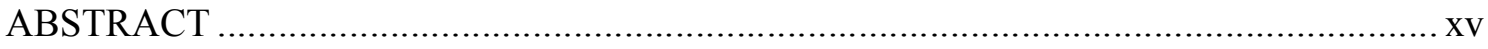

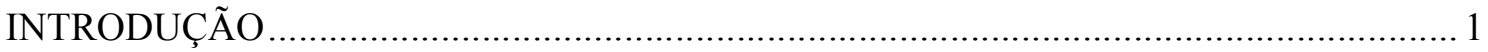

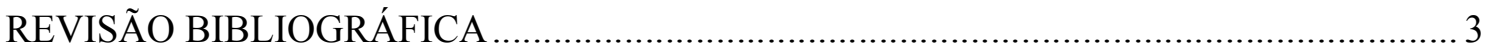

1. USO DE MEDICAMENTOS E PREJUÍZO À SAÚDE ........................................... 3

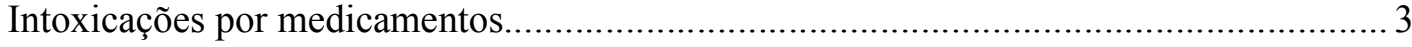

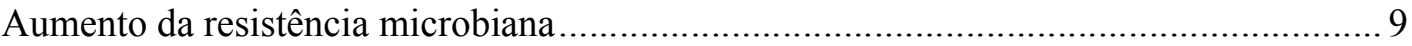

2. GASTOS COM SAÚDE E MEDICAMENTOS ........................................................ 11

3. ESTUDOS DE UTILIZAÇÃO DE MEDICAMENTOS ........................................... 14

Estudos de utilização de medicamentos no Brasil .......................................................... 14

Estudos de utilização de medicamentos em outros países ......................................... 22

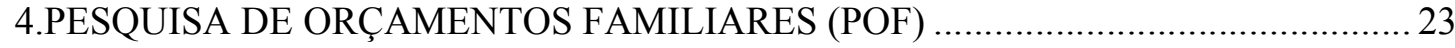

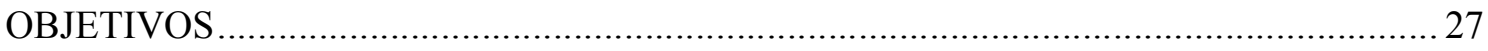

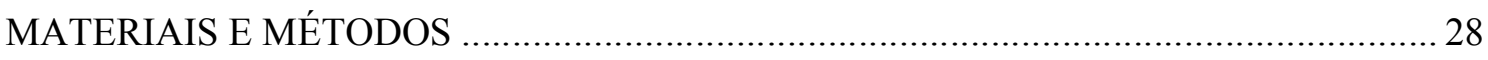

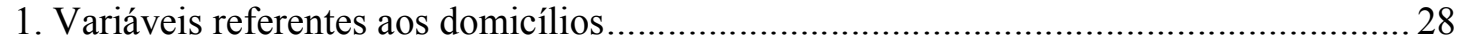

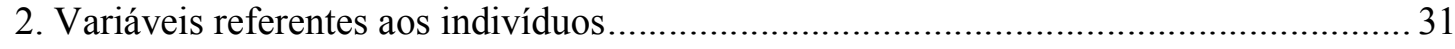

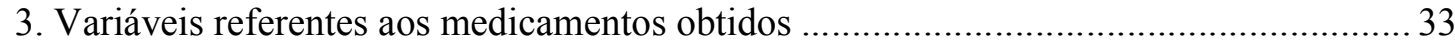

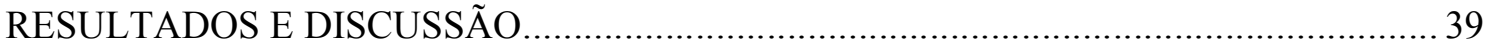

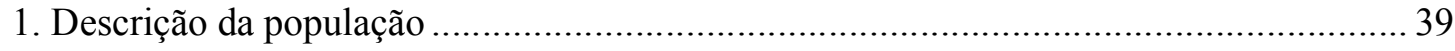

2. Aquisição de medicamentos e variáveis socioeconômicas....................................... 45

3. Acesso e característica dos medicamentos adquiridos ........................................... 48

3.1. Medicamentos obtidos por doação - Sistema Único de Saúde (SUS)..................... 54

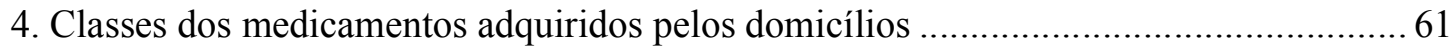

5. Disponibilidade de medicamentos no domicílio e intoxicação...................................... 65

6. Classe ATC do medicamento adquirido e características dos domicílios e sua população

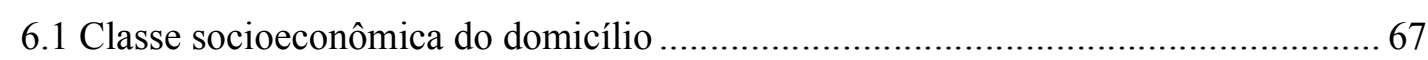

6.2. Condições sanitárias e localização do domicílio e aquisição de álcool e fumo ........ 72 
6.3. Características da população residente............................................................... 76

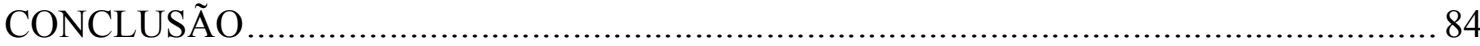

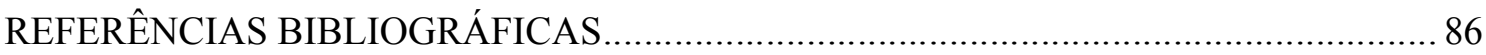

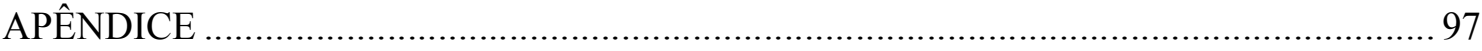

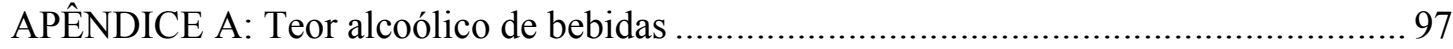

APÊNDICE B: Classificação das respostas relativas a medicamentos............................ 102 


\section{LISTA DE FIGURAS}

Figura 1: Número de intoxicações registradas no Brasil pelo SINITOX, entre 1999 e 2011, por

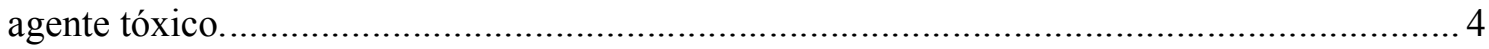

Figura 2: Circunstâncias de intoxicação por medicamentos no Brasil de 1999 a 2011 registradas pelo SINITOX.

Figura 3: Casos de intoxicação exógena por agente tóxico no Brasil registrados pelo SINAN de 2007 a 2012

Figura 4: Circunstâncias de intoxicação por medicamentos no Brasil de 2007 a 2012 registradas no SINAN

Figura 5: Circunstâncias de intoxicação por medicamentos registradas no SINAN de 2007 a 2012, por faixa etária.

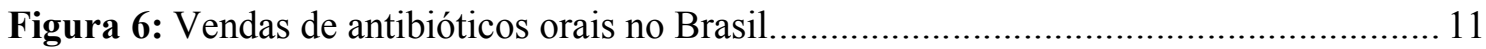

Figura 7: Questionário POF 4 da Pesquisa de Orçamentos Familiares 2008-2009 .............. 26

Figura 8: Percentual de domicílios que relataram a aquisição de pelo menos um medicamento no período recordatório de 30 dias no Brasil, nas regiões urbana e rural e nas macrorregiões brasileiras. (\% em relação aos valores expandidos)

Figura 9: Percentual de domicílios entrevistados que relataram a aquisição de pelo menos um medicamento, no período recordatório de 30 dias, por unidade federativa.

Figura 10: Diagnóstico nutricional da população residente em domicílios em que houve relato de obtenção de algum medicamento e da população residente em domicílios em que não houve obtenção de algum medicamento, por faixa etária. 44

Figura 11: Número de medicamentos obtidos por pessoa no Brasil, nas regiões urbana e rural e nas macrorregiões brasileiras

Figura 12: Percentual de domicílios que adquiriram algum medicamento versus a renda per capta média das classes econômicas sob estudo (A1, A2, B1, B2, C1, C2, D, E). Renda em reais.

Figura 13: Número de medicamentos por 100 habitantes versus a renda per capta média das classes econômicas sob estudo (A1, A2, B1, B2, C1, C2, D, E). Renda em reais. 48

Figura 14: Percentual de domicílios em que houve relato de obtenção de medicamentos genéricos no Brasil, em regiões urbana e rural e nas macrorregiões brasileiras.

Figura 15: Características dos medicamentos adquiridos no Brasil, por classe econômica dos domicílios onde os medicamentos foram obtidos.

50

Figura 16: Número de medicamentos adquiridos por 10 habitantes e percentual de habitantes que tiveram necessidade de algum medicamento, mas não tiveram acesso ao(s) medicamento(s) necessário(s), por falta de dinheiro no Brasil, por regiões urbana e rural e nas macrorregiões brasileiras. 52

Figura 17: Percentual de domicílios em que pelo menos um morador é filiado a plano de saúde considerando-se o grupo de domicílios em que houve obtenção de medicamentos e o grupo de domicílios em que não houve obtenção de medicamento, no Brasil, nas regiões urbana e rural e nas macrorregiões brasileiras. 53 Figura 18: Percentual de indivíduos filiados a plano de saúde considerando-se o grupo de domicílios em que houve obtenção de medicamentos e o grupo de domicílios em que não houve obtenção de medicamento, no Brasil, nas regiões urbana e rural e nas macrorregiões brasileiras. 
Figura 19: Proporção de medicamentos obtidos por meio de recurso próprios, obtidos por doação e por outras formas de acesso de acordo com a classe econômica no Brasil. 55

Figura 20: Local de aquisição dos medicamentos obtidos por meio de doação no Brasil, nas macrorregiões brasileiras e por região urbana e rural.

Figura 21: Percentual de domicílios que obtiveram algum medicamento por meio do SUS, no Brasil, nas regiões urbana e rural e nas macrorregiões brasileiras.

Figura 22: Percentual de domicílios dentro de cada classe econômica que receberam pelo menos um medicamento do SUS no Brasil, nas regiões urbana e rural e nas macrorregiões brasileiras. 58

Figura 23: Aquisição de medicamentos por 1000 habitantes no Brasil, nas regiões urbana e rural e nas macrorregiões brasileiras. 64

Figura 24: Principais classes de medicamentos presentes em domicílios que possuem crianças menores de cinco anos, de acordo com o segundo nível de classificação ATC.

Figura 25: Número de medicamentos obtidos por 1000 habitantes dentro de cada classe social, segundo o primeiro nível da classificação ATC. 69

Figura 26: Número de medicamentos obtidos por 1000 habitantes dentro de cada classe social, segundo o primeiro nível da classificação ATC.

Figura 27: Número de medicamentos por 1.000 habitantes dentro de cada classe social, de acordo com o segundo nível da classificação ATC 70

Figura 28: Número de medicamentos por 1.000 habitantes dentro de cada classe social, de acordo com o segundo nível da classificação ATC. 71 


\section{LISTA DE TABELAS}

Tabela 1: Casos, óbitos e letalidade de intoxicação por medicamentos registrados pelo SINITOX, segundo faixa etária. Brasil, 1999 a 2011.

Tabela 2: Casos, óbitos e letalidade de intoxicação por medicamentos registrados no SINAN segundo faixa etária. Brasil, 2007 a 2012.

Tabela 3: Os dez maiores mercados mundiais de medicamentos nos anos de 2007, 2012 e 2017.

Tabela 4: Principais classes de medicamentos utilizadas pela população brasileira de acordo com estudos de utilização de medicamentos conduzidos no país. ........................................ 21

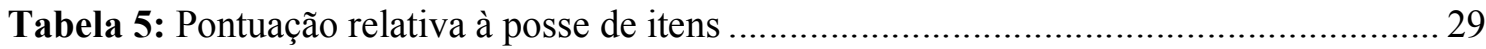

Tabela 6: Pontuação relativa ao grau de instrução do chefe da família................................ 30

Tabela 7: Classificação econômica a partir das pontuações dos domicílios.......................... 30

Tabela 8: Critérios utilizados no diagnóstico nutricional de crianças, adolescentes, adultos e

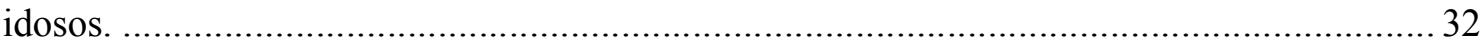

Tabela 9: Número de domicílios e de indivíduos envolvidos na amostra original da POF e na amostra expandida no Brasil, por região urbana e rural e nas macrorregiões brasileiras........ 39 Tabela 10: Distribuição das características dos domicílios pesquisados na POF 2008-2009, em

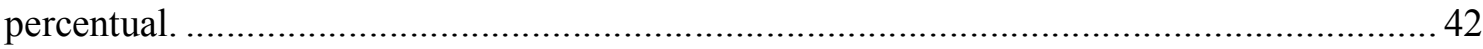

Tabela 11: Distribuição das características da população participante da POF 2008/2009, em percentual.

Tabela 12: Renda per capta média dos domicílios envolvidos na POF 2008-2009, segundo as

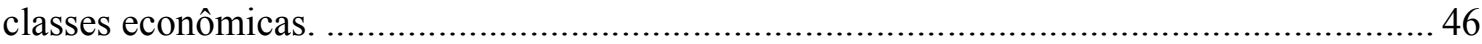

Tabela 13: Formas de acesso e características dos medicamentos adquiridos..................... 49 Tabela 14: Proporção de medicamentos fornecidos pelo SUS em relação ao total de medicamentos obtidos por classe econômica no Brasil, nas regiões rural e urbana e nas macrorregiões brasileiras 59

Tabela 15: Percentual de medicamentos obtidos que foram fornecidos pelo SUS de acordo com a classificação ATC, no Brasil, nas macrorregiões brasileiras e por região urbana e rural..... 60 Tabela 16: Características dos medicamentos fornecidos pelo SUS no Brasil, nas

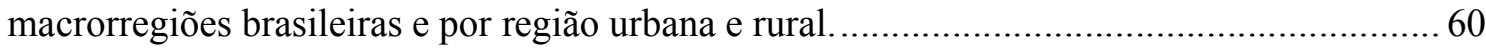

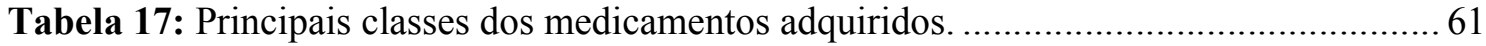
Tabela 18: Aquisição de medicamentos por 10.000 habitantes e intoxicações por medicamentos por 10.000 habitantes registradas no SINAN e no SINITOX nos anos de 2008 e 2009, para o Brasil e para as macrorregiões brasileiras.

Tabela 19: Características dos domicílios em que houve relato de obtenção de algum medicamento no período de referência de 30 dias, estratificadas de acordo com a classe de medicamento adquirido (segundo o primeiro nível da classificação ATC) e em percentual... 74 Tabela 20: Características dos domicílios em que houve relato de obtenção de algum medicamento no período de referência de 30 dias, estratificadas de acordo com a classe de medicamento adquirido (segundo nível da classificação ATC), em percentual. .................... 75

Tabela 21: Distribuição percentual da população residente em domicílios que relataram obtenção de algum medicamento no período de referência de 30 dias, estratificadas de acordo com a classe de medicamento adquirido (primeiro nível da classificação ATC) .77 
Tabela 22: Distribuição percentual da população residente em domicílios em que houve relato de obtenção de algum medicamento no período de referência de 30 dias, estratificadas de acordo com a classe de medicamento adquirido (segundo nível da classificação ATC). 78

Tabela 23: Distribuição do diagnóstico Nutricional (DN) da população residente em que houve relato de obtenção de algum medicamento no período de referência de 30 dias, estratificadas de acordo com a classe de medicamento adquirido (segundo o primeiro nível da classificação ATC) e em percentual. 80

Tabela 24: Distribuição do diagnóstico nutricional da população residente em domicílios em que houve relato de obtenção de algum medicamento no período de referência de 30 dias, estratificadas de acordo com a classe de medicamento adquirido (segundo nível da classificação

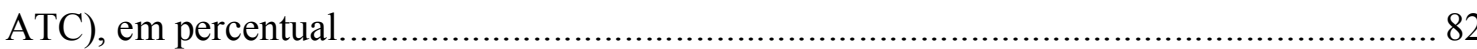




\section{LISTA DE QUADROS}

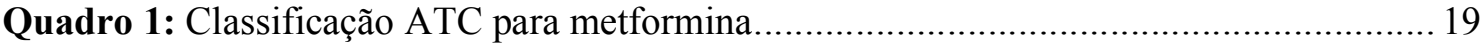

Quadro 2: Classificação ATC para prednisolona.......................................................... 20

Quadro 3: Classificação das respostas da POF 2008-2009 quanto a forma de acesso aos

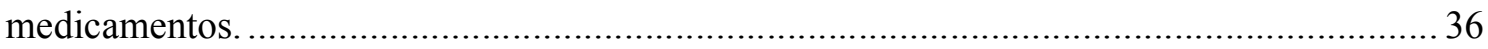

Quadro 4: Classificação das respostas da POF 2008-2009 relativas ao local de obtenção dos

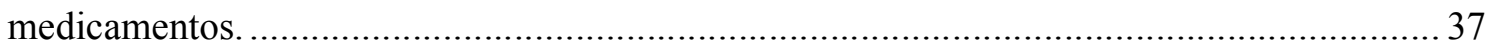




\section{LISTA DE ABREVIATURAS E SIGLAS}

ATC Sistema de classificação anatômico-terapêutico (Anatomical Therapeutic

A Chemical Classification System)

Aparelho digestivo e metabolismo

A02 Medicamentos para desordens ácidas relacionadas

A08 Preparações antiobesidade, exceto produtos dietéticos

A10 Medicamentos utilizados no diabetes

A11 Vitaminas

ANVISA Agência Nacional de Vigilância Sanitária

B Sangue e órgãos formadores do sangue

C Sistema cardiovascular

C00* Para hipertensão ou anti-hipertensivo

C10 Agentes modificadores lipídicos

CCHL Clínica, consultório, hospital ou laboratório

$\mathrm{CO} \quad$ Centro-Oeste

D Dermatológicos

D Direto para rio, lago ou mar

FR/V Fossa rudimentar ou vala

G Sistema gênito urinário e hormônios sexuais

G03 Hormônios sexuais e moduladores do sistema genital

H Preparações hormonais sistêmicas, excluindo hormônios sexuais e insulinas

IBGE Instituto Brasileiro de Geografia e Estatística

J Anti-infecciosos de uso sistêmico

J01 Antibacterianos de uso sistêmico

L Antineoplásicos e agentes imunomoduladores

M Sistema músculo esquelético

M01 Produtos anti-inflamatórios e antirreumáticos

MI Medicamento indeterminado

MPEM Medicamento à base de plantas ou ervas medicinais

N Norte

N Sistema nervoso

N02 Analgésicos 


\begin{tabular}{ll} 
N05 & Psicolépticos \\
N06 & Psicoanalépticos \\
NE & Nordeste \\
NOTEVISA & Sistema de Notificações em Vigilância Sanitária \\
OMS & Organização Mundial da Saúde \\
P & Antiparasitários, inseticidas e repelentes \\
P02 & Anti-helmínticos \\
PFPB & Programa Farmácia Popular do Brasil \\
POF & Pesquisa de Orçamentos Familiares \\
R & Sistema respiratório \\
R05 & Preparações para tosse e resfriado \\
R06 & Anti-histamínicos de uso sistêmico \\
RC/FS & Rede coletora ou fossa séptica \\
S & Sul \\
S & Órgãos sensoriais \\
SE & Sudeste \\
SINAN & Sistema de Informação de Agravos de Notificação \\
SINITOX & Sistema Nacional de Informações Toxico Farmacológicas \\
SUS & Sistema Único de Saúde \\
TA & Tratamento alternativo \\
V & Vários \\
& \\
\hline &
\end{tabular}




\section{RESUMO}

GOES, Fernanda Caroline Silva. Análise do perfil de aquisição domiciliar de medicamentos no Brasil a partir dos dados da Pesquisa de Orçamentos Familiares 2008-2009. Brasília, 2014. Dissertação (Mestrado em Ciências Farmacêuticas) - Faculdade de Ciências da Saúde, Universidade de Brasília, Brasília, 2014.

O uso irracional de medicamentos é um problema mundial, com impacto negativo na efetividade do tratamento, na ocorrência de reações adversas e de resistência microbiana, e no desperdício de recursos. Estudos de utilização de medicamentos são importantes fontes de informação para subsidiar intervenções efetivas que minimizem o problema. Este é um estudo transversal de base populacional, realizado a partir dos dados da Pesquisa de Orçamentos Familiares (POF) de 2008/2009 do IBGE, com o objetivo de investigar a aquisição de medicamentos nos domicílios brasileiros (últimos 30 dias). A POF teve a participação de 55.970 domicílios, e seus resultados foram extrapolados para toda a população brasileira a partir de fatores de expansão. Os medicamentos obtidos foram classificados de acordo com o Anatomical Therapeutic Chemical (ATC). A aquisição de medicamentos foi reportada por $81,2 \%$ dos domicílios, com média nacional de 2,4 medicamentos por domicilio e 0,72 medicamento por habitante, sendo maiores nas regiões Sul e Sudeste (0,81 e 0,79 medicamento/habitante, respectivamente). Segundo dados do SINAN e SINITOX, essas regiões apresentam as maiores incidências de intoxicação por medicamentos no país, indicando uma possível correlação entre aquisição e ocorrência de intoxicações. As classes de medicamentos mais adquiridas foram Sistema nervoso, Sistema cardiovascular e Aparelho digestivo/metabolismo. Como esperado, domicílios de classes econômicas menos privilegiadas, que se localizam principalmente em regiões com condições sanitárias mais precárias, adquiriram mais medicamentos da classe de antiparasitários. Mais de $80 \%$ dos medicamentos foram adquiridos com recursos próprios e 15\% por doação, dos quais $91 \%$ foram fornecidos pelo Sistema Único de Saúde. Em 22,3\% dos domicílios brasileiros houve necessidade de algum medicamento, mas o acesso não foi possível por falta de recursos financeiros, situação mais frequente nas regiões Norte e Nordeste e áreas rurais. Uma das limitações deste estudo está relacionada a como os medicamentos são reportados na POF, que dificulta sua classificação pela ATC. Adicionalmente, os dados não permitem uma correlação direta entre aquisição e uso individual. Porém, como os dados refletem a totalidade dos domicílios brasileiros e as informações são de extrema importância 
para subsidiar as autoridades de saúde a planejar ações que visem ao uso racional de medicamentos no país e ao maior acesso da população aos medicamentos necessários para a manutenção da saúde.

Palavras-chave: Pesquisa de Orçamentos Familiares, domicílios brasileiros, aquisição de medicamentos, acesso a medicamentos, classificação ATC 


\section{ABSTRACT}

GOES, Fernanda Caroline Silva. Analysis of the household medicine acquisition profile in Brazil based on data of the 2008-2009 Household Budget Survey. Brasília, 2014. Dissertação (Mestrado em Ciências Farmacêuticas) - Faculdade de Ciências da Saúde, Universidade de Brasília, Brasília, 2014.

The irrational use of medicines is a worldwide problem, with serious consequences, such as reduction in the treatment efficacy, increase of adverse reactions and microbial resistance, and waste of financial resources. Studies concerning the used of medicines are important source of information to support effective interventions that minimize the problem. This a transversal population study that used data from the IBGE 2008/2009 Household Budget Survey, and aimed to investigate the acquisition of medicine products by the Brazilian households (last 30 days reporting). A total of 55.970 households participated in the Survey and the results were extrapolated to the whole Brazilian population by using expansion factors provided by the IBGE. The medicines were classified according to the Anatomical Therapeutic Chemical (ATC). The acquisition of medicines was reported by $81.2 \%$ households, with an average of 2.4 products per household and 0.72 products per inhabitants, with larger rates for households located in the South and South Eastern regions (0,81 and 0,79 products/inhabitants). According to the SINAN and SINITOX database, these regions have also a higher number of intoxications related to medicine ingestion, an indication of a possible correlation between acquisition and intoxication. Medicine products classified as for the nervous system, cardiovascular system, and gastrointestinal tract/metabolism were the most acquired by the households. As expected, low economical class households, which were mostly located in regions with poor sanitary conditions, acquire more anti parasitic products. Over $80 \%$ of the medicines were acquired using the household financial resources and $15 \%$ were donated, from which $91 \%$ were provided by the Brazilian Health System. In 22.3\% of the households, the acquisition of medicines was not possible due to lack of financial resources, situation that was more frequent in the North and Northeast regions and in rural areas. The main limitations of this study are related to how the medicines are reported in the Survey, which difficult the classification by the ATC, and to the fact that no direct correlation between acquisition by the household and individual use is possible. However, as the results reflect the behavior of medicine acquisition by all Brazilian households, the information is extremely important to 
health authorities when designing programs to promote the rational use of medicines and increase the public access to products that are essential to maintain the health.

Key-words: Brazilian Household Budget Survey, medicine acquisition by the household, access to medicines, ATC classification. 


\section{INTRODUÇÃO}

Medicamentos são insumos fundamentais para medicina moderna, sendo inegável a contribuição deles para proteção, manutenção e recuperação da saúde das pessoas (BRASIL, 2011a). Nas últimas décadas, os medicamentos tiveram um efeito positivo sem precedentes na saúde, levando à redução da mortalidade, diminuição da carga da doença e, consequentemente, à melhoria da qualidade de vida (WHO, 2012). Entretanto, os benefícios proporcionados pelos medicamentos foram acompanhados de inadequações na sua comercialização e consumo (WHO, 2009; 2012).

Atualmente, o uso inadequado de medicamentos é considerado um problema de saúde pública no mundo (HOLLOWAY; VAN DIJK, 2011). Em países em desenvolvimento, menos de $40 \%$ dos pacientes do setor público e $30 \%$ dos pacientes do setor privado são tratados de acordo com diretrizes terapêuticas padronizadas (HOLLOWAY; VAN DIJK, 2011). O uso inapropriado de medicamentos pode ter graves consequências, como a redução da efetividade do tratamento, o aumento das reações adversas, o aumento da resistência microbiana e o desperdício de recursos de saúde (WHO, 2009).

O consumo de medicamentos numa população é influenciado não apenas por fatores de origem farmacológica, mas também por fatores socioantropológicos, comportamentais e econômicos (LEE; BERGMAN, 2012). Sendo assim, informações sobre o perfil de consumo de medicamentos e o acesso aos mesmos são estratégicos para o delineamento de intervenções eficazes para promover seu uso seguro e racional (HARDON et al., 2004; WHO, 2004).

O Brasil é um dos principais mercados de medicamentos no mundo (RICKWOOD; KLEINROCK; NUÑEZ-GAVIRIA, 2013), e os medicamentos representam a principal causa de intoxicações no país (FIOCRUZ, 2014a). Tais intoxicações estão principalmente relacionadas a casos de acidente individual e tentativa de suicídio, circunstâncias que dependem grandemente da disponibilidade destes medicamentos no domicílio (BRASIL, 2014a; FIOCRUZ, 2014a). Entretanto, o Brasil ainda carece de sistemas abrangentes, que possam fornecer informações básicas sobre o uso de medicamentos na população em geral (GALVÃO et al., 2014).

Entre os estudos de utilização de medicamentos conduzidos no Brasil estão aqueles realizados a partir de dados institucionais, como hospitais e outras unidades de saúde (LUZ et al 2012; FERREIRA et al., 2012; OLIVEIRA; NOVAES, 2012) e estudos transversais de base populacional, conduzidos principalmente em municípios (BERTOLDI, 2014; COSTA et al., 
2011; BERTOLDI et al., 2012; GALVÃO et al.,2014), ou com populações específicas(DIEHL; GRASSI, 2010; OLIVEIRA et al 2010, VOSGERAL et al., 2011, CARVALHO et al., 2012, OLIVEIRA et al., 2012). Estudos publicados que reflitam a situação nacional são escassos (LEITE; VIEIRA; VEBER, 2008; CARVALHO et al., 2005; GARCIA et al., 2013a).

A última Pesquisa de Orçamentos Familiares (POF) do Instituto Nacional de Geografia e Estatística (IBGE) realizada no período de junho 2008 a maio de 2009 incluiu dados sobre aquisição individual de produtos farmacêuticos nos domicílios (IBGE, 2010; 2012a). Essas informações são importantes para o planejamento de políticas de assistência farmacêutica e de regulação sanitária, bem como para a promoção do uso racional de medicamentos (ROZENFELD; VALENTE, 2004). 


\section{REVISÃO BIBLIOGRÁFICA}

\section{USO DE MEDICAMENTOS E PREJUÍZO À SAÚDE}

\section{Intoxicações por medicamentos}

No Brasil, pode-se obter informações relativas a prejuízos a saúde decorrentes do uso de medicamentos por meio de três sistemas de informação: o Sistema Nacional de Notificações para a Vigilância Sanitária (NOTIVISA), o Sistema Nacional de Informações Tóxicofarmacológicas (SINITOX) e o Sistema de Informação de Agravos de Notificação (SINAN).

O NOTIVISA foi instituído pela Portaria ${ }^{\circ} 1.660$, de 22 de julho de 2009, do Ministério da Saúde, para receber notificações sobre eventos adversos e queixas técnicas relativas ao uso de medicamentos e outros produtos para saúde (ANVISA, 2014a). É um sistema informatizado, alimentado por profissionais de serviços de saúde (de hospitais, clínicas, hemocentros, laboratórios e centros de informação toxicológica - CIT), profissionais da vigilância sanitária, profissionais de universidades ou centros de pesquisa e profissionais de saúde liberais, dentre outros. Os cidadãos também podem ser agentes notificadores (ANVISA, 2014a). Entre os anos de 2008 a 2012, foram notificados junto ao NOTIVISA 52.603 casos de eventos adversos e destes, 22.623 (43\%) foram decorrentes do uso de medicamentos (ANVISA, 2014b).

As informações do SINITOX são coletadas pela Rede Nacional de Centros de Informação e Assistência Toxicológica (Renacinat), a partir de telefonemas feitos por profissionais da saúde ou cidadãos em geral, em busca de informações sobre qual o procedimento a ser adotado na ocorrência de algum caso de intoxicação. (FIOCRUZ, 2014b). A Renacinat é composta atualmente por 35 unidades (CIT), localizadas em 18 estados e no Distrito Federal, sendo a Agência Nacional de Vigilância Sanitária (ANVISA) responsável pela coordenação dessa rede (FIOCRUZ, 2014b).

De acordo com dados do SINITOX, já no ano de 1993, os medicamentos foram a principal causa de intoxicação exógena no Brasil, no conjunto dos treze agentes tóxicos considerados (BORTOLETTO; BOCHNER, 1999). Dados referentes ao período de 1999 a 2011 mostram que os medicamentos continuam sendo a principal causa de intoxicação exógena no Brasil. Dos 1.193.378 casos de intoxicação humana registrados, 339.032 casos $(28,14 \%)$ envolveram medicamentos; destes 1.042 evoluíram para óbito, o que representa uma taxa de letalidade de 0,31\% (FIOCRUZ, 2014a). O número de intoxicações por medicamentos foi crescente ao longo dos anos, com picos nos anos 2006 e 2007 (Figura 1). 


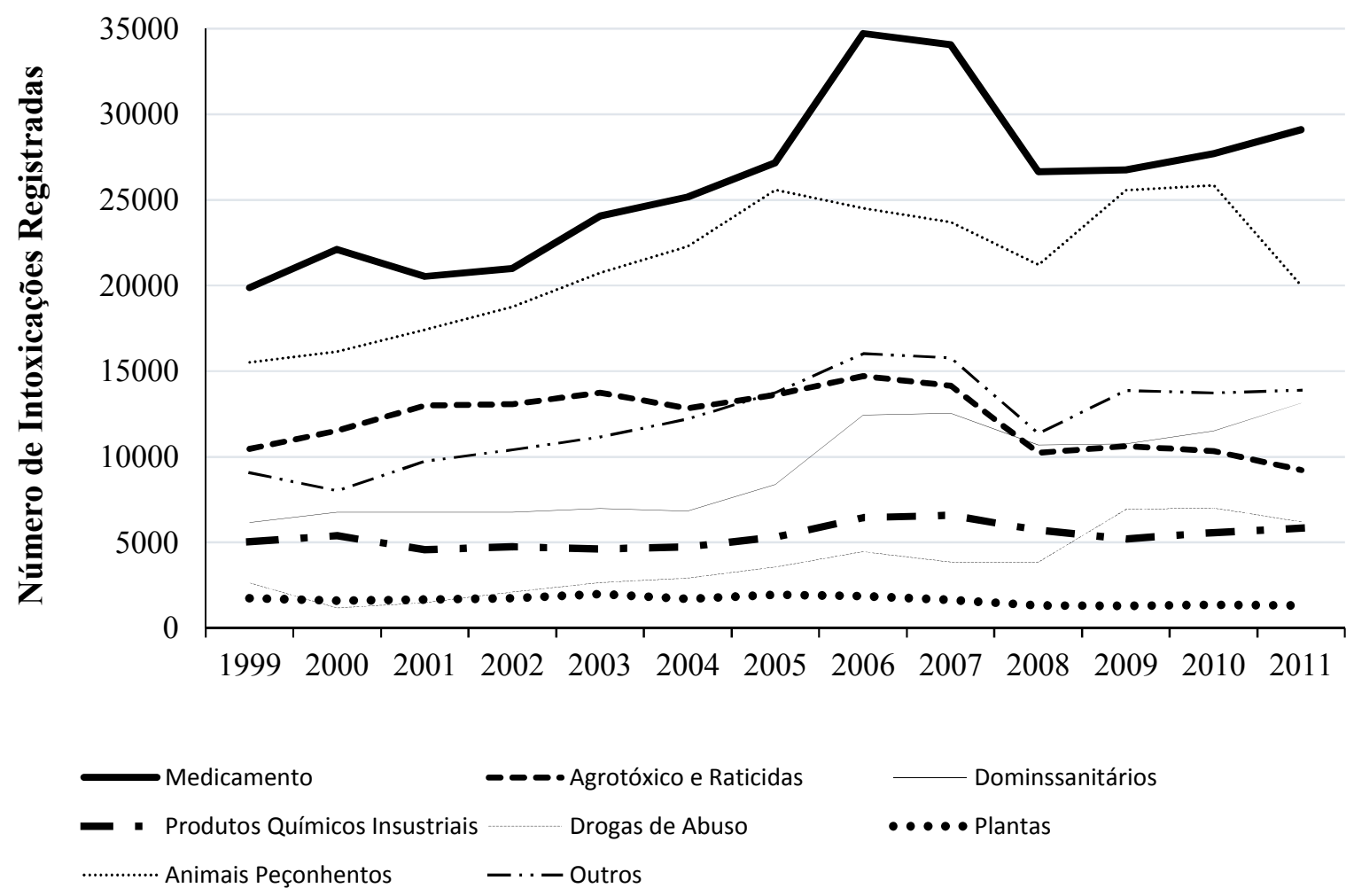

Figura 1: Número de intoxicações registradas no Brasil pelo SINITOX, entre 1999 e 2011, por agente tóxico.

Fonte: FIOCRUZ, 2014a.

Considerando-se as principais circunstâncias nas quais ocorreram os casos de intoxicação por medicamentos nos anos de 1999 a 2011, observa-se que a tentativa de suicídio é a principal, envolvida em 41\% dos casos (Figura 2). Circunstâncias de intoxicação que remetem ao uso inadequado de medicamentos tais como acidente individual, auto medicação, erro de administração, uso indevido e abuso representam $45 \%$ dos casos (Figura 2). 


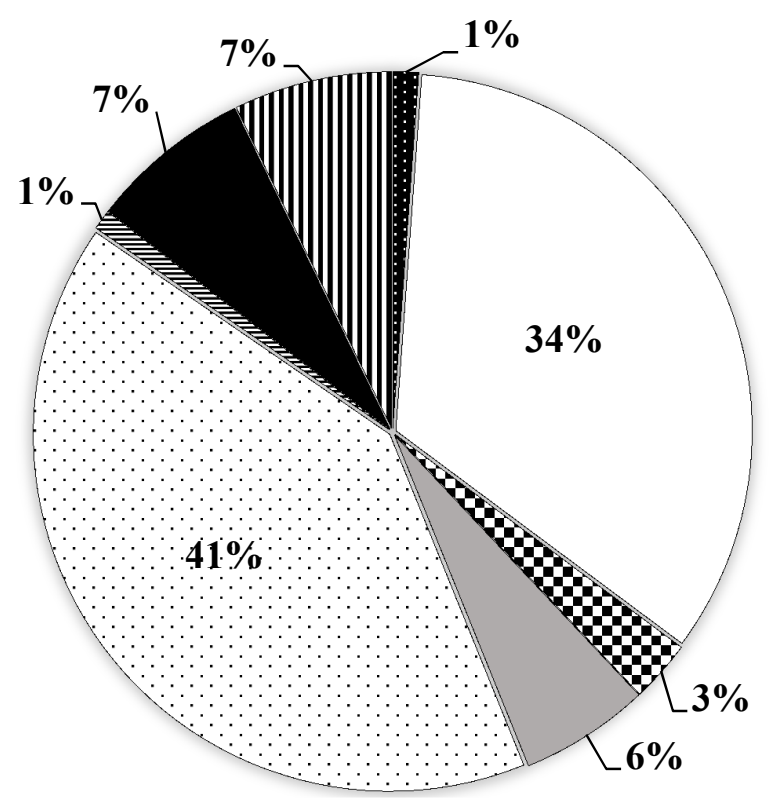

Abuso

$\square$ Acidente individual

ه Automedicação

$\square$ Erro de Administração

$\square$ Tentativa de Suicídio

E Uso Indevido

Uso Terapêutico

III Outras

Figura 2: Circunstâncias de intoxicação por medicamentos no Brasil de 1999 a 2011 registradas pelo SINITOX.

Fonte: FIOCRUZ, 2014b.

Crianças de 1 a 4 anos são as maiores vítimas de intoxicações causadas por medicamentos, participando com $28,46 \%$ dos casos registrados no país, sendo $0,23 \%$ deles letais. Adultos de 20 a 39 anos responderampor 39,1\% das mortes por medicamentos (Tabela 1).

Tabela 1: Casos, óbitos e letalidade de intoxicação por medicamentos registrados pelo SINITOX, segundo faixa etária. Brasil, 1999 a 2011.

\begin{tabular}{cccccc}
\hline \multirow{2}{*}{ Faixa etária } & \multicolumn{2}{c}{ Casos } & \multicolumn{2}{c}{ Óbitos } & Letalidade \\
\cline { 2 - 5 } $\mathbf{( \% )}$ & $\mathbf{N}$ & $\mathbf{\%}$ & $\mathbf{N}$ & $\mathbf{\%}$ & \\
\hline$<1$ & 11.400 & 3,36 & 26 & 2,50 & 0,23 \\
$01-04$ & 96.481 & 28,46 & 66 & 6,33 & 0,07 \\
$05-09$ & 24.448 & 7,21 & 12 & 1,15 & 0,05 \\
$10-14$ & 18.340 & 5,41 & 25 & 2,40 & 0,14 \\
$15-19$ & 33.498 & 9,88 & 77 & 7,39 & 0,23 \\
$20-29$ & 61.170 & 18,04 & 202 & 19,39 & 0,33 \\
$30-39$ & 40.276 & 11,88 & 205 & 19,67 & 0,51 \\
$40-49$ & 25.766 & 7,60 & 152 & 14,59 & 0,59 \\
$50-59$ & 11.859 & 3,50 & 108 & 10,36 & 0,91 \\
$60-69$ & 4.909 & 1,45 & 85 & 8,16 & 1,73 \\
$70-79$ & 2.810 & 0,83 & 40 & 3,84 & 1,42 \\
$80+$ & 1.654 & 0,49 & 29 & 2,78 & 1,75 \\
Ignorada & 6.421 & 1,89 & 15 & 1,44 & 0,23 \\
\hline
\end{tabular}

Fonte: FIOCRUZ, 2014a. 
O SINAN é um sistema de informação de abrangência nacional, gerido pela Secretaria de Vigilância em Saúde (SVS) do Ministério da Saúde (BRASIL, 2007). Esse sistema foi implantado de forma gradual a partir de 1993, e a partir de 1998, sua alimentação pelos municípios, estados e Distrito Federal tornou-se obrigatória (BRASIL, 1998; 2007).

O SINAN é alimentado principalmente pelos serviços de saúde (públicos ou privados) a partir da notificação e investigação de casos de doenças e agravos presentes na lista nacional de doenças de notificação compulsória, sendo facultado aos estados e aos municípios a inclusão de outros problemas de saúde (BRASIL, 2007; 2014b; 2014c).

Dados disponibilizados pelo SINAN mostram que os medicamentos foram a principal causa de intoxicação exógena no Brasil de 2007 a 2012 (Figura 3), respondendo por 29,8\% dos casos de intoxicação registrados. Cerca de $38 \%$ casos de intoxicação registrados apresentam agente tóxico ignorado (BRASIL, 2014a). Dentre os 107.934 casos de intoxicação por medicamentos registrados, 823 evoluíram para óbito, o que representa uma taxa de letalidade de $0,76 \%$ (BRASIL, 2014a). A circunstância mais frequente foi a tentativa de suicídio, envolvida em 58,8\% das intoxicações por medicamentos (Figura 4).

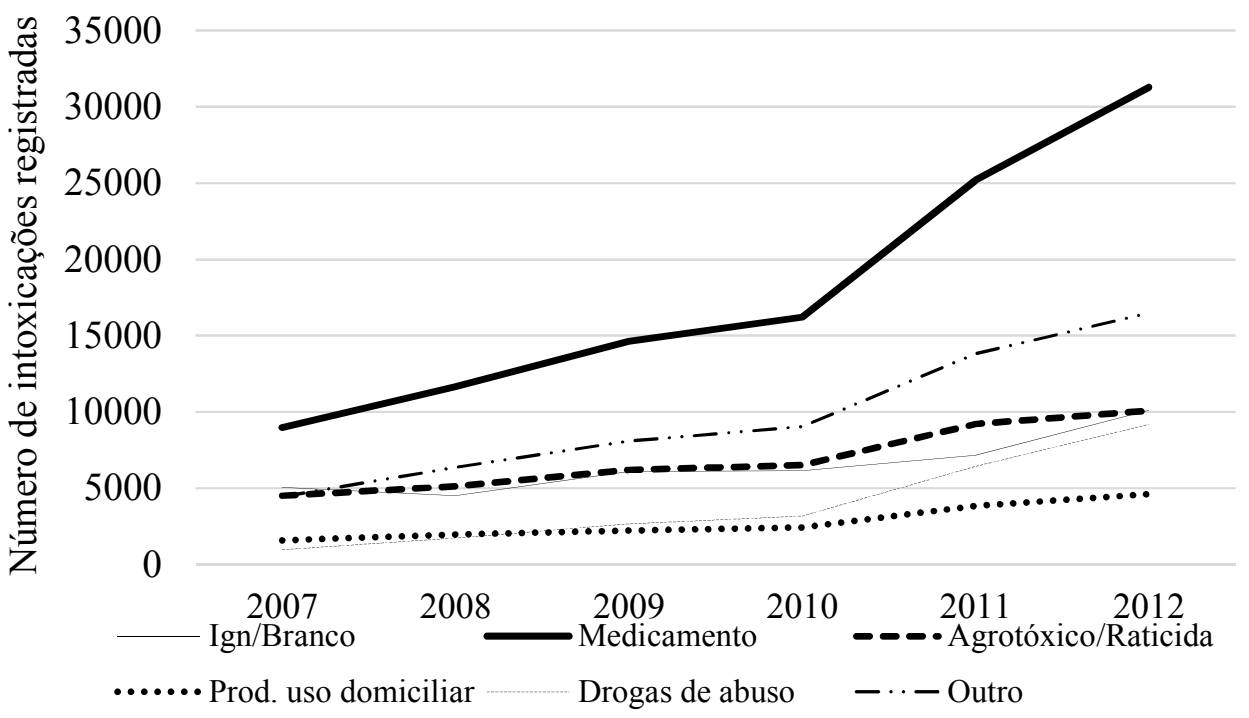

Figura 3: Casos de intoxicação exógena por agente tóxico no Brasil registrados pelo SINAN de 2007 a 2012.

Fonte: Ministério da Saúde/SVS - Sistema de Informação de Agravos de Notificação - SINAN Net (http://dtr2004.saude.gov.br/sinanweb/) 


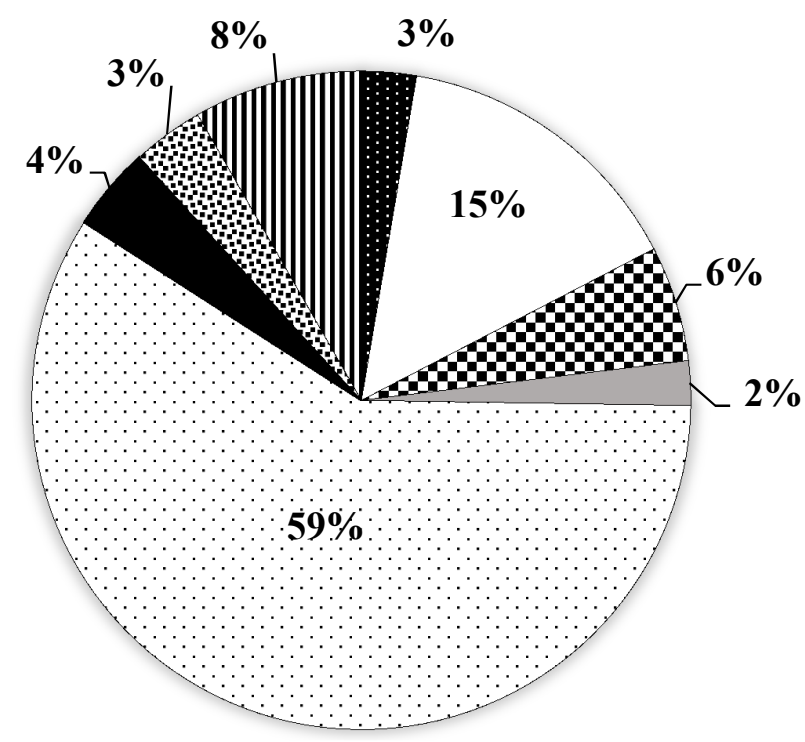

Abuso

$\square$ Acidental

Q Automedicação

$\square$ Erro de administração

$๑$ Tentativa de suicídio

Uso terapêutico

Uso Habitual

II Outra

Figura 4: Circunstâncias de intoxicação por medicamentos no Brasil de 2007 a 2012 registradas no SINAN.

Fonte: Ministério da Saúde/SVS - Sistema de Informação de Agravos de Notificação - SINAN Net (http://dtr2004.saude.gov.br/sinanweb/)

A tentativa de suicídio ocorre especialmente na faixa etária de 20 a 39 anos, mas também é expressiva nas faixas etárias de 10 a 19 anos e 40 a 59 anos. A principal circunstância de intoxicação por medicamentos entre crianças de até nove anos de idade é a intoxicação acidental (Figura 5). 


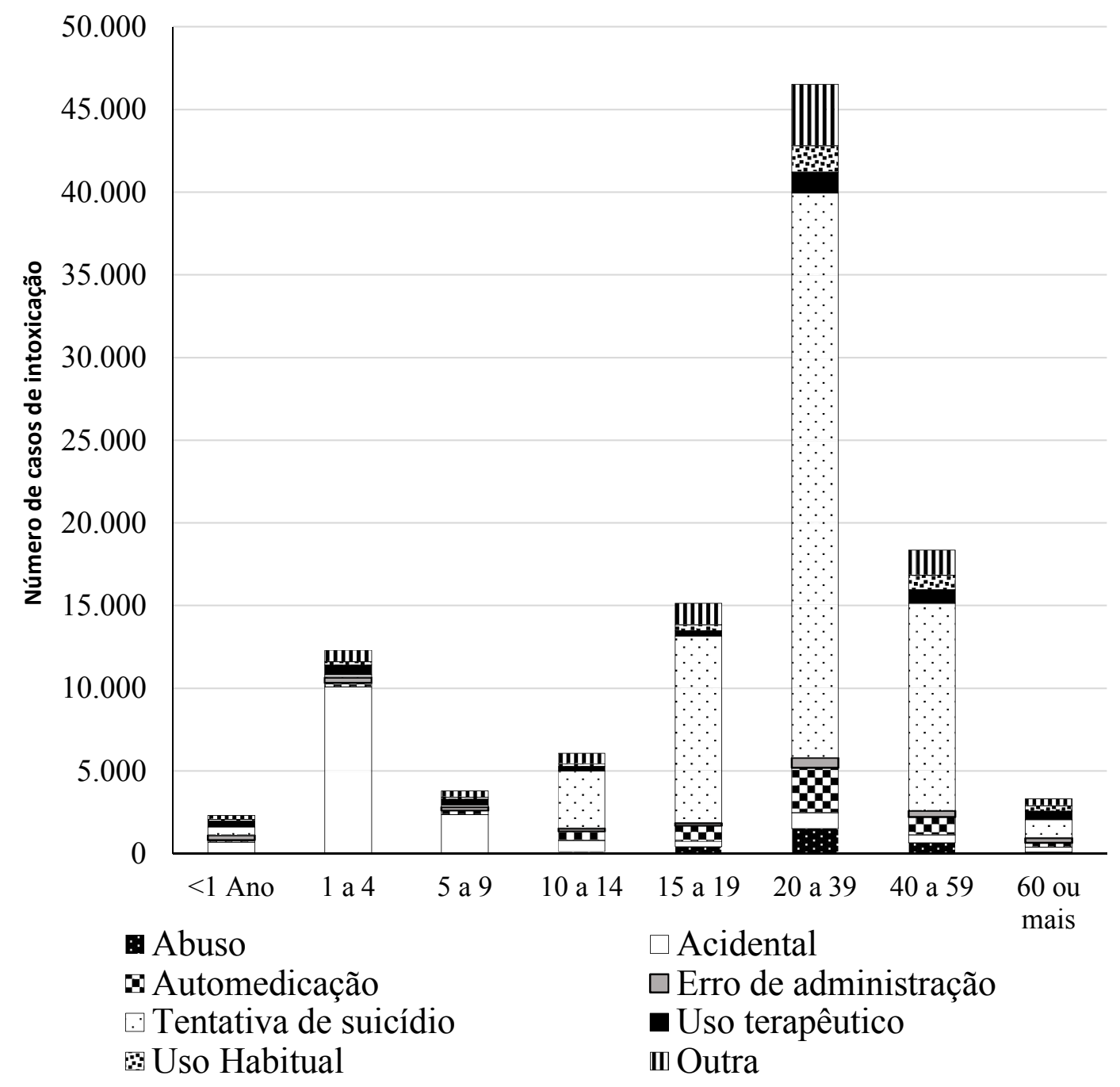

Figura 5: Circunstâncias de intoxicação por medicamentos registradas no SINAN de 2007 a 2012, por faixa etária.

Fonte: Ministério da Saúde/SVS - Sistema de Informação de Agravos de Notificação - SINAN Net (http://dtr2004.saude.gov.br/sinanweb/)

De acordo com os dados do SINAN, as maiores vítimas de intoxicações causadas por medicamentos são adultos de 20 a 39 anos, participando com 43,1\% dos casos registrados no país (Tabela 2). Adultos, de 40 a 59 anos, consituem a segunda faixa etária mais vulnerável, com $17,0 \%$ dos casos registrados, seguida pelas faixas de 15 a 19 anos $(14,0 \%)$ e de 1 a 4 anos (11,4\%). Adultos de 20 a 39 anos responderam por 41,7\% das mortes (BRASIL, 2014a). 
Tabela 2: Casos, óbitos e letalidade de intoxicação por medicamentos registrados no SINAN segundo faixa etária. Brasil, 2007 a 2012.

\begin{tabular}{cccccc}
\hline \multirow{2}{*}{ Faixa etária } & \multicolumn{2}{c}{ Casos } & \multicolumn{2}{c}{ Óbitos } & Letalidade \\
\cline { 2 - 5 } & $\mathbf{N}$ & $\mathbf{\%}$ & $\mathbf{N}$ & $\mathbf{\%}$ & $\mathbf{( \% )}$ \\
\hline$<\mathbf{1 ~ A n o}$ & 2.326 & 2,16 & 7 & 0,85 & 0,30 \\
$\mathbf{1 - 4}$ & 12.306 & 11,4 & 14 & 1,70 & 0,11 \\
$\mathbf{5 - 9}$ & 3.803 & 3,52 & 5 & 0,61 & 0,13 \\
$\mathbf{1 0 - 1 4}$ & 6.090 & 5,64 & 14 & 1,70 & 0,23 \\
$\mathbf{1 5 - 1 9}$ & 15.147 & 14,0 & 51 & 6,20 & 0,34 \\
$\mathbf{2 0 - 3 9}$ & 46.534 & 43,1 & 343 & 41,7 & 0,74 \\
$\mathbf{4 0 - 5 9}$ & 18.371 & 17,0 & 282 & 34,3 & 1,54 \\
$\mathbf{6 0 - 6 4}$ & 1.136 & 1,05 & 31 & 3,77 & 2,73 \\
$\mathbf{6 5 - 6 9}$ & 738 & 0,68 & 19 & 2,31 & 2,57 \\
$\mathbf{7 0 - 7 9}$ & 922 & 0,85 & 39 & 4,74 & 4,23 \\
$\mathbf{8 0} \mathbf{e}+$ & 535 & 0,50 & 18 & 2,19 & 3,36 \\
Em branco/ignorada & 26 & 0,02 & 0 & 0,00 & 0,00 \\
\hline
\end{tabular}

Fonte: Ministério da Saúde/SVS - Sistema de Informação de Agravos de Notificação - SINAN Net (http://dtr2004.saude.gov.br/sinanweb/)

Os dados de três sistemas de informações existentes no país - SINITOX, NOTIVISA e SINAN - relativos a intoxicações e agravos a saúde decorrentes do uso de medicamentos, põe em destaque o problema da utilização inadequada de medicamentos nos domicílios brasileiros, indicada pelas circuntancias envolvidas, como uso acidental, automedicação e acidente individual, este principalmente com crianças.

\section{Aumento da resistência microbiana}

O uso inadequado e excessivo de antibióticos é um problema de abrangência global e sua principal consequência é a ocorrência de resistência bacteriana (HOLLOWAY; VAN DIJK, 2011). Enquanto a resistência aos antibióticos mais antigos tem aumentado, o desenvolvimento de novos antibióticos está estagnado (KAPLAN et al., 2013; ECDC; EMEA, 2009).

Algumas consequências previsíveis da resistência antimicrobiana para o setor saúde são o aumento da morbidade, o prolongamento da doença, o aumento do risco de complicações e a elevação das taxas de mortalidade. As consequências econômicas incluem o aumento nos custos do diagnóstico e do tratamento e a perda de produtividade devido ao absenteísmo (WHO, 2012).

Embora o uso excessivo ou incorreto de antibióticos, com consequente resistência bacteriana ocorra, predominantemente, em ambientes hospitalares, estão crescendo preocupações relativas à utilização de antibióticos na comunidade e em cuidados primários de 
saúde, bem como em ambientes de cuidados de longa duração (ALANIS 2005; WELLER; JAMIESON, 2004).

No Brasil, o uso excessivo de antibióticos foi impulsionado pela facilidade de aquisição desses medicamentos. Um estudo conduzido 2002 em uma cidade de médio porte da região sul do Brasil, constatou que cerca de $74 \%$ das 107 farmácias envolvidas no estudo venderam antibióticos sem prescrição médica (VOLPATO et al., 2005). Mesmo assim, estudo conduzido em oito países da América Latina (Argentina, Brasil, Chile, Colômbia, México, Peru, Uruguai e Venezuela), que avaliou as vendas de antibióticos orais e injetáveis, mostrou que no ano de 2007, o Brasil apresentou a menor aquisição desses medicamentos para 1.000 habitantes (WIRTZ; DRESER; GONZALES, 2010).

A fim de conter o uso inadequado e excessivo de antibióticos no Brasil, a ANVISA publicou resoluções que dispõem sobre o controle de medicamentos à base de substâncias classificadas como antimicrobianos, estabelecendo critérios para prescrição, dispensação, controle, embalagem e rotulagem de medicamentos cujos fármacos são agentes antimicrobianos registrados (RDC 44/2010, RDC 61/2010, RDC 17/2011) as quais foram revogadas pela RDC 20/2011 (ANVISA, 2010a; 2010b; 2011a; 2011b).

Segundo a RDC 20/2011, a movimentação da compra e venda de antimicrobianos deve ser feita no sistema Nacional de Gerenciamento de Produtos Controlados (SNGPC), o que permite o monitoramento da utilização desses medicamentos pela população brasileira (ANVISA, 2011b). A Instrução Normativa 7/2011 (ANVISA, 2011c) definiu o dia 16 de janeiro de 2013 para o início da escrituração eletrônica obrigatória dos medicamentos antimicrobianos no SNGPC por farmácias e drogarias privadas.

Estima-se que, desde a publicação da RDC 44 - em 26 de outubro de 2010 -, o controle do uso de antimicrobianos já tenha proporcionado uma redução de $18 \%$ nas vendas de antibióticos no Brasil (Figura 6). 


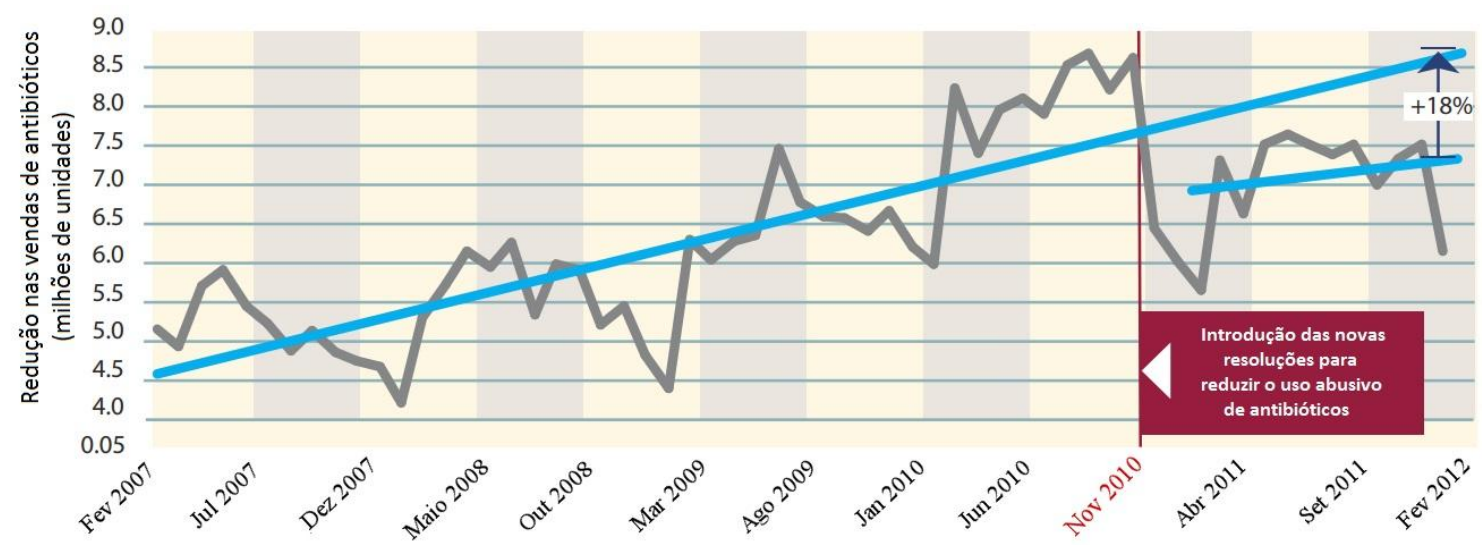

Figura 6: Vendas de antibióticos orais no Brasil. Fonte: IMS INSTITUTE FOR HEALTHCARE INFORMATICS, 2012.

Além do fato que o uso excessivo de antimicrobianos desempenha um papel importante no surgimento da resistência bacteriana, sua subutilização, pela escolha inadequada ou da dosagem insuficiente, e a baixa adesão ao tratamento desempenham um papel importante no surgimento e difusão da resistência microbiana. Portanto, a principal estratégia de contenção desse mal é aumentar uso racional de antibióticos (WHO, 2012).

\section{GASTOS COM SAÚDE E MEDICAMENTOS}

Medicamentos ocupam posição de destaque nos gastos com saúde no mundo todo (WHO, 2011), e tanto os gastos com saúde quanto com medicamentos têm crescido mais que a renda em diversos países (WHO, 2012). Gastos com medicamentos em países de alta renda representam $16 \%$ do gasto total com saúde, enquanto que em países de renda média ou baixa esse percentual é de $24 \%$ e $29 \%$, respectivamente (WHO, 2012).

O Brasil, considerado um país de renda média, ocupa um lugar de destaque no mercado farmacêutico internacional. Já em 1976, o Brasil estava entre os 10 países que mais consumiam medicamentos no mundo (WHO, 1988). Dados mais recentes revelam que o Brasil foi o $6^{\circ}$ maior mercado consumidor de medicamentos, em 2012, e há projeções de que ele seja o $4^{\circ}$ maior mercado em 2017 (Tabela 3). 
Tabela 3: Os dez maiores mercados mundiais de medicamentos nos anos de 2007, 2012 e 2017.

\begin{tabular}{|c|c|c|c|c|c|c|}
\hline \multirow{2}{*}{ Posição } & \multicolumn{2}{|l|}{2007} & \multicolumn{2}{|l|}{2012} & \multicolumn{2}{|l|}{2017} \\
\hline & País & Índice ${ }^{a}$ & País & Índice ${ }^{a}$ & País & Índice $^{a}$ \\
\hline 1 & Estados Unidos & 100 & Estados Unidos & 100 & Estados Unidos & 100 \\
\hline 2 & Japão & 27 & Japão & 27 & China & 45 \\
\hline 3 & França & 13 & China & 25 & Japão & 29 \\
\hline 4 & Alemanha & 13 & Alemanha & 13 & Brasil & 13 \\
\hline 5 & China & 11 & França & 11 & Alemanha & 13 \\
\hline 6 & Itália & 8 & Brasil & 8 & França & 10 \\
\hline 7 & Reino Unido & 7 & Itália & 8 & Itália & 8 \\
\hline 8 & Espanha & 7 & Reino Unido & 7 & Rússia & 7 \\
\hline 9 & Canadá & 7 & Canadá & 7 & Reino Unido & 7 \\
\hline 10 & Brasil & 5 & Espanha & 6 & Canadá & 7 \\
\hline
\end{tabular}

Fonte: RICKWOOD; KLEINROCK; NUÑEZ-GAVIRIA, 2013; ${ }^{a} \mathrm{O}$ índice é baseado na razão dos gastos dos países em relação às vendas nos Estados Unidos no ano.

De acordo com a Constituição da República Federativa do Brasil (1988), “a saúde é direito de todos e dever do Estado" (BRASIL, 2010a). O texto constitucional referente à saúde é regulamentado pela Lei Orgânica da Saúde (Lei n. 8080, de 1990), a qual descreve como campo de atuação do Sistema Único de Saúde (SUS) a assistência terapêutica integral, inclusive a farmacêutica (BRASIL, 1990).

O acesso a medicamentos tem impacto direto sobre a resolubilidade das ações de saúde (PANIZ et al., 2008; GARCIA et al., 2013a). Dessa forma, a garantia de acesso a esses insumos é uma questão crucial no SUS, sendo um eixo norteador de políticas públicas como a Política Nacional de Medicamentos, a Política Nacional de Assistência Farmacêutica e o Pacto pela Saúde, quando a assistência farmacêutica passou a ter financiamento específico (BRASIL, 2001; 2004a; 2006; 2011a). No entanto, apesar dos esforços em se priorizar políticas públicas que valorizam a assistência farmacêutica, o SUS ainda não consegue atender satisfatoriamente todas as demandas por medicamentos, o que faz com que o componente privado tenha um papel relevante nos gastos com medicamentos (SILVEIRA; OSORIO; PIOLA, 2002; GARCIA et al., 2013a). Isso impacta principalmente sobre o orçamento de famílias de menor renda: enquanto entre essas famílias os gastos com medicamentos comprometeram cerca de $6 \%$ da renda mensal, nos anos de 2008-2009, entre as de maior renda os medicamentos responderam por cerca de $1,6 \%$ do orçamento familiar (GARCIA et al., 2013b). 
No período de 2007 a 2009, os gastos públicos no Brasil com serviços de saúde representaram 5,5\% do Produto Interno Bruto (PIB), sendo que os medicamentos foram responsáveis por 22,0\% deste percentual, ou R \$ 10,5 bilhões no ano de 2009 (IBGE, 2012b).

Além disso, no período de 2007 a 2009, as despesas das famílias brasileiras com bens e serviços de saúde corresponderam, em média, a 4,8\% do PIB e os gastos com medicamentos foram equivalentes a $1,7 \%$ do PIB nacional (IBGE, 2012b). O gasto per capita com medicamentos no Brasil é de aproximadamente US\$ 0.07 por habitante, inferior ao de países como Canadá (US\$ 0.57) e Espanha (US\$ 2,17) (CONASS, 2010). Entretanto, a expectativa é que os mercados farmacêuticos emergentes, incluindo o brasileiro, tenham um crescimento maior que os mercados de países desenvolvidos nos próximos anos (RICKWOOD; KLEINROCK; NUÑEZ-GAVIRIA, 2013).

No Brasil, entre os anos de 2005 a 2009, por exemplo, houve aumento de $65,3 \%$ nos recursos financeiros da União para aquisição de medicamentos no país. Nesse mesmo período, os estados e o Distrito Federal aumentaram em 112,4\% o volume de recursos próprios alocados no financiamento da aquisição de medicamentos (VIEIRA; ZUCCHI, 2013).

Estudo utilizando os dados da Pesquisa de Orçamentos Familiar do IBGE (POF) mostrou que o gasto médio com medicamentos para o total das famílias brasileiras correspondeu a 53,54 reais, nos anos de 2002 e 2003 e a 59,02 reais nos anos de 2008 e 2009, sendo que as famílias de maior renda gastam mais com medicamentos (GARCIA et al., 2013a).

No mundo, cerca de $8 \%$ do total das despesas com saúde poderia ser evitado com o uso otimizado de medicamentos, o que significaria uma economia de 500 bilhões de dólares por ano (IMS INSTITUTE FOR HEALTHCARE INFORMATICS, 2012.). Dado o impacto positivo sobre a despesa global e sobre os resultados da saúde das populações, o uso racional de medicamentos deve ser uma prioridade da política de saúde. (IMS INSTITUTE FOR HEALTHCARE INFORMATICS, 2012.).

O monitoramento do uso de medicamentos é essencial para a promoção do uso racional desses insumos. Em muitos países desenvolvidos, o uso de medicamentos é monitorado rotineiramente e os dados gerados têm sido eficazes na promoção da melhor utilização desses insumos. Em países em desenvolvimento, tais registros são muitas vezes ausentes ou não estão amplamente implantados (HOLLOWAY; VAN DIJK, 2011). 


\section{ESTUDOS DE UTILIZAÇÃO DE MEDICAMENTOS}

Estudos de utilização de medicamentos envolvem aspectos relativos à comercialização, distribuição e prescrição, com especial ênfase sobre as consequências médicas, sociais e econômicas (WHO, 2003). Esses estudos contemplam não apenas fatores fisiológicos, mas também fatores comportamentais, sócio antropológicos e econômicos que influenciem na utilização de medicamentos, bem como os efeitos dessa utilização (LEE; BERGMAN, 2012). Estudos de utilização de medicamentos são essenciais para a implementação de medidas que objetivem a melhoria dos hábitos de prescrição (WHO, 2003).

A importância dos estudos de utilização de medicamentos foi inicialmente abordada nos anos 60, em um simpósio sobre toxicologia de medicamentos organizado pela OMS (DUKES, 1993). O trabalho pioneiro foi conduzido em seis países europeus durante o período de 1966 e 1967 e mostrou grandes diferenças na utilização de medicamentos entre os grupos populacionais estudados, mas não permitiu comparações detalhadas dos dados porque a fonte e a forma da informação variaram entre eles (WHO, 2003; 2013). Desde então, a realização desses estudos tem atraído interesse crescente, motivado primeiramente por considerações de ordem econômica, mas posteriormente pela investigação de questões referentes à eficácia e segurança no contexto da utilização de medicamentos (DUKES, 1993).

Os estudos de utilização de medicamentos podem ser quantitativos ou qualitativos (WHO, 2003). Estudos quantitativos têm como objetivo quantificar o estado presente e desenvolver tendências ao longo do tempo relativas ao uso de medicamentos. Dados estatísticos rotineiramente compilados ou de estudos sobre o tema podem ser utilizados para se estimar a utilização de medicamentos nas populações por idade, sexo, classe social, morbidade e outras características, bem como para identificar áreas de possível excesso ou falta de utilização (LEE; BERGMAN, 2012; WHO, 2003). Estudos qualitativos avaliam a adequação da utilização de medicamentos, usualmente relacionando dados de prescrição e as razões da prescrição (LEE; BERGMAN, 2012).

\section{Estudos de utilização de medicamentos no Brasil}

Vários estudos observaram que o uso de medicamentos é maior entre mulheres (CARVALHO et al., 2005; COSTA et al., 2011; VOSGERAU et al., 2011; BOING; BERTOLDI; PERES, 2011; GALVÃO et al., 2014), indivíduos com maior escolaridade, maior renda, doenças crônicas (CARVALHO et al., 2005; COSTA et al., 2011; VOSGERAU et al., 2011; GALVÃO, 2014), indivíduos com presença de morbidade (CARVALHO et al., 2005; 
COSTA et al., 2011), indivíduos com uma auto avaliação ruim da própria saúde (CARVALHO et al., 2005; VOSGERAU et al., 2011); indivíduos com filiação a plano de saúde (VOSGERAU et al., 2011), indivíduos desempregados ou aposentados (GALVÃO et al., 2014) e indivíduos que tiveram consulta médica recente (GALVÃO et al., 2014). A associação entre uso de medicamentos e escolaridade ou renda não foi observada por Galvão et al. (2014) entre brasilienses de 18 a 65 anos.

A análise dos dados da World Health Survey, uma pesquisa conduzida pela OMS no Brasil em 2003 (WHO, 2014) e que possui uma amostra representativa da população brasileira, mostrou que $38,9 \%$ dos brasileiros de 18 a 39 anos e $54 \%$ dos adultos de 40 a 59 anos utilizaram algum medicamento no período de 15 dias (CARVALHO et al., 2005). Nessa mesma população, o número médio de medicamentos utilizados foi de 0,61 entre indivíduos de 18 a 39 anos e de 1,01 entre indivíduos de 40 a 59 anos (CARVALHO et al., 2005).

COSTA et al. (2011) avaliaram a utilização de medicamentos entre os habitantes de Campinas (São Paulo), no período de três dias, por meio de um estudo de base populacional (941 entrevistados). Foi observado um percentual de utilização de medicamentos de 34,6\% entre indivíduos de 18 a 29 anos, de 38,2\% entre indivíduos de 30 a 39 anos; 53,2\% entre indivíduos de 40 a 49 anos e 54,7\% entre indivíduos de 50 a 59 anos. Nessa mesma população, o número médio de medicamentos utilizados foi de 1,24 medicamentos para indivíduos de 18 a 29 anos,1,21 medicamentos para indivíduos de 30 a 39 anos, 1,52 para indivíduos de 40 a 49 anos e 2,03 para indivíduos de 50 a 59 anos (COSTA et al., 2011).

Estudo de base populacional conduzido em Brasília (Distrito Federal) indicou o uso de medicamentos por 60,4\% dos brasilienses de 18 a 25 anos (GALVÃO et al., 2014). Esse percentual diminuiu com a idade, sendo $46,3 \%$ na faixa etária de 26 a 35 anos, 31,7\% na de 36 a 45 anos, e $26,8 \%$ na de 46 a 55 anos.

No sul do Brasil, Boing, Bertoldi e Peres. (2011) observaram uma prevalência de uso de medicamentos de 76,5\%, entre 1.720 adultos (20 a 59 anos) de Florianópolis (Santa Catariana), utilizando um período recordatório de 30 dias. Bertoldi et al. (2009) analisaram o perfil de utilização de medicamentos, no período de 15 dias, na população de Porto Alegre (Rio Grande do Sul) atendida por equipes da Estratégia Saúde da Família. A maioria (54 a 87,2\%) dos 2988 entrevistados (20-69 anos) utilizaram algum tipo de medicamento no período estipulado pela pesquisa, com percentuais maiores em indivíduos mais velhos. Em estudo conduzido em Ponta Grossa (Paraná), com 374 indivíduos assistidos pelo mesmo programa 
mostrou que $67,1 \%$ dos indivíduos de 20 a 59 anos utilizaram algum medicamento no período de sete dias (VOSGERAU et al., 2011).

\section{Uso de medicamentos por idosos}

Em geral, a prevalência de utilização de medicamentos é maior entre idosos -60 anos ou mais - (> 70\%), chegando a mais de $80 \%$ entre aqueles acima de 70 anos (CARVALHO et al., 2005; BERTOLDI et al., 2009; COSTA et al., 2011). Nesta população, o número médio de medicamentos utilizados também é maior. Considerando-se a população brasileira como um todo, o número médio de medicamentos utilizados no período de 15 dias, entre indivíduos de 60 anos ou mais, foi de 1,64 medicamentos por pessoa (CARVALHO et al., 2005). Em Porto Alegre, esse número foi de 3,50 também no período de 15 dias (BERTOLDI et al., 2009) e em Campinas, no período de 3 dias, esse número foi de 2,62 medicamentos (COSTA et al., 2011).

Uma preocupação relacionada ao uso de medicamentos por idosos é o uso de vários medicamentos concomitantemente - polifarmácia (MEDEIROS-SOUZA et al., 2007). Estudo conduzido em Goiânia (Goiás) mostrou que a prevalência de automedicação entre idosos é de $35,7 \%$, e a de polifarmácia de 26,4 \% (SANTOS et al., 2013). No município de São Paulo, observou-se uma prevalência de polifarmácia ainda maior, 36\% (CARVALHO et al., 2012).

Dentre as características positivamente associadas à polifarmácia encontram-se o sexo feminino, idade superior a 74 anos, maior renda, estar trabalhando, ter uma auto avaliação de saúde regular ou ruim e sofrer de doenças crônicas como hipertensão, diabetes ou doença reumática (CARVALHO et al., 2012).

\section{Uso de medicamentos por crianças e adolescentes}

Bertoldi et al (2012) observaram uma prevalência de uso de medicamentos de 52\% no primeiro ano de vida em crianças da cidade de Pelotas, e de 35\%entre crianças de 4 anos. Indivíduos que declararam utilizar medicamentos em alguma das visitas da pesquisa foram mais propensos a declarar o mesmo em visitas seguintes, independentemente da idade, renda e escolaridade materna, mostrando uma manutenção do comportamento em relação ao uso de medicamentos desde a infância até a adolescência. Estudo anterior, também conduzido em Pelotas, mostrou uma prevalência de uso de medicamentos ainda maior: $65 \%$ entre crianças de um ano e 55\% entre crianças de dois anos, no período de 15 dias (OLIVEIRA et al., 2010). Em estudo conduzido em Porto Alegre, a prevalência de utilização de medicamentos entre crianças de 0 a 4 anos foi de 50,6\% e entre crianças de 5-9 anos, de 35,2\% (BERTOLDI et al., 2009). 
Entre os fatores associados ao uso de medicamentos em crianças, encontram-se a maior escolaridade das mães, o fato de o filho ser primogênito, a percepção da saúde da criança pela mãe como regular ou ruim e o fato de a mãe possuir plano de saúde (OLIVEIRA et al., 2012).

$\mathrm{O}$ uso de medicamentos entre adolescentes também possui alta prevalência. Bertoldi et al. (2014) observaram que, entre adolescentes de Pelotas (São Paulo), a prevalência de consumo de medicamentos foi de 41,1\%. Estudo conduzido por Moraes et al. (2011), em Maringá (Paraná) mostrou que 55\% dos 991adolescentes de 14 a 18 anos utilizaram algum medicamento nos 15 dias anteriores ao instrumento de coleta. Um fator preocupante levantando por esse estudo é de que a maioria dos adolescentes não sabia os nomes dos medicamentos por eles utilizados. Em Porto Alegre, estudo envolvendo amostra representativa de estudantes de 14 a 16 anos, mostrou que a prevalência de consumo de medicamentos, no período de sete dias foi de 47,9\% (SILVA; GIUGLIANE, 2004). Também em Porto Alegre, BERTOLDI et al., (2009) mostrou que prevalência de utilização de medicamentos entre adolescentes (10 a 19 anos) foi de $38,7 \%$.

\section{Práticas de risco no uso de medicamentos}

Um dos fatores de risco para a intoxicação de crianças com medicamentos é sua disponibilidade no domicílio, principalmente devido ao armazenamento inadequado. Em um estudo de abrangência nacional, foi demonstrado que $71,1 \%$ dos indivíduos participantes da pesquisa armazenavam algum medicamento em casa, sendo que o percentual de indivíduos que armazenam medicamentos foi maior entre mulheres e indivíduos mais velhos (CARVALHO et al., 2005). Indivíduos com maior escolaridade tendem a manter medicamentos em casa com maior frequência (CARVALHO et al., 2005). Outros estudos conduzidos no Brasil mostraram que em mais de 90\% dos domicílios há medicamentos em estoque (LASTE et al., 2012; MASTROIANNI et al., 2011). Em estudo conduzido no DF, 77\% dos 997 participantes afirmaram estocar medicamentos em armários e gavetas da cozinha, guarda roupas e banheiros, e apenas $13 \%$ deles afirmaram estocar medicamentos fora do alcance de crianças (ALMEIDA; CASTRO; CALDAS, 2011). Laste et al.(2012), ao estudarem o estoque domiciliar de medicamentos em comunidades atendidas pela Estratégia Saúde da Família de um município do Rio Grande do Sul, encontraram que 43,5\% dos lugares utilizados para a guarda, os medicamentos ficavam exposto ao calor, em 39,6\% à umidade e em 16,5\% à luz. Além disso, em $37,3 \%$ desses locais os medicamentos estavam ao alcance das crianças do domicílio. 
Estudos de utilização de medicamentos conduzidos no Brasil também discutem sobre atitudes praticadas em relação à utilização de medicamentos. Estudo conduzido no Distrito Federal mostrou que $45,9 \%$ dos 997 entrevistados relataram que sempre leem a bula dos medicamentos que consome, sendo que esta prática é mais comum entre as mulheres. Além disso, $74 \%$ dos entrevistados afirmaram verificar o prazo de validade dos medicamentos, sendo que $9,3 \%$ deles relataram consumir medicamentos após o fim do prazo de validade (ALMEIDA; CASTRO; CALDAS, 2011).

Entre as práticas relacionadas a medicamentos que podem contribuir para o uso de medicamentos de forma irracional destaca-se a automedicação. Em estudo de abrangência nacional conduzido em 2003, 25\% das pessoas que relataram ter utilizado pelo menos um medicamento no tempo determinado pelo estudo, não possuíam prescrição médica para nenhum dos medicamentos utilizados. A presença da prescrição médica foi significativamente mais frequente entre mulheres, pessoas mais velhas e aqueles que consideravam seu próprio estado de saúde como ruim ou muito ruim (CARVALHO et al., 2005). ALMEIDA; CASTRO; CALDAS (2011) mostraram que a indicação de algum medicamento pelo farmacêutico, pelo balconista da farmácia ou por outros indivíduos promove a prescindibilidade da receita médica. Também foi mostrado que, no contexto da automedicação, opta-se principalmente por algum medicamento que já tenha sido usado no passado e que $64 \%$ dos entrevistados indicam medicamentos a outras pessoas.

Estudo conduzido por Moraes et al. (2011) em Maringá mostrou que 53\% dos adolescentes que consumiram algum medicamento, nos 15 dias anteriores ao instrumento de coleta de informações utilizado na pesquisa, o fizeram no contexto da automedicação. Outros estudos conduzidos no Brasil mostram que aproximadamente metade dos medicamentos utilizados por adolescentes é por automedicação (SILVA; GIUGLIANI, 2004; PEREIRA et al., 2007). Em Pelotas, a automedicação, considerando-se um período recordatório de 15 dias, foi reportada por $26,7 \%$ dos 4.106 adolescentes entrevistados (BERTOLDI et al., 2014). Em relação aos medicamentos utilizados no Brasil, ARRAIS et al. (1997) mostrou que 44\% das especialidades procuradas para automedicação exigiam apresentação obrigatória de receita médica, 79\% não estavam incluídos na lista de medicamentos essenciais da OMS e 72\% não faziam parte da Relação Nacional de Medicamentos Essenciais (RENAME). 


\section{Classes terapêuticas mais utilizadas}

O Anatomical Therapeutic Chemical (ATC) é o sistema de classificação de medicamentos recomendado pela Organização mundial da saúde para realização de estudos de utilização de medicamentos (WHO, 2013). Esse sistema é amplamente utilizado ao redor do mundo e tal utilização contribui para a comparação entre estudos de utilização de medicamentos conduzidos em diferentes países (WHO, 2013).

Por meio do ATC, os medicamentos são classificados de acordo com o órgão ou sistema em que atuam e também em suas propriedades terapêuticas, farmacológicas e químicas (WHO, 2013). A classificação ATC envolve o agrupamento dos medicamentos em cinco níveis sequenciais. No primeiro nível, os princípios ativos são agrupados em 14 classes principais, de acordo com o sistema no organismo em que atuam. No segundo nível, são consideradas as propriedades terapêuticas, no terceiro, as características farmacológicas e, no quarto nível, as características químicas dos princípios ativos. No quinto nível da classificação ATC, o próprio princípio ativo do medicamento é definido. O Quadro 1 exemplifica a classificação ATC do princípio ativo metformina.

Quadro 1: Classificação ATC para metformina

\begin{tabular}{|c|c|c|}
\hline Código ATC & \multicolumn{1}{c|}{ Nível } & Classificação ATC \\
\hline A & $1^{0}$ nível: anatômico & Trato alimentar e metabolismo \\
\hline A10 & $2^{0}$ nível: subgrupo terapêutico & Medicamentos utilizados no diabetes \\
\hline A10B & $3^{0}$ nível: subgrupo farmacológico & Redutores de glicose sanguínea \\
\hline A10BA & $4^{0}$ nível: subgrupo químico & Biguanidas \\
\hline A10BA02 & $5^{0}$ nível: sustância química & Metformina \\
\hline
\end{tabular}

Fonte: WHO, 2013

A classificação ATC tem algumas limitações. De acordo com esse sistema, um fármaco pode ter mais de uma classificação conforme a indicação terapêutica, via de administração ou forma farmacêutica, como exemplificado para a prednisolona (Quadro 2). Além disso, medicamentos à base de plantas medicinais, produtos homeopáticos e muitas associações medicamentosas em dose fixa não são classificados pelo sistema ATC. Entretanto, pelo fato de esse sistema ser referendada pela OMS para padronização de estudos de utilização de medicamentos, esta classificação é amplamente utilizada (WHO, 2013). 
Quadro 2: Classificação ATC para prednisolona

Fonte: WHO, 2013

\begin{tabular}{|l|l|}
\hline Código ATC & \multicolumn{1}{l|}{ Classificação ATC } \\
\hline A07EA01 & Anti-inflamatórios intestinais \\
\hline C05AA04 & Anti-hemorroidais de uso tópico \\
\hline D07AA03 & Produtos dermatológicos \\
\hline H02AB06 & Corticosteroides de uso sistêmico \\
\hline R01AD02 & Descongestionantes nasais \\
\hline S01BA04 & Oftalmológicos \\
\hline S02BA03 & Otológicos \\
\hline
\end{tabular}

Diversos estudos de utilização de medicamentos conduzidos no Brasil utilizam o Anatomical Therapeutic Chemical (Tabela 4). Dentre os medicamentos mais utilizados pela população brasileira estão medicamentos que atuam sobre o sistema nervoso e sobre o sistema cardiovascular. Esse perfil varia com a idade e com a população estudada. Entre crianças de três meses de Pelotas, por exemplo, os medicamentos mais utilizados são medicamentos dermatológicos (como antifúngicos, emolientes, antissépticos), já entre crianças de um ano de idade a maior parte dos medicamentos utilizados foram medicamentos que atuam sobre o sistema respiratório (OLIVEIRA et al., 2010).

Estudo conduzido com indígenas de uma aldeia Guaraní do litoral de Santa Catarina mostrou que, dentre os medicamentos mais utilizados estavam medicamentos para tosse e resfriado, ou seja, medicamentos que atuam no sistema respiratório (DIEHL; GRASSI, 2010). 
Tabela 4: Principais classes de medicamentos utilizadas pela população brasileira de acordo com estudos de utilização de medicamentos conduzidos no país.

\begin{tabular}{|c|c|c|c|c|c|c|c|c|}
\hline Estudo & $\begin{array}{l}\text { Ano da } \\
\text { pesquisa }\end{array}$ & Local & Amostragem & $\begin{array}{l}\text { Idade } \\
\text { (anos) }\end{array}$ & $\begin{array}{c}\text { Tamanho } \\
\text { da amostra }\end{array}$ & $\begin{array}{l}\text { Período recor- } \\
\text { datório, dias }\end{array}$ & Classificação & $\begin{array}{l}\text { Principais grupos } \\
\text { (ordem crescente) }\end{array}$ \\
\hline $\begin{array}{l}\text { Carvalho et al., } \\
2005\end{array}$ & 2003 & Brasil & Estratificada; Censo & $\geq 18$ & $\begin{array}{l}5.000 \\
\text { indivíduos }\end{array}$ & 15 & $*$ & $* * ; \mathrm{C} ; \mathrm{R} ; * * *$ \\
\hline $\begin{array}{l}\text { Bertoldi et al., } \\
2009\end{array}$ & 2003 & $\begin{array}{l}\text { Porto Alegre } \\
\quad(\mathrm{RS})\end{array}$ & $\begin{array}{l}\text { Sistemática; área de cobertura de } \\
\text { Equipes de Saúde da Família }\end{array}$ & Todas & $\begin{array}{l}2.988 \\
\text { indivíduos }\end{array}$ & 15 & ATC & $\mathrm{N} ; \mathrm{C} ; \mathrm{M} ; \mathrm{A}$ \\
\hline $\begin{array}{l}\text { Costa et al., } \\
2011\end{array}$ & 2001-2002 & Campinas (SP) & $\begin{array}{c}\text { Sistemática e conglomerados; } \\
\text { senso }\end{array}$ & $\geq 18$ & $\begin{array}{l}941 \\
\text { indivíduos }\end{array}$ & 3 & ATC & $\mathrm{C} ; \mathrm{N} ; \mathrm{A} ; \mathrm{G}$ \\
\hline $\begin{array}{l}\text { Vosgerau et } \\
\text { al., } 2011\end{array}$ & 2006-2007 & $\begin{array}{l}\text { Ponta Grossa } \\
\text { (PR) }\end{array}$ & $\begin{array}{l}\text { Sistemática; área de cobertura de } \\
\text { uma Unidade de Saúde da Família }\end{array}$ & $\begin{array}{l}20-59 \\
\text { anos }\end{array}$ & $\begin{array}{l}347 \\
\text { indivíduos }\end{array}$ & 7 & ATC & $\mathrm{N} ; \mathrm{C} ; \mathrm{A} ; \mathrm{G}$ \\
\hline $\begin{array}{l}\text { Oliveira; } \\
\text { Novaes, } 2012\end{array}$ & 2007 & Brasília (DF) & $\begin{array}{l}\text { Conveniência; instituições de } \\
\text { longa permanência de idosos }\end{array}$ & $\geq 60$ & $\begin{array}{l}154 \\
\text { indivíduos }\end{array}$ & - & ATC & $\mathrm{C} ; \mathrm{N} ; \mathrm{A} ; \mathrm{H}$ \\
\hline $\begin{array}{l}\text { Santos et al., } \\
2013\end{array}$ & $2009-2010$ & Goiânia (GO) & Conglomerados; Censo & $\geq 60$ & $\begin{array}{c}934 \\
\text { indivíduos }\end{array}$ & $\begin{array}{l}\text { Uso regular de } \\
\text { medicamentos }\end{array}$ & ATC & $\mathrm{C} ; \mathrm{N} ; \mathrm{A} ; \mathrm{B}$ \\
\hline $\begin{array}{l}\text { Galvão et al., } \\
2014\end{array}$ & 2012 & Distrito Federal & $\begin{array}{c}\text { Conglomerados e estratificada; } \\
\text { Censo }\end{array}$ & $(18-65)$ & $\begin{array}{l}1.583 \\
\text { indivíduos }\end{array}$ & 7 & ATC & $\mathrm{C} ; \mathrm{A} ; \mathrm{N} ; \mathrm{G}$ \\
\hline
\end{tabular}

*Dicionário de Especialidades Farmacêuticas e/ou Dicionário Terapêutico Guanabara. **Analgésicos, antipiréticos, antiinflamatórios, relaxantes musculares; ***Medicamentos psicoativos. $\mathrm{A}=$ Aparelho digestivo e metabolismo, $\mathrm{B}=$ Sangue e órgãos hematopoiéticos, $\mathrm{C}=\mathrm{Sistema}$ cardiovascular, $\mathrm{G}=$ Sistema geniturinário e hormônios sexuais, $\mathrm{M}=$ Sistema músculo esquelético, $\mathrm{N}=$ Sistema nervoso, $\mathrm{R}=\mathrm{Sistema}$ respiratório 


\section{Estudos de utilização de medicamentos em outros países}

Um estudo quantitativo realizado nos Estados Unidos entre os anos de 2007 a 2010 mostrou que quase metade da população obteve pelo menos um medicamento de prescrição, no período de 30 dias. Essa utilização aumentou com a idade, envolvendo $24,0 \%$ das crianças e adolescentes de até 18 anos, 38,7\% dos adultos de 18 a 44 anos, $66,2 \%$ dos adultos de 45 a 64 anos e 89,7\% dos idosos de 65 anos ou mais (ESTADOS UNIDOS, 2013). Houve utilização de quatro ou mais medicamentos de prescrição em 23,2\% dos menores de 18 anos, 35,6\% dos adultos de 18 a 44 anos, $49,4 \%$ das pessoas de 45 a 64 anos e 50,0\% dos idosos de 65 anos ou mais. Medicamentos para doenças crônicas estão entre os mais comumente utilizados pelos norte-americanos, sendo que os destinados ao tratamento de doenças cardiovasculares são utilizados por $17,7 \%$ das pessoas de 18 a 64 anos e por 70,2\% das pessoas com 65 anos ou mais (ESTADOS UNIDOS, 2013).

Dados da Noruega, baseados nas vendas de medicamentos de prescrição mostram que, no ano de 2013, 68,6\% dos noruegueses tiveram pelo menos uma prescrição dispensada, sendo que a prevalência de prescrições foi maior entre homens até 14 anos. A partir dessa faixa etária, a prevalência é maior entre as mulheres e aumenta com a idade; cerca de $90 \%$ dos indivíduos de 70 anos ou mais receberam algum medicamento de prescrição (SAKSHAUG et al., 2014). Medicamentos para doenças do sistema nervoso; preparações hormonais de uso sistêmico e medicamentos para doenças respiratórias foram os grupos de medicamentos mais dispensados (SAKSHAUG et al., 2014).

$\mathrm{Na}$ Inglaterra, considerando-se o número de medicamentos de prescrição, observa-se que, em média, foram dispensados 19 medicamentos per capita no ano de 2013, sendo que o maior número de itens dispensados pertence à classe de medicamentos utilizados no tratamento de doenças cardiovasculares (INGLATERRA, 2014).

Dados do Inquérito Nacional de Saúde do Chile conduzido entre indivíduos maiores de 15 anos em 2009 e 2010, mostram que a prevalência de utilização de medicamentos de 52,4\%, sendo maior entre as mulheres (64\%). Cada chileno consume em média 1,4 medicamentos, com uma tendência de aumento com a idade e maior no grupo de menor escolaridade. Dentre os medicamentos mais consumidos pela população chilena estão os analgésicos e os agentes antihipertensivos (CHILE, 2013).

Diversos estudos qualitativos têm documentado a extensão das prescrições inadequadas de medicamentos entre idosos (BRADLEY et al., 2014; KOVACERVIC et al., 2014; CAHIR et al., 2010). Em estudos envolvendo hospitais de seis países europeus, a prevalência de 
medicação potencialmente inadequada entre idosos variou de 34,7\% em Praga a 77,3\% em Genebra (GALLAGHER et al., 2011). As causas frequentemente apontadas para esse mal são a duplicação terapêutica (BRADLEY et al., 2014; CAHIR et al., 2010), o uso de aspirina sem indicação (BRADLEY et al., 2014; KOVACERVIC et al., 2014), o uso inadequado de inibidores da bomba de prótons (BRADLEY et al., 2014; CAHIR et al., 2010), a prescrição de anti-inflamatórios não esteroidais por período maior que três meses, e de benzodiazepínicos por período maior que um mês (LIU et al, 2012; CAHIR et al 2010). Alguns estudos mostram que pacientes com mais de quatro prescrições (polifarmácia) têm risco maior de utilizar medicamentos potencialmente inapropriados (BRADLEY et al., 2014; KOVACERVIC et al., 2014; CAHIR et al., 2014).

\section{PESQUISA DE ORÇAMENTOS FAMILIARES (POF)}

A POF é conduzida pelo Instituto Brasileiro de Geografia e Estatística (IBGE) e tem como objetivo principal a obtenção de dados sobre a composição dos orçamentos dos domicílios brasileiros, sobre o estado nutricional e sobre as condições de vida da população brasileira. Tais informações são obtidas a partir da análise da alocação de gastos e da distribuição dos rendimentos dos domicílios e das pessoas (IBGE, 2012a). A partir dos dados coletados pela POF, pode-se conhecer os produtos adquiridos e os serviços utilizados pelas famílias brasileiras de todas as Unidades da Federação, durante um ano, bem como o que representa cada um desses produtos e serviços em relação ao total adquirido por essas famílias(IBGE, 2008; 2010).

A POF 2008-2009 é a quinta pesquisa realizada pelo IBGE sobre orçamentos familiares. Antes dela existiram quatro pesquisas: o Estudo Nacional da Despesa Familiar - ENDEF 19741975, no territorial nacional, com exceção das áreas rurais das Regiões Norte e Centro-Oeste; a POF 1987-1988; a POF 1995-1996; e a POF 2002-2003 (IBGE, 2010). A POF 2008-2009 apresenta diferenças relevantes em relação às pesquisas anteriores. Ela foi realizada em todo território brasileiro, incluindo áreas rurais e foram investigadas as aquisições não monetárias das famílias. Isso ocorreu devido à necessidade de obtenção de informações detalhadas sobre as condições de vida a partir do consumo, em especial, das famílias de menor rendimento (IBGE, 2010; 2012a). A POF 2008-2009 foi conduzida ao longo de 12 meses, entre os dias 19 de maio de 2008 e 18 de maio de 2009, período definido para contemplar as alterações a que os orçamentos estão sujeitos ao longo do ano (IBGE, 2010; 2012a). 
A seleção dos domicílios a serem visitados durante a POF 2008-2009 foi feita mediante a utilização da técnica estatística de amostragem. Cada domicílio pertencente à amostra da POF representa um determinado número de domicílios da população de onde esta amostra foi selecionada. Sendo assim, cada domicílio visitado está associado a um peso amostral, ou seja, a um fator de expansão (Fator de Expansão 2), o qual permite a obtenção de estimativas das características de interesse para o universo da pesquisa (IBGE, 2012a).

O desenho da amostra selecionada para a POF 2008-2009 foi estruturado de tal modo que propicia a publicação de resultados nos seguintes níveis: Brasil, Grandes Regiões (Norte, Nordeste, Sudeste, Sul e Centro-Oeste) e também por situações urbana e rural. Tal amostragem foi feita a partir de um cadastro comum de seleção de amostras conhecido como Amostra Mestra, o qual foi construído com base no Censo Demográfico do ano 2000 (IBGE, 2010). Como em outras pesquisas por amostragem realizadas pelo IBGE, o planejamento amostral da POF 2008-2009 envolveu a técnica de amostragem por conglomerados em dois níveis de seleção. No primeiro nível, foram selecionados setores censitários estratificados geograficamente e segundo a renda média dos chefes dos domicílios - estratificação estatística (IBGE, 2012a).

A estratificação geográfica envolveu a formação de grupos formados por unidades vizinhas e "parecidas". Sendo assim, levar em consideração o estrato geográfico significa que, que durante o processo de amostragem, foram escolhidos representantes de grupos que são, ao mesmo tempo, homogêneos segundo características escolhidas (renda média dos responsáveis pelo domicílio, taxa de desocupação, densidade demográfica e proporção de ocupados em atividades agrícolas) e vizinhos (IBGE, 2007).

A estratificação socioeconômica (estatística) ocorreu para formar subgrupos a partir de grupos formados na estratificação geográfica. A estratificação estatística consiste na formação de grupos homogêneos de setores censitários segundo a renda total dos responsáveis pelos domicílios (IBGE, 2007; 2012a).Ressalta-se que, nesse primeiro nível de seleção, os setores foram selecionados por amostragem, com probabilidade proporcional ao número de domicílios existentes em cada setor (IBGE, 2012a). A seleção dos setores censitários foi feita de forma aleatória, a partir de um quantitativo de setores censitários pertencentes à amostra mestra, respeitando as estratificações construídas na amostra mestra para cada Unidade da Federação (IBGE, 2007; 2008). Nessa etapa de seleção, foram selecionados 4.696 setores para a amostra da POF 2008-2009, a partir de um total de 12.800 setores censitários pertencentes à amostra mestra (IBGE, 2012a). 
Após a seleção dos setores censitários, foram selecionadas, de forma aleatória, as unidades secundárias de amostragem, ou seja, os domicílios particulares permanentes. Estes foram selecionados por amostragem aleatória simples sem reposição, dentro de cada um dos setores selecionados. Nesta etapa, foram selecionados para cada setor censitário em torno de 13 domicílios, para as áreas urbanas, e 18 domicílios para as áreas rurais. No total, foram selecionados 68.373 domicílios, considerando uma perda média de 15\%. No entanto, a perda foi maior do que a esperada, e 55970 domicílios foram entrevistados, o que corresponde a uma perda média de $18 \%$ (IBGE, 2012a).

A coleta de informações da POF é feita por meio de questionários (Figura 7), os quais são organizados conforme o tipo de informação a ser coletada (IBGE, 2008; 2010; 2012a) e aplicados em cada domicílio visitado (IBGE, 2008). Para a pesquisa de obtenção de medicamentos, os questionários relevantes são POF 1, POF 2, POF 3 e POF 4.

- POF 1 (Características do Domicílio e dos Moradores): por meio deste questionário são coletadas informações sobre os domicílios visitados, a relação e as características de seus moradores. Este questionário é aplicado no primeiro dia de entrevistas da POF.

- POF 2 (Questionário de Aquisição Coletiva): este questionário é preenchido para cada domicílio pela pessoa de referência e por cada membro do domicílio, sendo preenchido entre o segundo e o oitavo dia da entrevista. A pessoa de referência é aquela pessoa responsável por uma das seguintes despesas: aluguel, prestação do imóvel ou outras despesas de habitação. A POF 2 contém dados referentes às aquisições monetárias e não monetárias de produtos de uso comum da família, como despesas monetárias com serviços e taxas, despesas com serviços domésticos; construção; reforma e pequenos reparos no domicílio, dados que podem ser utilizadas na classificação econômica dos domicílios.

- POF 3(Caderneta de Aquisição Coletiva): este questionário tem informações sobre as aquisições do domicílio, incluindo alimentos, bebidas, artigos de higiene pessoal e de limpeza. Ele é entregue no primeiro dia da entrevista e preenchido ao longo de sete dias consecutivos.

- POF 4 (Questionário de Aquisição Individual): este questionário é preenchido entre o segundo e o oitavo dia da entrevista, por cada membro da família que tenha realizado aquisições que resultaram em despesas monetárias e/ou não monetárias. Nele são coletadas informações sobre a aquisição de produtos e serviços, incluindo a aquisição de produtos farmacêuticos no período de referência de 30 dias que antecede à data de realização da coleta no domicílio (quadro 29). Adicionalmente, têm informação de aquisição de artigos de fumo nos últimos 7 dias (quadro 25). 

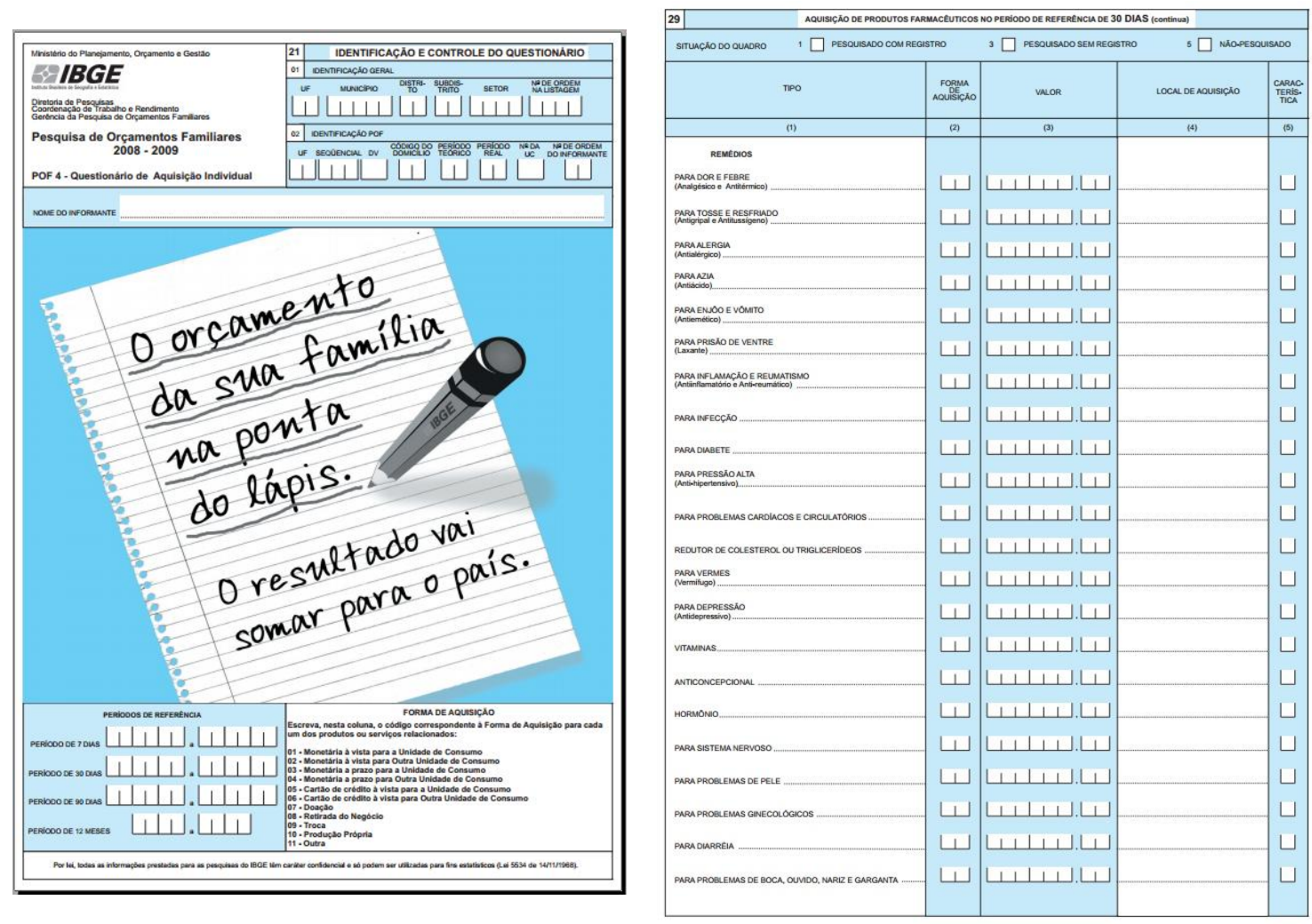

Figura 7: Questionário POF 4 da Pesquisa de Orçamentos Familiares 2008-2009 


\section{OBJETIVOS}

\section{Geral}

Analisar a aquisição de medicamentos pelos domicílios brasileiros a partir dos dados obtidos na Pesquisa de Orçamentos Familiares 2008-2009.

\section{Específicos}

- Caracterizar os domicílios brasileiros em que houve relato de obtenção de medicamentos bem como a população residente nesses domicílios;

- Caracterizar a aquisição de medicamentos de acordo com o status socioeconômico do domicílio, forma de acesso, local de obtenção e característica do medicamento;

- Classificar os medicamentos adquiridos conforme a Anatomical Therapeutic Chemical (ATC);

- Identificar as classes ATC mais adquiridas pelos domicílios;

- Relacionar a aquisição de medicamentos com o número de intoxicações medicamentosas registradas em sistemas de informação nacionais;

- Relacionar as classes ATC adquiridas com o status socioeconômico dos domicílios, suas características (condições sanitárias, localização, aquisição de fumo e álcool)

- Relacionar as classes ATC adquiridas com as características da população residente (sexo, faixa etária, anos de estudo e status nutricional);

- Avaliar a POF como fonte de informação sobre aquisição e uso de medicamentos no país. 


\section{MATERIAIS E MÉTODOS}

Este é um estudo transversal de base populacional que utilizou dados da Pesquisa de Orçamentos Familiares (POF 2008-2009), conduzida pelo IBGE por meio de questionários aplicados entre maio/2008 e maio/2009 em 55.970 residências em todo o Brasil (IBGE, 2014). As unidades de análise foram os domicílios participantes da pesquisa, a população residente nesses domicílios (indivíduos) e os medicamentos adquiridos nos 30 dias anteriores à entrevista. (IBGE, 2010; 2012a).

Os dados da POF de interesse para este trabalho foram extraídos dos arquivos tipo .txt disponibilizados pelo IBGE (2014) para um banco de dados criado em ambiente Microsoft ${ }^{\circledR}$ Office Access ${ }^{\mathrm{TM}}$. Os dados categorizados foram exportados para uma planilha do Microsoft ${ }^{\circledR}$ Office Excel ${ }^{\mathrm{TM}}$ e depois para o software IBM ${ }^{\circledR}$ SPSS Statistics, versão 20 para a realização das análises descritivas. As análises foram realizadas com a utilização do fator de expansão 2, um peso amostral associado a cada domicílio da amostra, o que permite que as observações feitas sejam válidas para toda população brasileira.

No presente trabalho foram realizadas análises descritivas. Testes de significância não foram aplicados porque, devido ao grande número de unidades amostrais, a análise estatística de significância não é confiável, pois efeitos não importantes podem ser considerados estatisticamente significativos (FIELD; HOLE, 2003).

\section{Variáveis referentes aos domicílios}

Localização dos domicílios e número de moradores-quadro 2 do questionário POF 1: foram utilizadas informações referentes à Unidade Federativa e à área em que o domicílio participante está localizado (urbana ou rural), bem como a informação referente ao número de moradores por domicílio.

Classe econômica: a classificação econômica das famílias participantes da POF 2008-2009 foi feita de acordo com o Critério de Classificação Econômica Brasil da Associação Brasileira de Empresas de Pesquisa (ABEP, 2008; 2009). Tal classificação é feita com base na posse de alguns bens, bem como no grau de instrução do chefe da família (Tabelas 5 e 6) e permite a classificação dos domicílios em sete estratos, sendo que o estrato A1 representa a melhor condição econômica e o estrato E, a pior (ABEP, 2008; 2009).

As informações requeridas pelo Critério de Classificação Econômica Brasil foram obtidas a partir dos dados dos questionários POF 1 e POF 2. Informações sobre o número de 
banheiros do domicílio foram obtidas do quadro 2 (Características do Domicílio) do questionário POF 1. Informações relativas aos bens de consumo (como automóvel, geladeira e televisão) foram obtidas do quadro 14 (Inventário de bens duráveis do domicílio principal) do questionário POF 2. Informações referentes a empregada mensalista foram obtidas do quadro 19 (Serviços domésticos no período de referência de 12 meses) do questionário POF 2. Neste quadro foram coletadas informações sobre o tipo de serviço contratado pelas famílias (como empregada, motorista, cozinheiro e babá) e também informações sobre a espécie de serviço prestado (se a pessoa contratada é mensalista, diarista ou se não se sabe qual o tipo de relação de trabalho). Para classificação econômica dos domicílios, foram considerados apenas os serviços domésticos em que o empregado foi classificado como mensalista, conforme a determinação prevista na classificação (ABEP, 2008-2009).

Tabela 5: Pontuação relativa à posse de itens

\begin{tabular}{|c|c|c|c|c|c|}
\hline \multirow{2}{*}{ Itens avaliados } & \multicolumn{5}{|c|}{ Pontuação em relação à quantidade de itens } \\
\hline & 0 & 1 & 2 & 3 & 4 ou + \\
\hline Televisão em cores & 0 & 1 & 2 & 3 & 4 \\
\hline Rádio & 0 & 1 & 2 & 3 & 4 \\
\hline Banheiro & 0 & 4 & 5 & 6 & 7 \\
\hline Automóvel & 0 & 4 & 7 & 9 & 9 \\
\hline Empregada mensalista & 0 & 3 & 4 & 4 & 4 \\
\hline Máquina de lavar & 0 & 2 & 2 & 2 & 2 \\
\hline Videocassete e/ou DVD & 0 & 2 & 2 & 2 & 2 \\
\hline Geladeira & 0 & 4 & 4 & 4 & 4 \\
\hline $\begin{array}{l}\text { Freezer (aparelho independente } \\
\text { ou parte da geladeira duplex) }\end{array}$ & 0 & 2 & 2 & 2 & 2 \\
\hline \multicolumn{6}{|c|}{$\begin{array}{l}\text { Fonte: ABEP, 2008; } 2009 \\
\quad \text { Informações relativas ao grau de instrução do chefe da família foram obtidas do quadr }\end{array}$} \\
\hline \multicolumn{6}{|c|}{4 (Características do Morador) da POF 1, por meio da variável anos de estudo. Ressalta-se que } \\
\hline
\end{tabular}


Tabela 6: Pontuação relativa ao grau de instrução do chefe da família.

\begin{tabular}{ccc}
\hline Grau de instrução do chefe de família & $\begin{array}{c}\text { Anos de estudo } \\
\text { (POF 2008-2009) }\end{array}$ & Pontuação \\
\hline Analfabeto / Até 3 ${ }^{\text {a }}$ série fundamental & $0-3$ & 0 \\
Até 4 ${ }^{\text {a }}$ série fundamental & $4-7$ & 1 \\
Fundamental completo $^{\text {Médio completo }}$ & $8-10$ & 2 \\
Superior completo & $11-14$ & 4 \\
15 ou mais & 8 \\
\hline
\end{tabular}

Fonte: ABEP, 2008; 2009; IBGE, 2014

A partir das pontuações de posse de itens e grau de instrução do chefe da família, foi obtida a classificação econômica de cada domicílio (Tabela 7).

Tabela 7: Classificação econômica a partir das pontuações dos domicílios.

\begin{tabular}{cc}
\hline Pontos obtidos pelo domicílio & Classificação Econômica \\
\hline $42-46$ & A1 \\
$35-41$ & A2 \\
$29-34$ & B1 \\
$23-28$ & B2 \\
$18-22$ & C1 \\
$14-17$ & C2 \\
$8-13$ & D \\
$0-7$ & E \\
\hline
\end{tabular}

Fonte: ABEP, 2008; 2009

Após a classificação econômica dos domicílios, avaliou-se a renda per capta média de cada classe econômica por meio dos dados de renda monetária mensal do domicílio e quantidade de moradores.

Aquisição de bebidas alcoólicas: no questionário POF 3 (Caderneta de Aquisição Coletiva), foram registradas informações sobre as aquisições de bebidas alcoólicas nos domicílios entrevistados, durante o período de sete dias (IBGE, 2014). Para cada bebida alcoólica consumida, foi calculada a quantidade de álcool, a partir da média de teor alcoólico da bebida correspondente, obtido na legislação brasileira (Apêndice A) e dos dados da variável quantidade final em $\mathrm{Kg}$, do questionário POF 3 (Equação). Ressalta-se que, a densidade de todas as bebidas citadas na POF 2008-2009 foi considerada como sendo $1 \mathrm{~g} / \mathrm{cm}^{3}$. As quantidades de álcool das bebidas adquiridas nos domicílios foram então somadas, dando origem à variável Quantidade de álcool adquirida $(\mathrm{mL})$. 
Quantidade de álcool $(\mathrm{mL})=\underline{\text { Grau alcoólico médio }(\% \mathrm{v} / \mathrm{v}) \times \text { quantidade final }(\mathrm{kg}) \times 1000}$

100

Ressalta-se que grau alcoólico médio utilizado para cervejas e chopes, foi calculado a partir da média de teor alcoólico das 6 cervejas mais comercializadas no mercado consumidor brasileiro e que o grau alcoólico da resposta Bebida alcoólica não-especificada foi considerado como sendo a média dos teores alcoólicos médios das outras bebidas citadas na POF 20082009. Sendo assim, foi considerado o valor de $25,8 \% \mathrm{v} / \mathrm{v}$.

Aquisição de artigos de fumo no período de 7 dias-quadro 25 do questionário POF 4: foram obtidas informações sobre aquisições de artigos de fumo pelos morados de cada domicílio. Quando pelo menos um morador do domicílio adquiriu algum dos artigos de fumo mencionados na POF 4, foi considerado que no domicílio houve obtenção de artigos de fumo.

Outras variáveis - quadro 2 do questionário POF 1:outras variáveis analisadas foram a existência de água canalizada no domicílio, o tipo de escoadouro sanitário (rede coletora de esgoto ou pluvial; fossa séptica; fossa rudimentar; vala, direto para rio, lago ou mar; outra forma; não tem), proximidade a área industrial, proximidade a lixão ou depósito de lixo e a proximidade a esgoto a céu aberto ou valão.

\section{Variáveis referentes aos indivíduos}

Características dos indivíduos - quadros 3 e 4 do questionário POF 1: foram utilizadas informações referentes ao sexo idade e escolaridade (anos de estudo) dos moradores dos domicílios entrevistados. Neste estudo, os indivíduos foram classificados pela idade, de acordo com a norma técnica do Sistema de Vigilância Alimentar e Nutricional, com adaptações (BRASIL, 2011b), resultando na seguinte classificação:

- Crianças: indivíduos de zero a nove anos de idade;

- Adolescentes: indivíduos de dez a 19 anos de idade;

- Adultos jovens: indivíduos de 20 a 39 anos de idade;

- Adultos: indivíduos de 40 a 59 anos de idade;

- Idosos: indivíduos de 60 anos ou mais de idade. 
Diagnóstico Nutricional - quadros 3 e 4 do questionário POF 1: o diagnóstico nutricional dos indivíduos citados na POF 2008-2009 foi calculado a partir dos dados de peso imputado, altura imputada e idade, de acordo com a Norma Técnica da Vigilância Alimentar e Nutricional SIVAN (BRASIL, 2011b). Os critérios de classificação descritos nessa norma técnica estão descritos na Tabela 8.

Para a obtenção do diagnóstico nutricional dos participantes da POF 2008-2009, foram utilizadas as informações coletadas por meio do questionário POF 1 referentes a:

- Idade calculada em meses: utilizado para a identificação dos percentis de crianças e adolescentes de zero a 19 anos e 11 meses de idade;

- Idade calculada em anos: utilizado para o diagnóstico nutricional de adultos e idosos;

- Peso imputado: utilizado para o cálculo Índice de Massa Corporal (IMC);

- Altura imputada: utilizada para o cálculo de IMC;

- Comprimento imputado: utilizado para o cálculo de IMC de menores de 24 meses de idade.

Tabela 8: Critérios utilizados no diagnóstico nutricional de crianças, adolescentes, adultos e idosos.

\begin{tabular}{cc}
\hline \multicolumn{2}{c}{ Crianças $<\mathbf{5}$ anos } \\
\hline Critério: IMC para idade & Diagnóstico Nutricional \\
$<$ Percentil 0,1 & Magreza acentuada (MA) \\
$\geq$ Percentil 0,1 e $<$ Percentil 3 & Magreza (M) \\
$\geq$ Percentil $3 \mathrm{e} \leq$ Percentil 85 & Eutrofia (E) \\
$>$ Percentil 85 e $\leq$ Percentil 97 & Risco de sobrepeso (RS) \\
$>$ Percentil 97 e $\leq$ Percentil 99,9 & Sobrepeso (S) \\
$>$ Percentil 99,9 & Obesidade (O) \\
\hline \multicolumn{2}{c}{ Crianças $\geq \mathbf{5}$ anos e $<\mathbf{1 0}$ anos } \\
\hline Critério: IMC para idade & Diagnóstico Nutricional \\
$<$ Percentil 0,1 & Magreza acentuada (MA) \\
$\geq$ Percentil 0,1 e $<$ Percentil 3 & Magreza (M) \\
$\geq$ Percentil 3 e $\leq$ Percentil 85 & Eutrofia (E) \\
$>$ Percentil 85 e $\leq$ Percentil 97 & Sobrepeso (S) \\
$>$ Percentil 97 e $\leq$ Percentil 99,9 & Obesidade (O) \\
$>$ Percentil 99,9 & Obesidade Grave (OG)
\end{tabular}




\begin{tabular}{|c|c|}
\hline \multicolumn{2}{|c|}{ Adolescentes $(\mathrm{A} \geq 10$ anos $\mathrm{e}<20$ anos $)$} \\
\hline Critério: IMC para idade & Diagnóstico Nutricional \\
\hline$<$ Percentil 0,1 & Magreza acentuada (MA) \\
\hline$\geq$ Percentil $0,1 \mathrm{e}<$ Percentil 3 & Magreza (M) \\
\hline$\geq$ Percentil 3 e $\leq$ Percentil 85 & Eutrofia (E) \\
\hline$>$ Percentil 85 e $\leq$ Percentil 97 & Sobrepeso (S) \\
\hline$>$ Percentil 97 e $\leq$ Percentil 99,9 & Obesidade $(\mathrm{O})$ \\
\hline$>$ Percentil 99,9 & Obesidade Grave (OG) \\
\hline \multicolumn{2}{|c|}{ Adultos $(\mathrm{AA} \geq 20$ e $<60$ anos $)$} \\
\hline Critério: IMC & Diagnóstico Nutricional \\
\hline$<18,5$ & Baixo Peso (BP) \\
\hline$\geq 18,5$ e $<25$ & Eutrofia $(\mathrm{E})$ \\
\hline$\geq 25$ e $<30$ & Sobrepeso (S) \\
\hline$\geq 30$ & Obesidade (O) \\
\hline \multicolumn{2}{|c|}{ Idosos $(I \geq 60$ anos $)$} \\
\hline Critério: IMC & Diagnóstico Nutricional \\
\hline$\leq 22$ & Baixo Peso (BP) \\
\hline$>22 \mathrm{e}<27$ & Eutrofia $(\mathrm{E})$ \\
\hline$\geq 27$ & Sobrepeso (S) \\
\hline
\end{tabular}

Fonte: BRASIL, 2011b

Acesso a plano de saúde - quadro 4 do questionário POF 1: a variável tem plano de saúde identifica a filiação ou não a plano ou seguro de saúde de cada pessoa envolvida na pesquisa.

Acesso a medicamentos - quadros 3 e 4 do questionário POF 1: a variável teve necessidade de medicamento identifica o morador teve necessidade de algum medicamento, nos 30 dias anteriores à entrevista, mas não o adquiriu por falta de dinheiro. As categorias de resposta para essa variável, estabelecidas pelo IBGE foram: não aplicável, sim, não e não sabe. No presente estudo foram exploradas as respostas sim.

\section{Variáveis referentes aos medicamentos obtidos}

Aquisição de medicamento - quadro 29 do questionário POF 4: este quadro se refere a "aquisição de produtos farmacêuticos no período de referência de 30 dias" e apresenta 352 respostas diferentes referentes ao consumo de produtos farmacêuticos, que foram dadas pelos participantes da Pesquisa. Primeiramente, foram excluídas 89 respostas que não faziam referência a medicamentos, incluindo agulha de injeção, aparelho de medição de glicose, bolsa 
térmica, bomba para higiene nasal, chupeta ou bico, fita adesiva para curativo e fralda descartável.

As respostas referentes ao consumo de medicamentos (Apêndice B) foram classificadas de acordo com o sistema de classificação anatômica, terapêutica e química (Anatomical Terapeutic Chemical - ATC), recomendado para classificação em estudos de utilização de medicamentos (WHO, 2013). Como as respostas da POF não se encaixaram perfeitamente na classificação ATC, foram estabelecidos alguns critérios de classificação, os quais são descritos abaixo:

1. Respostas referentes a medicamentos que poderiam ser enquadradas em dois grupos principais do sistema ATC:

- Tratamento de alergia: os fármacos que são utilizados com maior frequência para aliviar os sintomas das alergias são os anti-histamínicos (BEERS, 2009). Sendo assim, as respostas referentes ao tratamento da alergia foram classificadas no grupo Sistema respiratório (código ATC: R) e no subgrupo Anti-histamínicos de uso sistêmico (código ATC: R06).

- Tratamento do lúpus: o tratamento medicamentoso do lúpus pode envolver medicamentos antimaláricos (como cloroquina e hidroxicloroquina), antiinflamatórios não esteroidais, glicocorticoides, entre outros (BEERS, 2009; BRASIL, 2013). No entanto, os glicocorticoides são os fármacos mais utilizados no tratamento (BRASIL, 2013). Sendo assim, as respostas referentes ao tratamento do lúpus foram classificadas no grupo Preparações hormonais sistêmicas, exceto hormônios sexuais e insulina (código ATC: H), no subgrupo Corticosteroides para uso sistêmico (código ATC: H02).

- Tratamento de enxaqueca: essas respostas foram classificadas no subgrupo Analgésicos (código ATC: N02) do grupo Sistema nervoso. Esta classe contempla fármacos analgésicos, opióides e preparações anti-enxaqueca tais como derivados ergotamínicos e agonistas seletivos dos receptores de serotonina (WHO, 2013). Apesar de essa classificação não abranger alguns medicamentos utilizados no tratamento da enxaqueca como beta bloqueadores, bloqueadores dos canais de cálcio (pertencentes ao grupo Sistema cardiovascular) e fármacos anti-inflamatórios não esteroidais (pertencentes ao grupo Sistema músculo esquelético), ela contempla a maioria dos medicamentos utilizados para este fim (BEERS, 2009). 
2. Respostas que não faziam referência direta nenhuma classe de medicamentos do sistema ATC.

- Medicamentos utilizados para o pâncreas: as respostas pancreático e para o pâncreas foram classificadas no subgrupo Analgésicos (código ATC: N02) do grupo Sistema Nervoso. Isso porque as principais doenças pancreáticas são a pancreatite (aguda ou crônica) e câncer do pâncreas (TOSKES; GREENBERGER, 2008; BEERS, 2009). O tratamento medicamentoso das pancreatites aguda e crônica costuma envolver a utilização de analgésicos (BEERS, 2009). O tratamento de câncer de pâncreas envolve o uso de medicamentos do grupo Agentes antineoplásicos e imunomoduladores (BEERS, 2009) e pela gravidade desse tratamento, considerouse que as pessoas submetidas a ele iriam indicar a utilização de algum medicamento para o tratamento do câncer.

3. Respostas que puderam ser classificadas dentro do grupo principal da ATC, mas não dentro de um subgrupo.

- Para essas respostas foram criados os itens Subgrupo não identificado, os quais foram codificados de acordo com a letra do grupo principal seguida de dois números zero. Por exemplo, a resposta "para problemas de coagulação", foi classificada no grupo Sangue e órgãos formadores do sangue (código ATC: B), mas essa resposta poderia ser agrupada no subgrupo Agentes antitrombóticos (código ATC: B01) ou no subgrupo Agentes anti-hemorrágicos (código ATC: B02). Portanto, essas respostas foram agrupadas no subgrupo B00 (Subgrupo não identificado).

\section{Respostas que não são contempladas pelo sistema ATC}

- Produtos homeopáticos e produtos à base de ervas da medicina tradicional: foi criado o grupo principal Tratamento Alternativo (TA).

- Medicamentos indeterminados: Para as respostas remédio indeterminado, remédio manipulado indeterminado, injeção ampola (não determinada) e pomada indeterminada, foi criado o grupo principal medicamento indeterminado (MI).

Ao final, as respostas da POF 2008-2009 referentes a aquisição de medicamentos foram classificadas em 16 grupos principais do sistema ATC. 
Características dos medicamentos obtidos - quadro 29 da POF 4: os participantes registraram informações sobre características dos medicamentos adquiridos sendo que as opções de resposta dadas pela POF foram: medicamento de marca (referência ou similar), medicamento genérico, medicamento a base de plantas medicinais e medicamento manipulado.

Forma de acesso aos medicamentos - quadro 29 da POF 4: as respostas desse quadro foram agrupadas em três variáveis: medicamento adquirido por meio de recursos próprios (A), medicamento doado (D) e outra forma de acesso ao medicamento (O) (Quadro 3). Quando a obtenção de medicamento foi destinada a outra unidade de consumo, ela foi considerada como sendo para o domicílio do indivíduo que obteve o medicamento.

Quadro 3: Classificação das respostas da POF 2008-2009 quanto a forma de acesso aos medicamentos.

\begin{tabular}{|c|l|}
\hline Classificação & \multicolumn{1}{c|}{ Resposta } \\
\hline Aquisição (A) & Monetária à vista para a unidade de consumo; \\
& Monetária à vista para outra unidade de consumo; \\
& Monetária a prazo para a unidade de consumo; \\
& Monetária a prazo para outra unidade de consumo; \\
& Cartão de crédito à vista para a Unidade de Consumo; \\
& Cartão de crédito à vista para outra Unidade de consumo; \\
& Retirada de negócio; \\
& Troca; \\
& Produção própria; \\
\hline Doação (D) & Doação \\
\hline Outra (O) & Outra \\
\hline
\end{tabular}

Local de obtenção de medicamentos - quadro 29 da POF 4: foram encontradas 162 respostas diferentes, as quais foram classificadas em 12 grupos (Quadro 4). Quando a forma de aquisição do medicamento foi a doação e o local de aquisição foram farmácias ou drogarias, tais locais de aquisição foram considerados como sendo farmácias do SUS. 
Quadro 4: Classificação das respostas da POF 2008-2009 relativas ao local de obtenção dos medicamentos.

\begin{tabular}{|c|c|}
\hline Categoria & Resposta \\
\hline Ambulante & $\begin{array}{l}\text { Ambulante, barraca (vendedor ambulante), barracão, camelo, fiteiro, } \\
\text { galego (vendedor ambulante), padeiro ambulante, prestação } \\
\text { (vendedor ambulante), regatão (vendedor ambulante embarcado), } \\
\text { representante de vendas, revendedor, sacoleiro, vendedor ambulante. }\end{array}$ \\
\hline $\begin{array}{l}\text { Bar, lanchonete, } \\
\text { restaurante }\end{array}$ & $\begin{array}{l}\text { Baiuca, bar, bar/lanchonete, barzinho, boteco, botequim (bar), } \\
\text { taberna, vitaminosa (açaí). }\end{array}$ \\
\hline $\begin{array}{l}\text { Clínica, } \\
\text { consultório, } \\
\text { hospital, } \\
\text { laboratório }\end{array}$ & $\begin{array}{l}\text { Clínica de estética, clínica de reabilitação, clínica especializada } \\
\text { médica e laboratorial, clínica médica, consultório médico, hospital } \\
\text { particular, laboratório de análise/radiologia/ultrassom/etc, Santa } \\
\text { Casa }\end{array}$ \\
\hline $\begin{array}{c}\text { Farmácia, } \\
\text { drogaria }\end{array}$ & $\begin{array}{l}\text { Drogaria, drogaria com convênio, farmácia, farmácia com convênio, } \\
\text { farmácia/drogaria, farmácia de manipulação. }\end{array}$ \\
\hline $\begin{array}{c}\text { Farmácia } \\
\text { homeopática }\end{array}$ & Farmácia homeopática \\
\hline $\begin{array}{c}\text { Programa } \\
\text { Farmácia Popular } \\
\text { do Brasil }\end{array}$ & $\begin{array}{l}\text { Drogaria (convênio farmácia popular), farmácia (convênio farmácia } \\
\text { popular), farmácia popular (estabelecimento próprio). }\end{array}$ \\
\hline Horta, mata & $\begin{array}{l}\text { Fazenda, horta, horta comunitária (associação de moradores), mata, } \\
\text { plantação própria, quintal, sítio/quintal. }\end{array}$ \\
\hline $\begin{array}{c}\text { Loja de produtos } \\
\text { naturais }\end{array}$ & $\begin{array}{l}\text { Flora de artigos religiosos, loja de artigos religiosos, loja de produtos } \\
\text { naturais e macrobióticos, loja de produtos terapêuticos, natural }\end{array}$ \\
\hline Mercado & $\begin{array}{l}\text { Agropecuária, armarinho, armazém, atacadista, bazar, bodega } \\
\text { (armazém), bodega (mercearia), casa do apicultor, casa de produtos } \\
\text { veterinários, casa de ração, feira, feira-livre, frangaria, free shop (loja } \\
\text { de importados), frutaria, hipermercado, hortifrúti, importadora e free } \\
\text { shop, loja atacadista, loja de artigos de higiene pessoal, loja de } \\
\text { conveniência, loja de cosméticos, loja de cosméticos e perfumaria, } \\
\text { loja de departamento, loja de importados, loja de produtos } \\
\text { hospitalares, loja de produtos veterinários, loja de utilidades, lojinha, } \\
\text { mercadinho, mercadinho (quitanda), mercado, mercado (armazém), } \\
\text { mercado estadual, mercado municipal, mercantil, mercearia, mini- } \\
\text { box, minimercado (armazém), negócio próprio, ótica, padaria, } \\
\text { panificadora, perfumaria, posto de combustível (loja de } \\
\text { conveniência), posto de pão, quitanda, sacolão, supermercado, } \\
\text { tabacaria, tendinha (quitanda), venda, veterinária (loja). }\end{array}$ \\
\hline SUS & $\begin{array}{l}\text { Funasa, governo (não especificado), governo do estado, governo } \\
\text { federal, hospital público, laboratórios oficiais, órgãos públicos, posto } \\
\text { de saúde público, prefeitura municipal, SUS (doação em posto de } \\
\text { saúde, hospital), SUS (doação em posto de saúde) }\end{array}$ \\
\hline Terceiro & $\begin{array}{l}\text { Agentes de comunicação, alfaiate, condomínio (síndico), domicílio } \\
\text { particular, estofaria (conserto de veículo), marcenaria, particular, } \\
\text { particular (terceiro), profissional liberal, técnico em computação } \\
\text { (particular), terceiro (particular) }\end{array}$ \\
\hline
\end{tabular}




\begin{tabular}{|c|l|}
\hline Categoria & \multicolumn{1}{|c|}{ Resposta } \\
\hline \multirow{5}{*}{ Outros } & $\begin{array}{l}\text { Academia de artes e esportes, academia de ginástica, administradora } \\
\text { de plano de saúde, asilo, associação (recreação, futebol, clube, etc), } \\
\text { associação comunitária, associação de caridade, atendimento } \\
\text { particular (catálogo Hermes, Avon, Natura, etc), Avon (catálogo), } \\
\text { bolicho, catálogo, catálogo (Hermes, Avon, Natura, etc), centro } \\
\text { espírita/de umbanda/etc, clínica veterinária, clube esportivo, } \\
\text { cooperativa de produtores rurais, empresa privada, empresa pública, } \\
\text { escola, estabelecimento escolar, estabelecimento filantrópico, } \\
\text { fabricante, faculdade, igreja, internet, instituto de previdência } \\
\text { pública, linha direta (venda por telefone), Natura (catálogo), pastoral, } \\
\text { produção própria, quartel, salão de beleza (clínica), sindicato de } \\
\text { classe, telemarketing, ignorado, não sabe. }\end{array}$ \\
\hline
\end{tabular}




\section{RESULTADOS E DISCUSSÃO}

\section{Descrição da população}

Dos 55.970 domicílios visitados pela POF 2008/2009, 13.022 (23,3\%) estão localizados em áreas rurais e 42.948 (76,7\%) em áreas urbanas. Cerca de 14\% são domicílios da Região Norte (7.611), 34,4\% da Região Nordeste (19.232), 14,9\% da Região Centro-Oeste (8.333), $25,2 \%$ da Região Sudeste (14.078) e 12\% da Região Sul (6.716). Quando aplicado o fator de expansão, estes domicílios somaram um total de 57.691 .781 domicílios brasileiros. O número de domicílios e indivíduos envolvidos na amostra original e da amostra expandida da POF está descrito na Tabela 9. A não ser que seja especificado o contrário, os resultados deste estudo foram expressos considerando-se o fator de expansão do domicílio.

Tabela 9: Número de domicílios e de indivíduos envolvidos na amostra original da POF e na amostra expandida no Brasil, por região urbana e rural e nas macrorregiões brasileiras.

\begin{tabular}{|c|c|c|c|c|}
\hline & \multicolumn{2}{|c|}{ Domicílios } & \multicolumn{2}{|c|}{ Indivíduos } \\
\hline & $\begin{array}{c}\text { Amostra } \\
\text { original }\end{array}$ & $\begin{array}{c}\text { Amostra } \\
\text { expandida }\end{array}$ & $\begin{array}{c}\text { Amostra } \\
\text { original }\end{array}$ & $\begin{array}{c}\text { Amostra } \\
\text { expandida }\end{array}$ \\
\hline \multicolumn{4}{|c|}{ Total de domicílios } & 190.519 .297 \\
\hline \multicolumn{5}{|c|}{ Domicílios em que houve relato de obtenção de medicamento } \\
\hline Brasil & 45.464 & 47.827 .234 & 158.574 & 161.556 .999 \\
\hline Região urbana & 35.179 & 40.546 .522 & 120.932 & 134.578 .986 \\
\hline Região rural & 10.285 & 7.280 .712 & 37.642 & 26.978 .013 \\
\hline Sudeste & 11.442 & 21.123 .934 & 36.903 & 67.709 .891 \\
\hline Sul & 5.616 & 7.511 .058 & 17.853 & 23.803 .028 \\
\hline Centro-Oeste & 6.479 & 3.445 .245 & 21.133 & 11.221 .035 \\
\hline Nordeste & 15.858 & 12.571 .862 & 58.466 & 45.949 .082 \\
\hline Norte & 6.069 & 3.175 .135 & 24.219 & 12.873 .963 \\
\hline
\end{tabular}

A aquisição de medicamentos foi reportada por 45.464 domicílios, ou seja, $81.2 \%$ dos domicílios visitados. O percentual de domicílios que relataram a aquisição de pelo menos um medicamento no Brasil, por macrorregião e por região urbana e rural é mostrado na Figura 8. Observa-se que a região sul apresentou o mais alto percentual de domicílios que obtiveram algum medicamento no período de referência da pesquisa $(84,6 \%)$, sendo que, nas regiões Sul, Nordeste e Sudeste, este percentual foi maior que o do Brasil. 


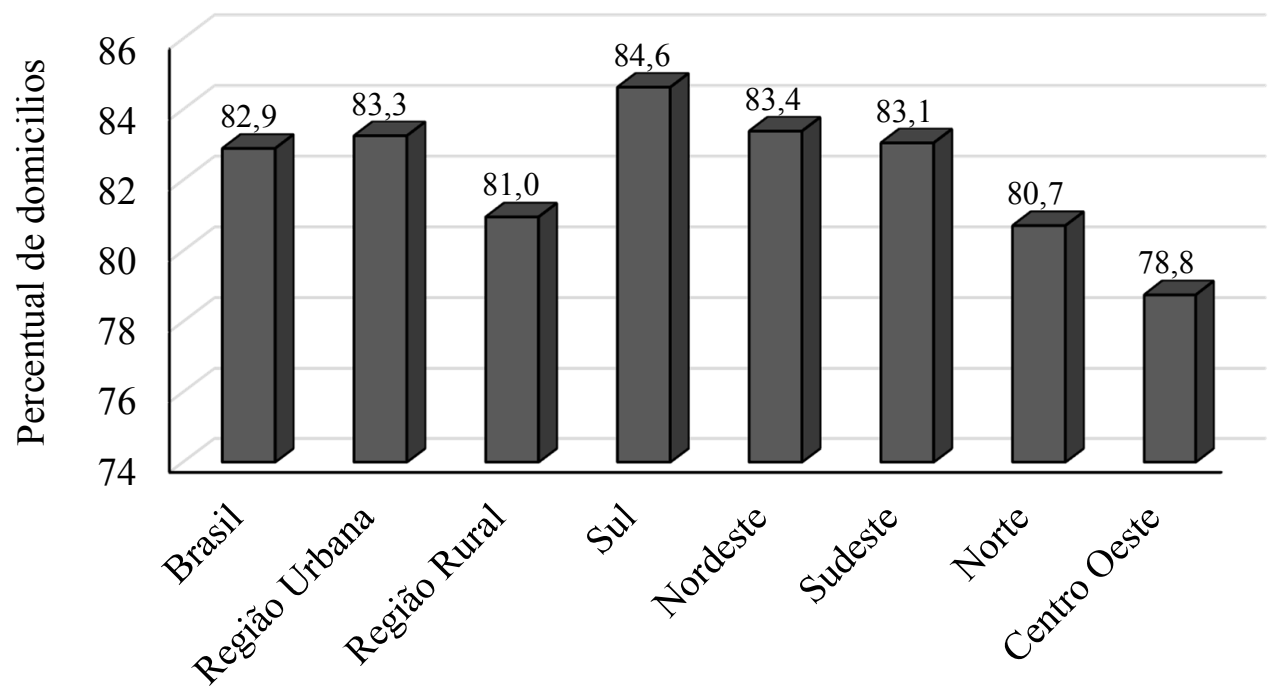

Figura 8: Percentual de domicílios que relataram a aquisição de pelo menos um medicamento no período recordatório de 30 dias no Brasil, nas regiões urbana e rural e nas macrorregiões brasileiras. (\% em relação aos valores expandidos)

Como visto anteriormente, a amostragem da POF 2008-2009 não permite a obtenção de resultados extrapolados para as unidades federativas, mas pode-se obter informações referentes às unidades federativas sem a utilização do fator de expansão. Na Figura 9 é mostrado o percentual de domicílios que relataram aquisição de medicamentos no período recordatório de 30 dias, por unidade federativa. Nela, observa-se grande diferença entre os estados, destacandose que o mais alto percentual de domicílios em que houve relato de obtenção de algum medicamento foi apresentado pelo Piauí $(89,7 \%)$, e o mais baixo percentual foi observado no Amapá (69,8\%). 


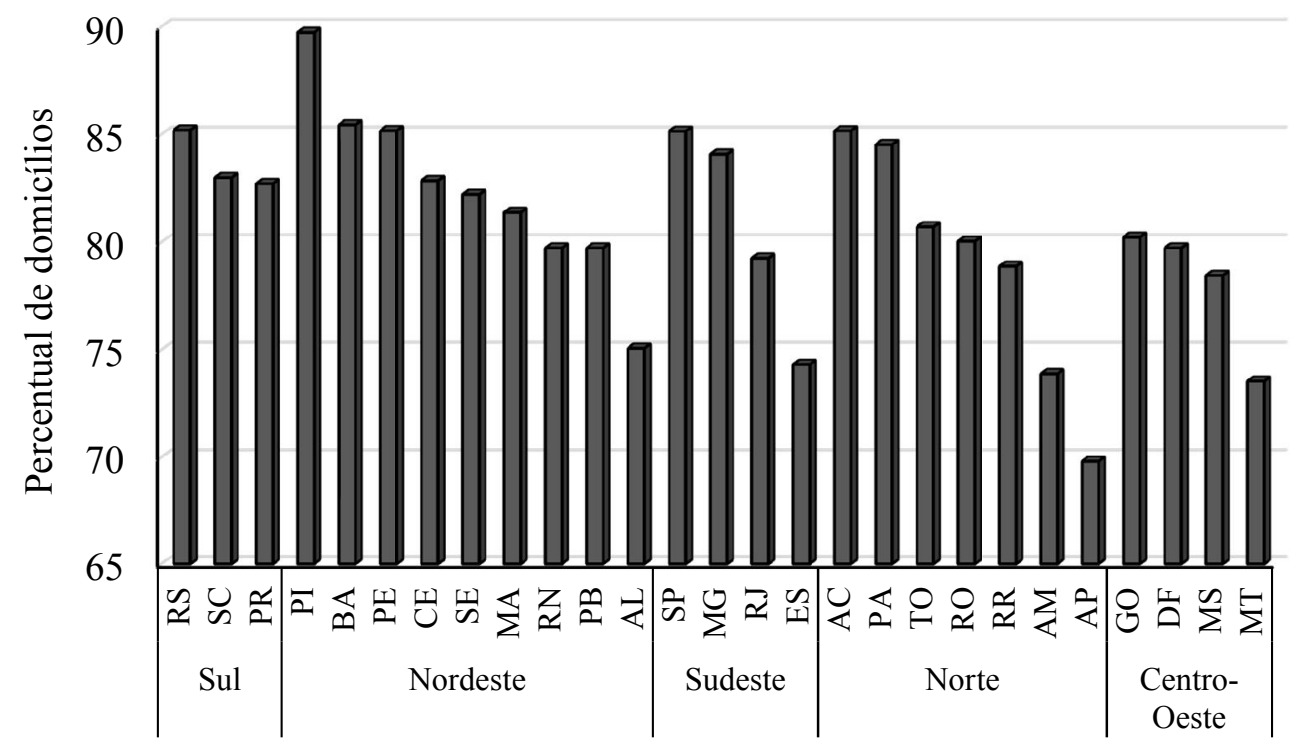

Figura 9: Percentual de domicílios entrevistados que relataram a aquisição de pelo menos um medicamento, no período recordatório de 30 dias, por unidade federativa.

Algumas características dos domicílios envolvidos na POF 2008-2009 estão descritas na Tabela 10. Como o percentual de domicílios que reportaram aquisição de medicamentos é alto (79\% a $85 \%)$, de maneira geral, as características dos domicílios que reportaram aquisição de medicamentos refletem as características de toda a população da Pesquisa. Como esperado, os resultados mostram um perfil socioeconômico menos privilegiado em domicílios das regiões Norte e Nordeste e também de áreas rurais. A distribuição dos domicílios em classes econômicas, por exemplo, revela que a maior proporção de domicílios de classes econômicas D e E está presente nas regiões Norte e Nordeste, seguida da apresentada pela região CentroOeste, sendo que, entre as macrorregiões brasileiras, a proporção dessas classes é menor nas regiões Sul e Sudeste. A proporção de domicílios de classes D e E também é maior em regiões rurais que em regiões urbanas.

Além disso, enquanto o percentual de domicílios sem água canalizada varia de $17 \%$ a $22,5 \%$ nas regiões Norte, Nordeste, nas outras regiões, cerca de 1-2\% dos domicílios sofrem com esse problema. Esse percentual é de 29,7\% nas áreas rurais, enquanto em áreas urbanas é 2,5\%. O mesmo raciocínio pode ser feito em relação às formas de escoamento sanitário. 
Tabela 10: Distribuição das características dos domicílios pesquisados na POF 2008-2009, em percentual.

\begin{tabular}{|c|c|c|c|c|c|c|c|c|c|}
\hline \multirow{2}{*}{\multicolumn{2}{|c|}{$\begin{array}{c}\text { Total de } \\
\text { domicílios }\end{array}$}} & \multicolumn{8}{|c|}{ Domicílios que reportaram aquisição de medicamentos } \\
\hline & & Brasil & Urbana & Rural & $\mathbf{S}$ & NE & SE & $\mathbf{N}$ & $\mathrm{CO}$ \\
\hline \multicolumn{10}{|c|}{ Classe econômica } \\
\hline A1 & 0,1 & 0,1 & 0,1 & 0,1 & 0,1 & 0,1 & 0,1 & 0,1 & 0,0 \\
\hline A2 & 2,0 & 2,1 & 2,5 & 0,2 & 1,8 & 0,9 & 3,2 & 0,7 & 1,9 \\
\hline B1 & 5,3 & 5,6 & 6,5 & 0,8 & 6,6 & 2,8 & 7,6 & 2,5 & 5,2 \\
\hline $\mathrm{B} 2$ & 12,1 & 12,7 & 14,3 & 4,0 & 18,4 & 6,0 & 15,7 & 7,2 & 12,2 \\
\hline $\mathrm{C} 1$ & 19,4 & 20,1 & 21,5 & 12,2 & 29,7 & 10,0 & 23,5 & 14,3 & 20,6 \\
\hline $\mathrm{C} 2$ & 22,8 & 22,9 & 24,0 & 16,9 & 22,7 & 20,4 & 23,8 & 23,8 & 26,1 \\
\hline $\mathrm{D}$ & 31,4 & 30,2 & 28,0 & 42,8 & 19,4 & 44,8 & 24,1 & 37,2 & 31,5 \\
\hline $\mathrm{E}$ & 6,9 & 6,2 & 3,1 & 23,1 & 1,4 & 14,9 & 2,1 & 14,2 & 2,4 \\
\hline \multicolumn{10}{|c|}{ Ausência de água canalizada } \\
\hline & 7,2 & 6,7 & 2,5 & 29,7 & 1,1 & 17,0 & 0,9 & 22,5 & 1,9 \\
\hline \multicolumn{10}{|c|}{ Escoadouro sanitário } \\
\hline $\mathrm{RC} / \mathrm{FS}$ & 69,2 & 70,0 & 78,0 & 25,3 & 75,1 & 48,5 & 86,4 & 49,3 & 56,1 \\
\hline $\mathrm{FR} / \mathrm{V}$ & 24,1 & 23,7 & 18,2 & 54,0 & 22,8 & 39,1 & 9,1 & 41,1 & 42,7 \\
\hline $\mathrm{D}$ & 2,7 & 2,6 & 2,5 & 3,3 & 0,9 & 1,8 & 4,0 & 3,4 & 0,2 \\
\hline Outra & 4,0 & 3,7 & 1,3 & 17,3 & 1,1 & 10,6 & 0,6 & 6,2 & 1,0 \\
\hline \multicolumn{10}{|c|}{ Proximidade à área industrial } \\
\hline & 5,6 & 5,6 & 6,1 & 2,9 & 6,7 & 4,9 & 6,2 & 3,2 & 4,5 \\
\hline \multicolumn{10}{|c|}{ Proximidade a lixão ou depósito de lixo } \\
\hline & 3,2 & 3,2 & 3,6 & 1,3 & 2,7 & 4,7 & 3,0 & 2,0 & 2,1 \\
\hline \multicolumn{10}{|c|}{ Proximidade a esgoto a céu aberto ou valão } \\
\hline & 8,9 & 9,0 & 10,1 & 3,4 & 6,9 & 14,3 & 7,9 & 7,6 & 2,6 \\
\hline \multicolumn{10}{|c|}{ Aquisição de bebida alcoólica ${ }^{a}$} \\
\hline & 9,7 & 9,9 & 10,5 & 6,3 & 14,5 & 5,3 & 11,8 & 5,8 & 8,4 \\
\hline \multicolumn{10}{|c|}{ Quantidade média de álcool adquirida por domicílio que reportaram aquisição, $\mathbf{m L}^{\mathrm{a}}$} \\
\hline & 31,3 & 30,9 & 31,9 & 25,8 & 44,3 & 19,6 & 34,8 & 20,9 & 28,8 \\
\hline \multicolumn{10}{|c|}{ Aquisição de artigos de fumo } \\
\hline & 21,1 & 21,1 & 20,7 & 23,4 & 23,2 & 19,2 & 22,0 & 21,4 & 18,1 \\
\hline
\end{tabular}

Algumas características da população participante da POF 2008/2009 estão descritas na Tabela 11. Enquanto em áreas urbanas a maioria da população é de mulheres, seguindo o perfil na população geral e das regiões, a maioria da população rural é de homens, refletindo a força masculina no campo. A proporção de crianças e adolescentes é maior nas populações das regiões Norte e Nordeste, enquanto a proporção de adultos de 40 a 59 anos é maior nas regiões 
Sul, Sudeste e Centro-Oeste, respectivamente. Além disso, a região norte é a que possui o maior percentual de mulheres grávidas ou lactante $(19,4 \%)$.

Nas regiões Norte e Nordeste há um menor percentual de pessoas maiores de 15 anos que sabem ler ou escrever e este percentual vai aumentando a medida em que se caminha para as regiões Centro-Oeste, Sul e Sudeste. Indivíduos das áreas urbanas e das regiões sul e sudeste são os mais escolarizados (pelo menos 6,2\% têm mais de 12 anos de estudo).

Destaca-se que a coerência apresentada entre as características sociodemográficas regionais obtidas por meio da POF 2008-2009 com dados já publicados pelo IBGE, como os dados do Censo de 2010 (IBGE, 2013) ratificam a qualidade das informações obtidas por meio da Pesquisa de Orçamentos Familiares e apresentadas neste estudo.

Tabela 11: Distribuição das características da população participante da POF 2008/2009, em percentual.

\begin{tabular}{|c|c|c|c|c|c|c|c|c|c|}
\hline \multirow[b]{2}{*}{ Variável } & \multirow[b]{2}{*}{ Total } & \multicolumn{8}{|c|}{ Relataram obtenção de algum medicamento } \\
\hline & & Brasil & Urbana & Rural & $\mathbf{S}$ & NE & SE & $\mathbf{N}$ & $\mathbf{C O}$ \\
\hline \multicolumn{10}{|l|}{ Sexo } \\
\hline Feminino & 51,2 & 51,6 & 52,3 & 48,3 & 52,2 & 51,7 & 51,7 & 50,0 & 51,8 \\
\hline Masculino & 48,8 & 48,4 & 47,7 & 51,7 & 47,8 & 48,3 & 48,3 & 50,0 & 48,2 \\
\hline \multicolumn{10}{|c|}{ Faixa etária (anos) } \\
\hline$<1$ & 1,4 & 1,4 & 1,4 & 1,5 & 1,2 & 1,6 & 1,1 & 1,9 & 1,5 \\
\hline $1-4$ & 5,8 & 5,8 & 5,7 & 6,5 & 5,4 & 6,4 & 5,1 & 8,3 & 5,8 \\
\hline $5-9$ & 8,6 & 8,4 & 8,1 & 10,0 & 8,0 & 9,4 & 7,4 & 10,8 & 8,6 \\
\hline $10-14$ & 9,2 & 9,0 & 8,6 & 10,8 & 8,3 & 9,8 & 8,2 & 11,3 & 8,8 \\
\hline $15-19$ & 8,8 & 8,9 & 8,7 & 9,9 & 8,2 & 9,8 & 8,3 & 10,0 & 8,8 \\
\hline $20-39$ & 32,0 & 31,7 & 32,4 & 28,4 & 30,1 & 32,3 & 31,6 & 32,3 & 33,7 \\
\hline $40-59$ & 23,0 & 23,0 & 23,5 & 20,7 & 25,8 & 19,8 & 25,3 & 18,0 & 22,3 \\
\hline $60-69$ & 6,3 & 6,5 & 6,4 & 6,9 & 7,2 & 6,0 & 7,1 & 4,4 & 6,1 \\
\hline$\geq 70$ & 4,9 & 5,3 & 5,3 & 5,2 & 5,9 & 5,0 & 5,9 & 3,0 & 4,3 \\
\hline \multicolumn{10}{|c|}{ Sabe ler e escrever (maiores de 15 anos) } \\
\hline & 89,6 & 89,8 & 92,2 & 77,0 & 94,2 & 80,0 & 94,4 & 88,0 & 92,1 \\
\hline \multicolumn{10}{|c|}{ Anos de estudo (maiores de 15 anos) } \\
\hline 0 & 8,5 & 8,4 & 6,6 & 18,2 & 5,2 & 14,6 & 5,4 & 10,9 & 7,1 \\
\hline $1-3$ & 11,8 & 11,8 & 9,9 & 21,6 & 10,3 & 15,7 & 9,6 & 14,0 & 10,7 \\
\hline $4-8$ & 35,2 & 34,7 & 33,8 & 39,2 & 39,2 & 32,3 & 34,6 & 34,8 & 34,6 \\
\hline $9-11$ & 30,4 & 30,6 & 33,0 & 17,5 & 28,1 & 28,2 & 32,8 & 31,0 & 31,3 \\
\hline $12-14$ & 5,2 & 5,4 & 6,1 & 1,5 & 6,7 & 3,4 & 6,2 & 3,6 & 6,5 \\
\hline 15 ou mais & 8,3 & 8,5 & 9,8 & 1,5 & 9,2 & 5,0 & 10,9 & 4,8 & 9,5 \\
\hline Ignorado & 0,7 & 0,6 & 0,7 & 0,5 & 1,3 & 0,7 & 0,4 & 0,8 & 0,3 \\
\hline \multicolumn{10}{|c|}{ Grávida ou lactante } \\
\hline & 11,1 & 11,3 & 10,8 & 13,9 & 8,9 & 14,0 & 9,0 & 19,4 & 10,0 \\
\hline
\end{tabular}


A Figura 10 compara o perfil nutricional das populações de domicílios da POF 2008/2009 que obtiveram medicamentos e daqueles que não obtiveram medicamento, no período recordatório de 30 dias. Nota-se que o perfil dessas duas populações é semelhante para as faixas etárias avaliadas, exceto para idosos. Entre eles, a proporção de indivíduos com baixo peso é cerca de 4\% menor no grupo de domicílios que obtiveram medicamento (18,5 e 22,8\%, respectivamente) e a proporção de indivíduos com sobrepeso é 5\% maior em relação aos idosos de domicílios em que não houve obtenção de medicamento (38 e 33\%, respectivamente).

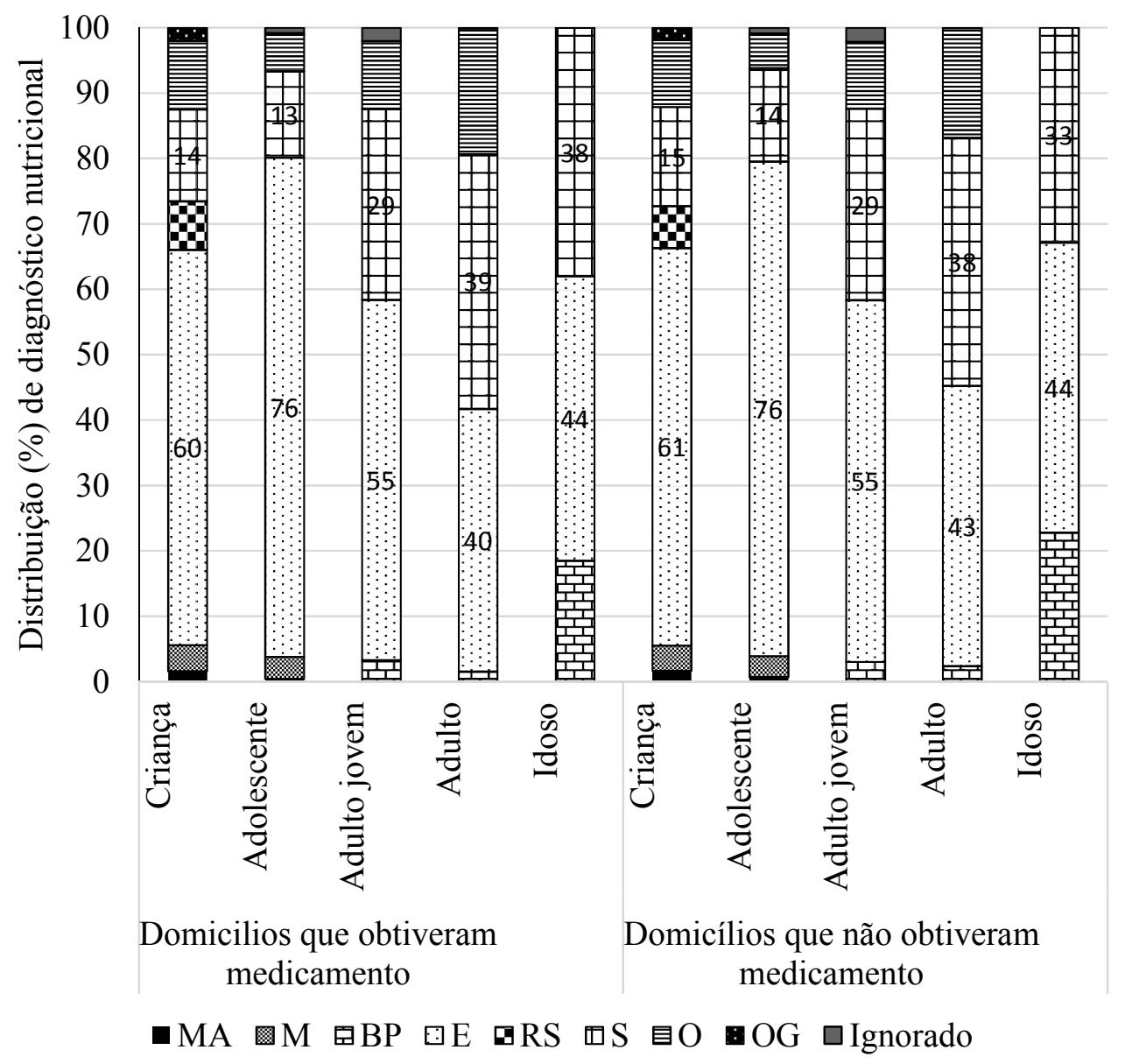

Figura 10: Diagnóstico nutricional da população residente em domicílios em que houve relato de obtenção de algum medicamento e da população residente em domicílios em que não houve obtenção de algum medicamento, por faixa etária.

$\mathrm{MA}=$ Magreza acentuada, $\mathrm{M}=$ Magreza, $\mathrm{BP}=$ Baixo peso, $\mathrm{E}=$ Eutrofia, $\mathrm{RS}=\mathrm{Risco}$ de sobrepeso, $\mathrm{S}=$ Sobrepeso, $\mathrm{O}=$ Obesidade, $\mathrm{OG}=$ Obesidade Grave. 


\section{Aquisição de medicamentos e variáveis socioeconômicas}

No Brasil, foram adquiridos, em média, 2,38 medicamentos em cada domicílio, o que o que representa a obtenção de 0,72 medicamentos por pessoa (período recordatório de 30 dias), sendo que esse número é maior nas regiões Sul e Sudeste (0,81 e 0,79 respectivamente) (Figura 11). Em estudo representativo da população brasileira (CARVALHO et al, 2005), envolvendo 5.000 indivíduos de 18 anos ou mais e conduzido no ano de 2003 (período recordatório de 15 dias) foram utilizados 0,9 medicamentos por pessoa. É importante observar que o estudo de Carvalho et al. não abrangeu a população de crianças e adolescentes, apesar de cobrir um período menor que aquele da POF 2008/2009. No geral, os estudos de utilização de medicamentos conduzidos no Brasil, indicam que a prevalência de utilização de medicamentos é em torno de 50\% nos primeiros quatro anos de vida (BERTOLDI et al., 2009; 2012), decrescendo com a idade até a adolescência, quando esta prevalência volta a aumentar com a idade (BERTOLDI et al., 2009; 2012; MORAES et al., 2011; SILVA; GUIGLIANI; 2004).

Ressalta-se que a POF 2008-2009 obteve informações sobre a aquisição de medicamentos e não sobre a utilização destes. Desta maneira, podem ocorrer situações em que o medicamento utilizado foi adquirido fora do período recordatório determinado pela pesquisa. Por exemplo, entre os indivíduos que utilizam os mesmos medicamentos mensalmente, pode haver aquisição de medicamentos para um período maior que um mês de tratamento, o que contribuiria para que o número de medicamentos obtido ser menor que o número de medicamentos utilizado.

O período recordatório de 30 dias da POF 2008-2009 favorece a obtenção de informações fidedignas por parte de indivíduos que utilizam os mesmos medicamentos com frequência (como indivíduos com doenças crônicas e mulheres que utilizam anticoncepcionais), mas acarreta em um viés de memória maior para os indivíduos que não utilizam e nem adquirem medicamentos com frequência. 


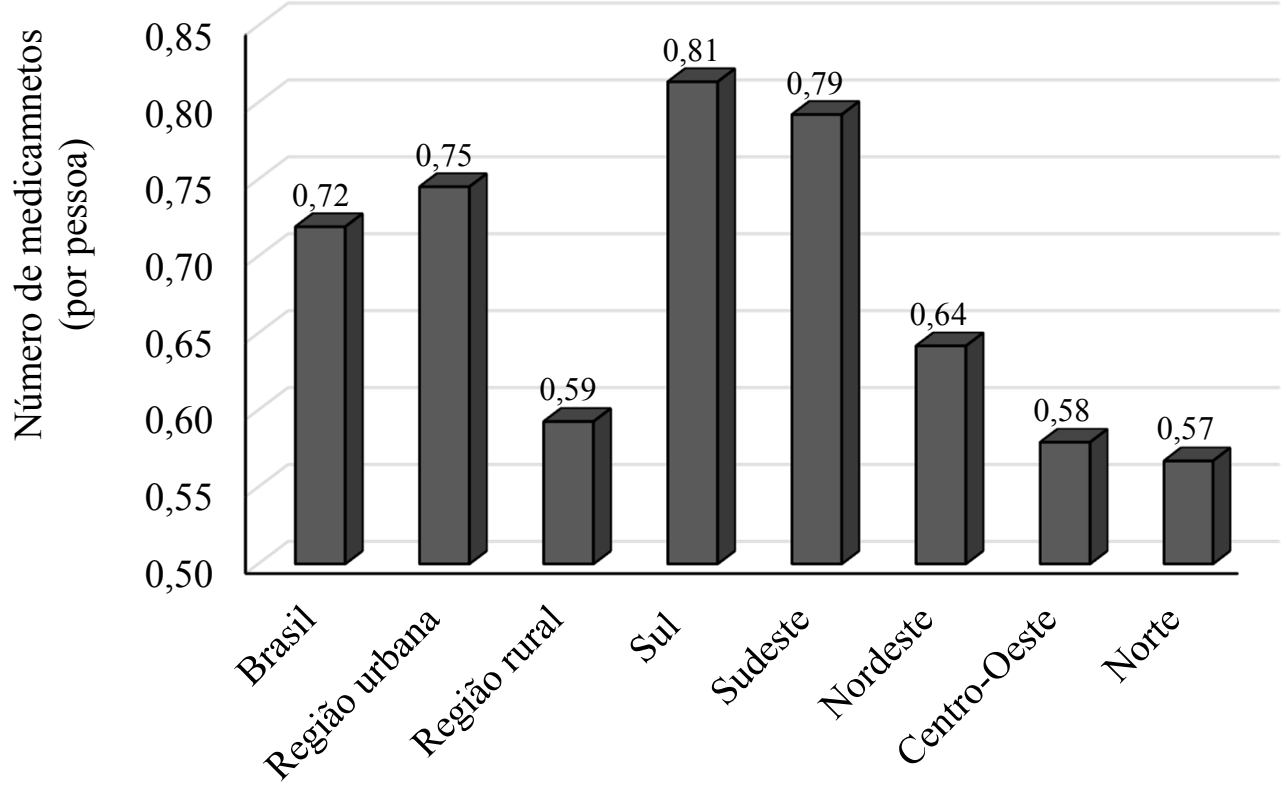

Figura 11: Número de medicamentos obtidos por pessoa no Brasil, nas regiões urbana e rural e nas macrorregiões brasileiras.

Após o agrupamento dos domicílios em classes econômicas, foi obtida a renda per capta média dos domicílios pertencentes a cada classe econômica (Tabela 12). Conforme esperado, domicílios de classes econômicas mais privilegiadas apresentaram uma renda per capta média mais alta.

Tabela 12: Renda per capta média dos domicílios envolvidos na POF 2008-2009, segundo as classes econômicas.

\begin{tabular}{ccc}
\hline Classe econômica & R\$ & Erro padrão \\
\hline A1 & 5631,26 & 14,95 \\
A2 & 4926,25 & 4,18 \\
B1 & 3373,96 & 2,32 \\
B2 & 1882,17 & 0,87 \\
C1 & 1110,22 & 0,41 \\
C2 & 675,76 & 0,19 \\
D & 481,33 & 0,24 \\
E & 305,15 & 0,18 \\
\hline
\end{tabular}


Considerando-se a obtenção de medicamentos, observa-se que quanto mais privilegiada a classe econômica, maior o percentual de domicílios que adquiriram algum medicamento (Figura 12) e maior o número de medicamentos por 100 habitantes (Figura 13). Observa-se também que essa relação é mais evidente entre as classes econômicas menos privilegiadas (E, $\mathrm{D}, \mathrm{C} 2$ e C1), as quais correspondem, respectivamente, aos quatro pontos de menor renda per capta das Figuras 12 e 13. Isso faz com que a relação entre a renda per capta média de cada classe econômica e o percentual de domicílios dentro de cada classe econômica que relatou obtenção de algum medicamento ou o número de medicamentos obtidos por habitante sejam melhor ajustadas pelo modelo logarítmico (Figuras 12 e 13). Tais observações apenas não são válidas entre as classes A1 e A2. Entre elas parece não haver relação entre renda e aquisição de medicamentos.

A relação positiva entre renda e utilização de medicamentos vai ao encontro de observações de estudos anteriormente conduzidos no Brasil (BERTOLDI et al., 2009). Também há estudos que mostram associação positiva entre o número de bens domésticos e o uso de medicamentos (CARVALHO et al., 2005).

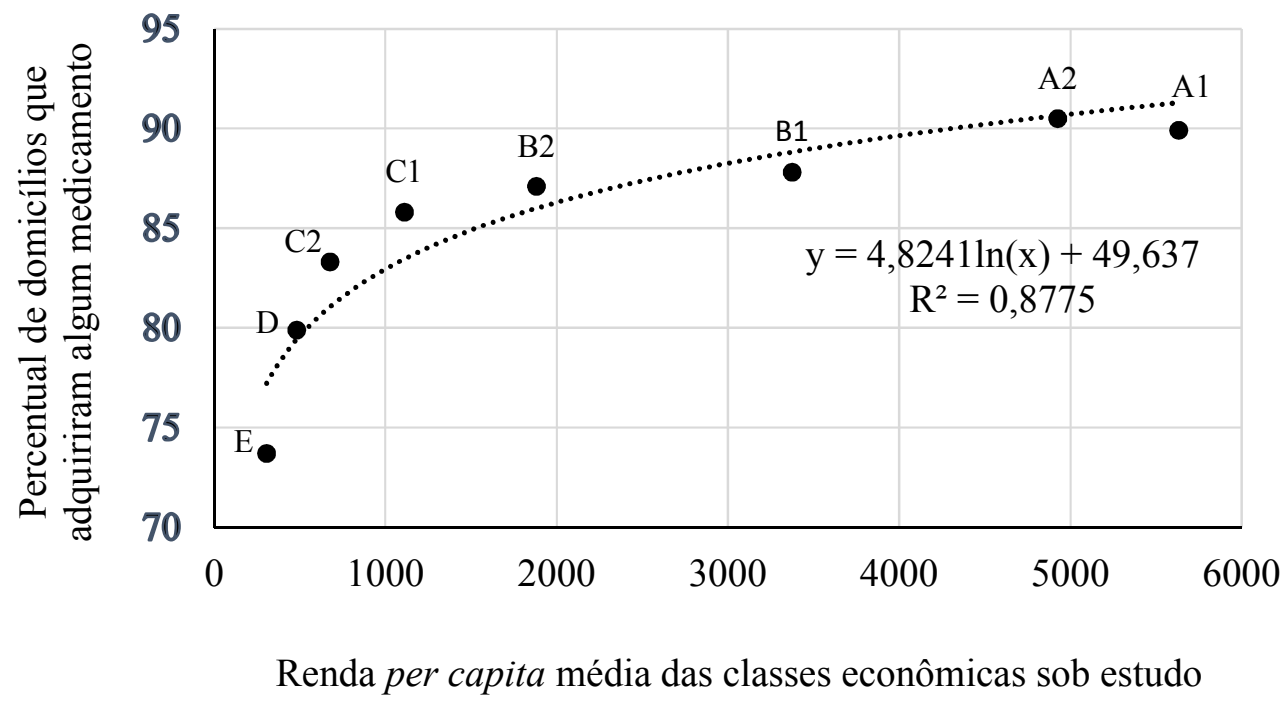

Figura 12: Percentual de domicílios que adquiriram algum medicamento versus a renda per capta média das classes econômicas sob estudo (A1, A2, B1, B2, C1, C2, D, E). Renda em reais. 


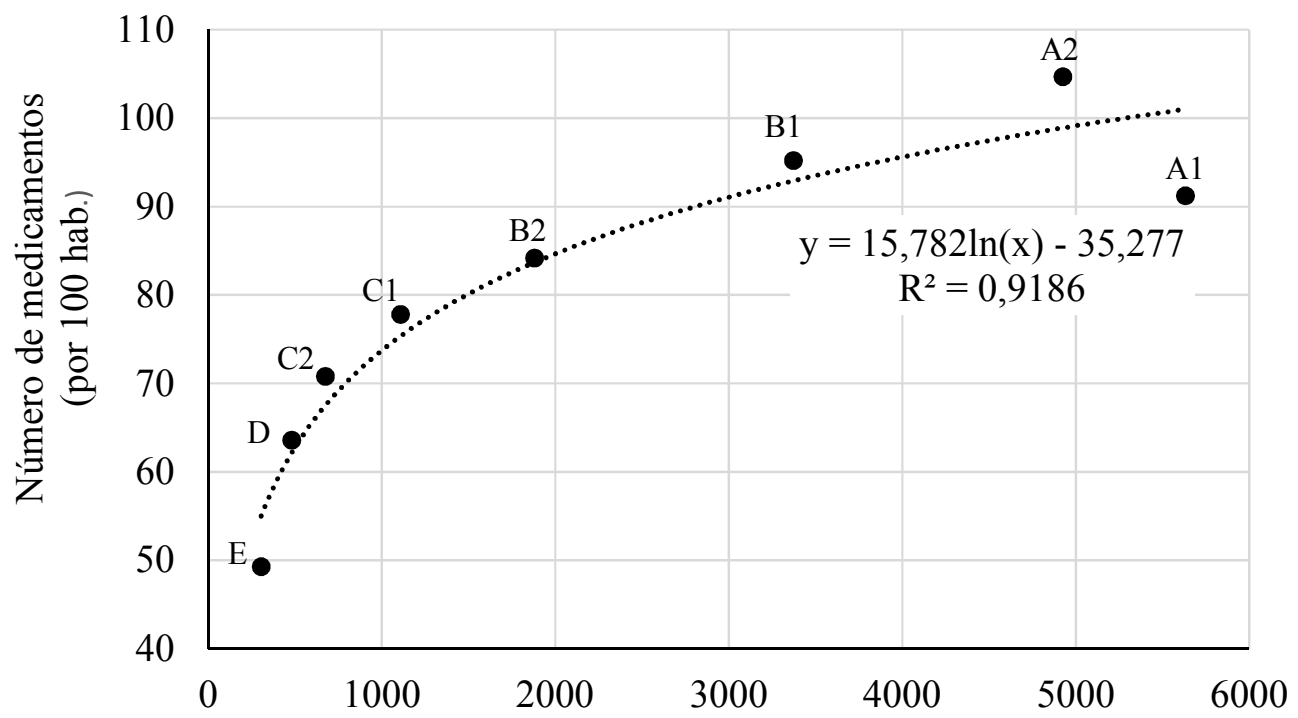

Figura 13: Número de medicamentos por 100 habitantes versus a renda per capta média das classes econômicas sob estudo (A1, A2, B1, B2, C1, C2, D, E). Renda em reais.

Em estudo recente, o qual avaliou os gastos das dos domicílios brasileiros com medicamentos por meio da análise dos dados da POF 2008-2009. Garcia et al. (2013a) também identificaram que os valores gastos com medicamentos aumentaram conforme a renda dos indivíduos, sendo que o gasto do grupo de maior renda foi 4,5 vezes maior que o gasto apresentado pelo grupo de menor renda. Nesse mesmo estudo, também foi observado que entre as famílias mais pobres, um percentual maior da renda é comprometido com o gasto com medicamentos: enquanto esse percentual foi de 5,8\%, entre as famílias de menor renda, ele foi de 1,6\%, o que mostra que entre as famílias mais de maior renda (GARCIA, 2013b).

\section{Acesso e característica dos medicamentos adquiridos}

A maioria dos medicamentos foi adquirida em farmácias ou drogarias $(79,3 \%)$ e com recursos próprios (85\%). Quase 70\% foram medicamentos de marca (referência ou similar) e $26,6 \%$ deles foram genéricos (Tabela 14). 
Tabela 13: Formas de acesso e características dos medicamentos adquiridos

\begin{tabular}{lcc}
\hline Formas de acesso & $\mathbf{N}$ & $\mathbf{\%}^{\mathbf{a}}$ \\
\hline Recursos Próprios & 106.084 & 85,0 \\
Doação & 16.678 & 14,9 \\
Outra & 221 & 0,11 \\
\hline Local de aquisição & $\mathbf{N}$ & $\mathbf{\%}^{\mathbf{a}}$ \\
\hline Farmácia/Drogaria & 98.389 & 79,3 \\
SUS & 15.667 & 13,9 \\
Mercado & 3.196 & 2,2 \\
Programa Farmácia Popular & 1.808 & 1,6 \\
Terceiro & 1.556 & 1,2 \\
Outros locais de aquisição & 2.367 & 1,8 \\
\hline Características & $\mathbf{N}$ & $\mathbf{\%}$ \\
\hline Marca (referência ou similar) & 84.656 & 66,8 \\
Genérico & 30.049 & 26,6 \\
Manipulado & 2.896 & 2,8 \\
A base de plantas e ervas medicinais & 2.560 & 2,0 \\
Não sabe & 2.822 & 1,9 \\
\hline
\end{tabular}

${ }^{\mathrm{a}} \mathrm{O}$ valor percentual é definido com base no número expandido de medicamentos.

Em estudo conduzido em Pelotas em 2002, os medicamentos genéricos representaram uma parcela ainda menor do total de medicamentos utilizados, representando apenas 3,9\% do total de medicamentos utilizados no período recordatório de 15 dias (BERTOLDI et al., 2005). Nesse mesmo estudo foi observado que 76,8\% dos medicamentos utilizados foram medicamentos de marca (referência ou similares) e a parcela de medicamentos manipulados e de medicamentos à base de plantas e ervas medicinais foi de $18 \%$ e $1,3 \%$ respectivamente. Em estudo conduzido no município de Tubarão, Santa Catarina, no ano de 2007, cerca de $85 \%$ dos 234 entrevistados declararam já ter utilizado medicamento genérico e 77,8\% destes declararam que costumam adquirir medicamentos genéricos com frequência (BLATT et al., 2012).

Entre os domicílios brasileiros que relataram aquisição de algum medicamento, 43,6\% adquiriram genérico, percentual que variou de 31,4\% na região Centro-Oeste a 49,8\% na região Sul. Além disso, esse percentual foi maior entre domicílios de regiões urbanas $(44,3 \%)$ que os de regiões rurais $(39,2 \%)$ (Figura 14$)$. 


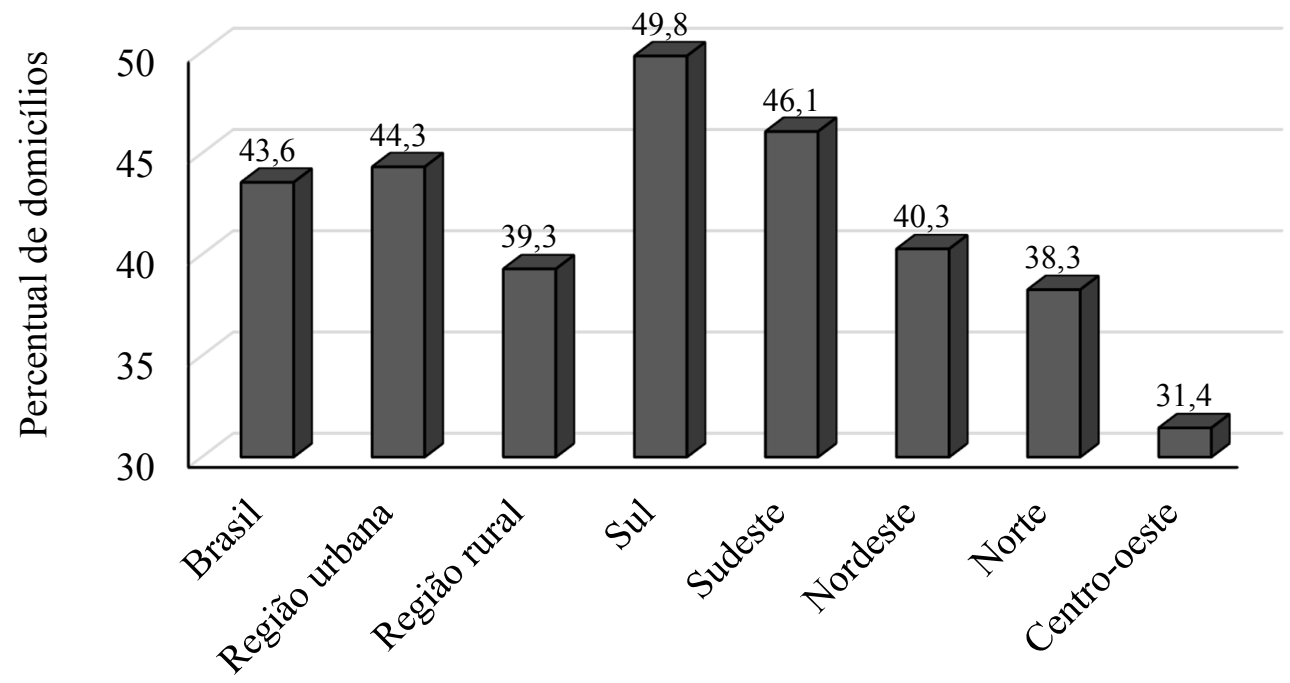

Figura 14: Percentual de domicílios em que houve relato de obtenção de medicamentos genéricos no Brasil, em regiões urbana e rural e nas macrorregiões brasileiras.

Os medicamentos genéricos representaram 13,6\% daqueles obtidos em domicílios da classe econômica A2, e 29,6\% do total de medicamentos obtidos em domicílios da classe D (Figura 15). Porém, o aspecto socioeconômico não fica claro na classe A1, que apresenta um percentual similar ao da classe B2 (cerca de $22 \%$ dos medicamentos adquiridos), nem na classe E, a qual apresenta um percentual menor que o apresentado na classe D.

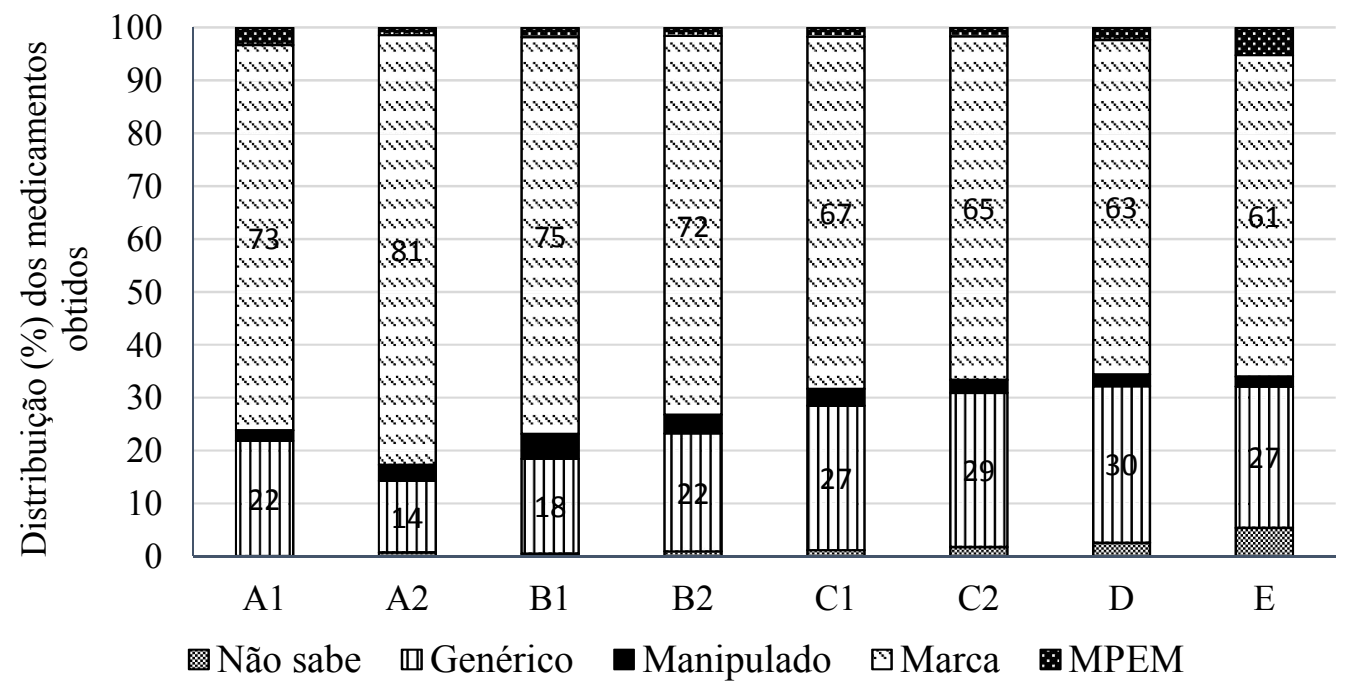

Figura 15: Características dos medicamentos adquiridos no Brasil, por classe econômica dos domicílios onde os medicamentos foram obtidos.

MPEM = Medicamentos à base de plantas ou ervas medicinais. 
Dados da ANVISA mostram que o mercado de medicamentos genéricos teve crescimento expressivo entre os anos de 2000 a 2007, o que reflete na utilização desses medicamentos pela população (ANVISA, 2014c). O crescimento desse mercado é positivo, pois a utilização de genéricos favorece o acesso a medicamentos mais baratos sem prejuízo terapêutico (VIEIRA; ZUCCHI, 2006; TOBAR, 2008). Dados do presente estudo mostram que o uso desses medicamentos ainda pode ser ampliado, especialmente em regiões rurais e entre domicílios de classe econômica E.

Em 22,3\% dos domicílios participantes da POF 2008-2009 houve pelo menos um morador que relatou ter tido a necessidade de algum medicamento, mas que o acesso não foi possível por falta de dinheiro. A Figura 16 mostra a relação entre o número de medicamentos adquiridos por pessoa e o percentual de pessoas que necessitaram, mas não tiveram acesso a estes produtos por falta de recursos. Nota-se que, no geral, quanto maior o número de medicamentos obtidos por pessoa, menor o percentual de pessoas que não tiveram acesso por falta de dinheiro. Em termos nacionais, 9,3\% da população não teve acesso a estes produtos por falta de recursos financeiros. A maior discrepância entre este percentual é encontrada entre as regiões sul e nordeste $(6,5 \%$ e $16,2 \%$, respectivamente).

No ano de 2004, foi conduzido no Brasil um estudo domiciliar de acesso a medicamentos, resultante de uma parceria entre o Ministério da Saúde, a FIOCRUZ e a OMS (BRASIL, 2005). Tal estudo envolveu a realização de visitas a 916 domicílios e demonstrou que, em 8,5\% dos domicílios visitados, os moradores não tiveram acesso a todos os medicamentos a eles prescritos por médicos ou dentistas (BRASIL, 2005).

CARVALHO et al. (2005), por meio de estudo de base populacional representativo da população brasileira conduzido no ano de 2003 e que envolveu a aplicação de questionários a 5.000 indivíduos de 18 anos ou mais, reportou que 13,0\% dos brasileiros não conseguiram adquirir todos os medicamentos necessários, um percentual maior que o identificado no presente estudo. Nos dois estudos citados, também foi mostrado que a principal razão apontada para falta de acesso aos medicamentos no Brasil é a falta de dinheiro (BRASIL, 2005; CARVALHO et al., 2005). 


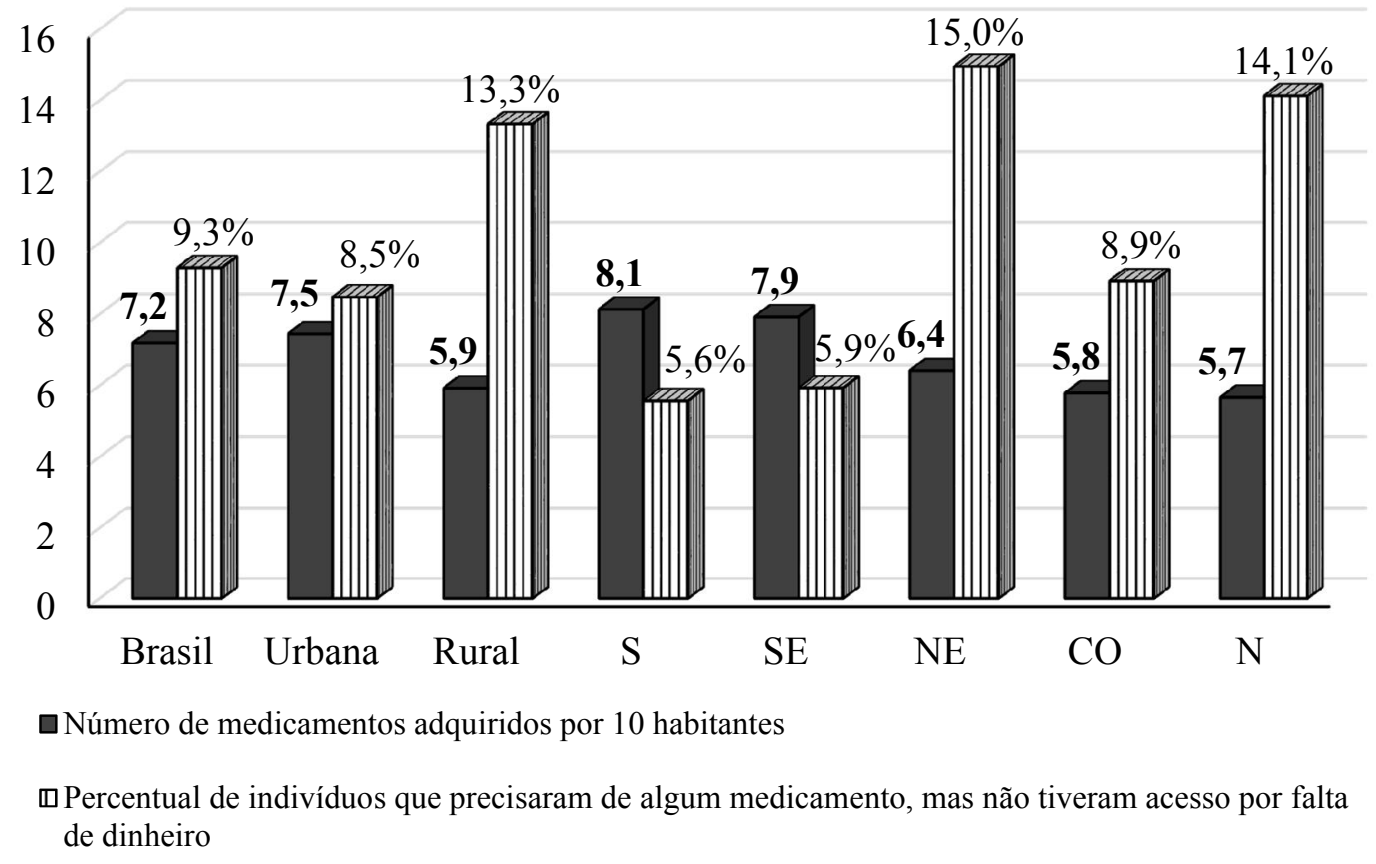

Figura 16: Número de medicamentos adquiridos por 10 habitantes e percentual de habitantes que tiveram necessidade de algum medicamento, mas não tiveram acesso ao(s) medicamento(s) necessário(s), por falta de dinheiro no Brasil, por regiões urbana e rural e nas macrorregiões brasileiras.

Essa observação é de grande importância, pois o acesso a medicamentos tem efeitos sobre a situação de saúde individual, sendo um indicador da qualidade e resolutividade do sistema de saúde e um dos determinantes do cumprimento do tratamento prescrito (PANIZ et al., 2008; GARCIA et al., 2013a). Destaca-se que a falta de acesso a medicamentos é um problema relatado mesmo em países desenvolvidos. Nos Estados Unidos, por exemplo, no ano de 2012, 22,4\% da população (de 18 a 64 anos) não coberta por seguro saúde relatou não ter obtido algum medicamento necessário devido ao custo desse medicamento (ESTADOS UNIDOS, 2013).

Em todos os estratos geográficos avaliados, o percentual de domicílios em que pelo menos um morador é filiado a plano de saúde é maior entre domicílios que obtiveram medicamento do que entre domicílios que não obtiveram. No Brasil, esses percentuais foram de $37,4 \%$ e $25,6 \%$, respectivamente (Figura 17). O mesmo ocorre em relação ao percentual de indivíduos com acesso à saúde suplementar (Figura 18). A relação positiva entre a filiação a 
plano de saúde e a utilização de medicamentos já foi reportada em estudos anteriormente conduzidos no Brasil. Bertoldi et al. (2009), em estudo conduzido com 2.988 indivíduos (de todas as idades), assistidos pela Estratégia Saúde da Família de Porto Alegre, mostrou que a prevalência de utilização de medicamentos foi significativamente maior entre os indivíduos filiados a plano de saúde. Resultado similar foi obtido por Vosgerau et al. (2011) em estudo conduzido com 374 adultos (20 a 59 anos) de Ponta Grossa assistidos pelo mesmo programa. Entretanto, em estudo conduzido com 1.583 indivíduos (18 a 45 anos) do Distrito Federal, não houve associação significativa entre a filiação a plano de saúde e a prevalência de utilização de medicamentos (GALVÃO et al, 2014).

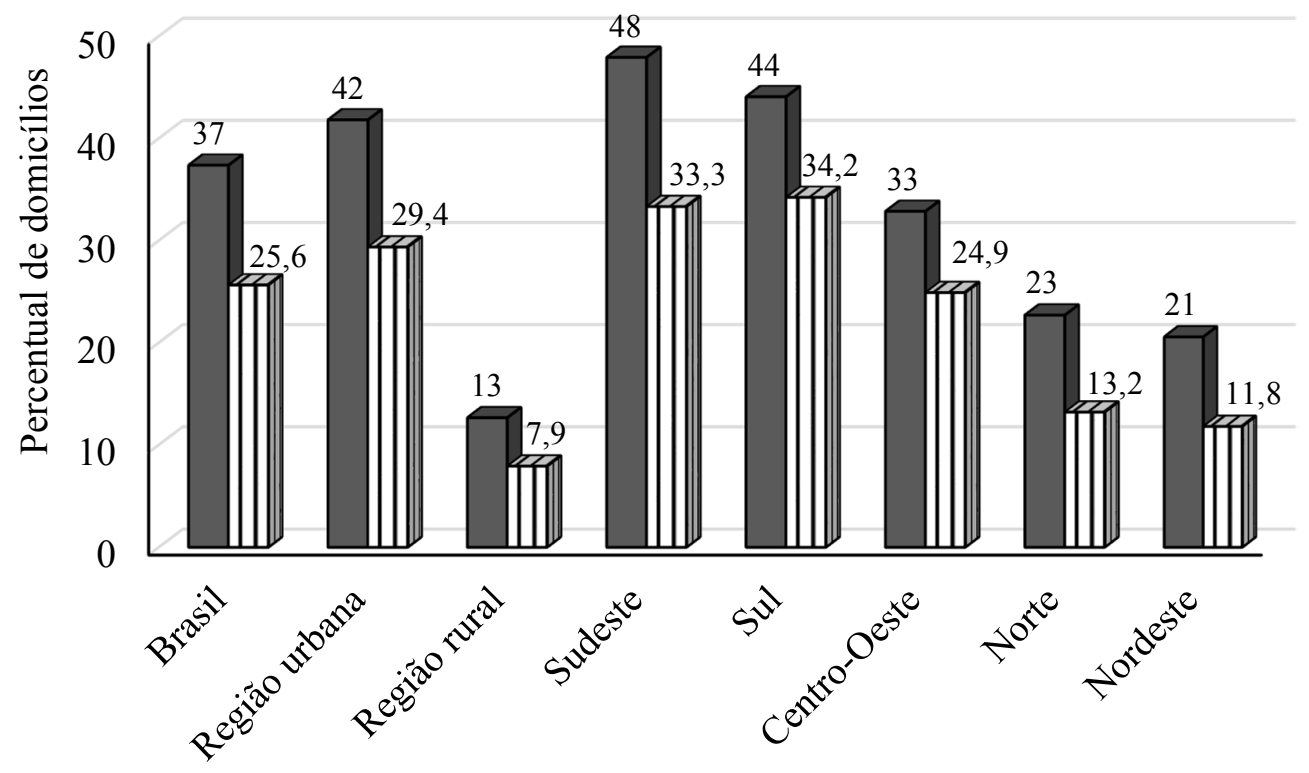

$\square$ Domicilios em que houve aquisição de medicamento(s)

巴Domicilios em que não houve aquisição de medicamento

Figura 17: Percentual de domicílios em que pelo menos um morador é filiado a plano de saúde considerando-se o grupo de domicílios em que houve obtenção de medicamentos e o grupo de domicílios em que não houve obtenção de medicamento, no Brasil, nas regiões urbana e rural e nas macrorregiões brasileiras. 


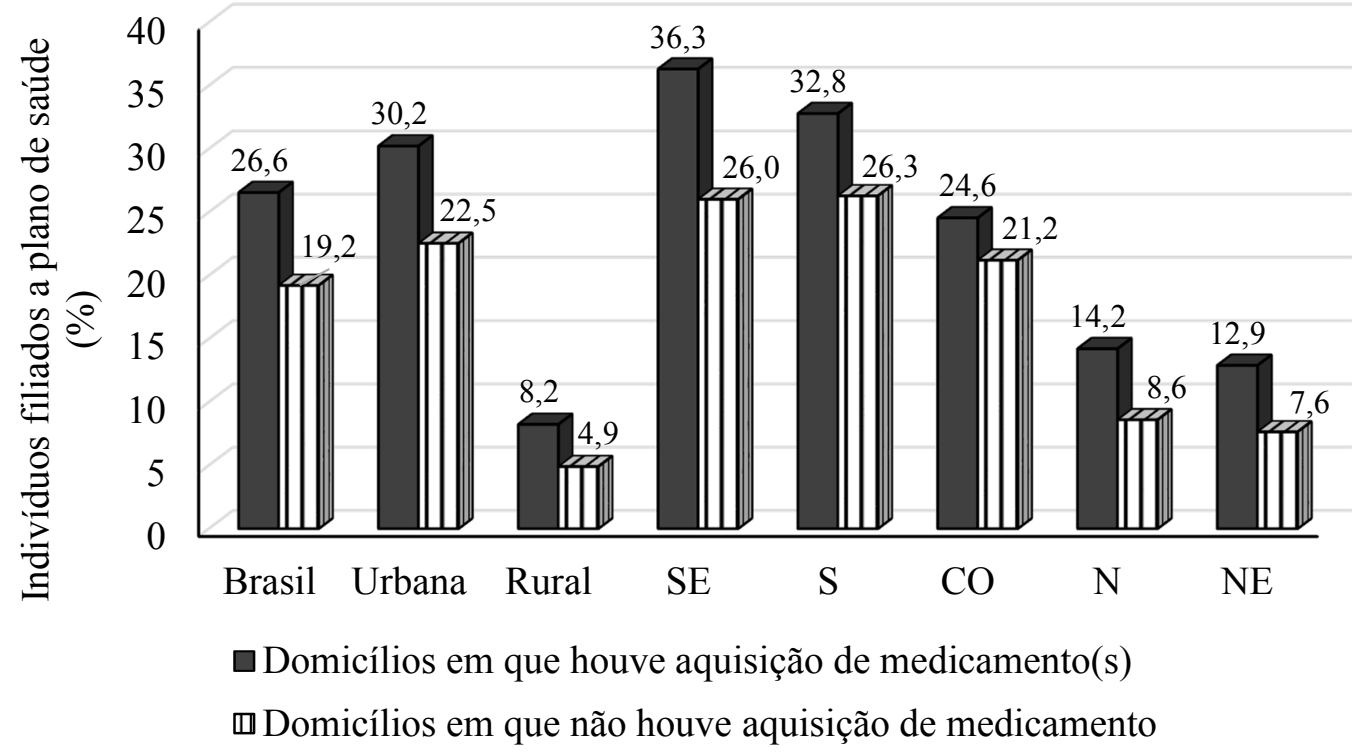

Figura 18: Percentual de indivíduos filiados a plano de saúde considerando-se o grupo de domicílios em que houve obtenção de medicamentos e o grupo de domicílios em que não houve obtenção de medicamento, no Brasil, nas regiões urbana e rural e nas macrorregiões brasileiras.

\subsection{Medicamentos obtidos por doação - Sistema Único de Saúde (SUS)}

Em relação à forma de obtenção, observa-se que 14,9\% dos medicamentos mencionados na POF 2008-2009 foram obtidos por doação (Tabela 13). Como esperado, quanto menos privilegiada a posição econômica, maior a proporção de medicamentos obtidos por doação (Figura 19). 


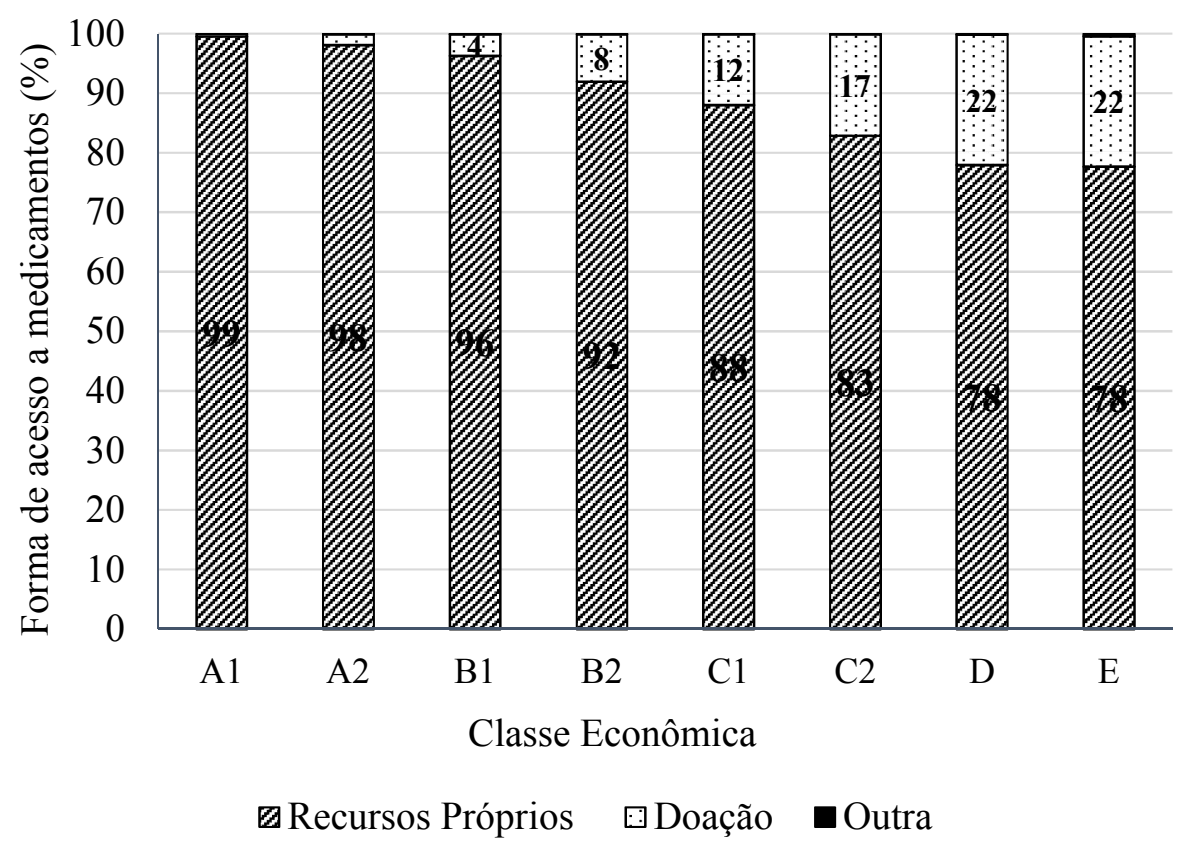

Figura 19: Proporção de medicamentos obtidos por meio de recurso próprios, obtidos por doação e por outras formas de acesso de acordo com a classe econômica no Brasil.

O SUS é o principal fornecedor dos medicamentos obtidos por doação (Figura 20). Os menores percentuais foram encontrados nas regiões Norte e Nordeste, o que indica a necessidade de uma maior presença do Sistema nessas regiões. A doação por terceiros representa uma forma importante de acesso a medicamentos, em especial nas regiões Norte e Nordeste (mais de 10\% das aquisições). Ressalta-se que, "doação" foi uma opção de resposta dada pelo próprio IBGE a fim de classificar os medicamentos que não foram obtidos com recursos próprios. Sabe-se, entretanto, que os medicamentos fornecidos pelo SUS não são doados, mas obtidos por meio de uma contraprestação realizada pela sociedade em um momento anterior à aquisição dos medicamentos, na forma de impostos.

Nota-se que apesar de o Programa Farmácia Popular do Brasil disponibilizar medicamentos de forma gratuita somente a partir de 2011 (BRASIL, 2014d), diversos indivíduos relataram ter obtido medicamentos de forma gratuita por meio desse programa nos anos de 2008 e 2009 (Figura 20). 


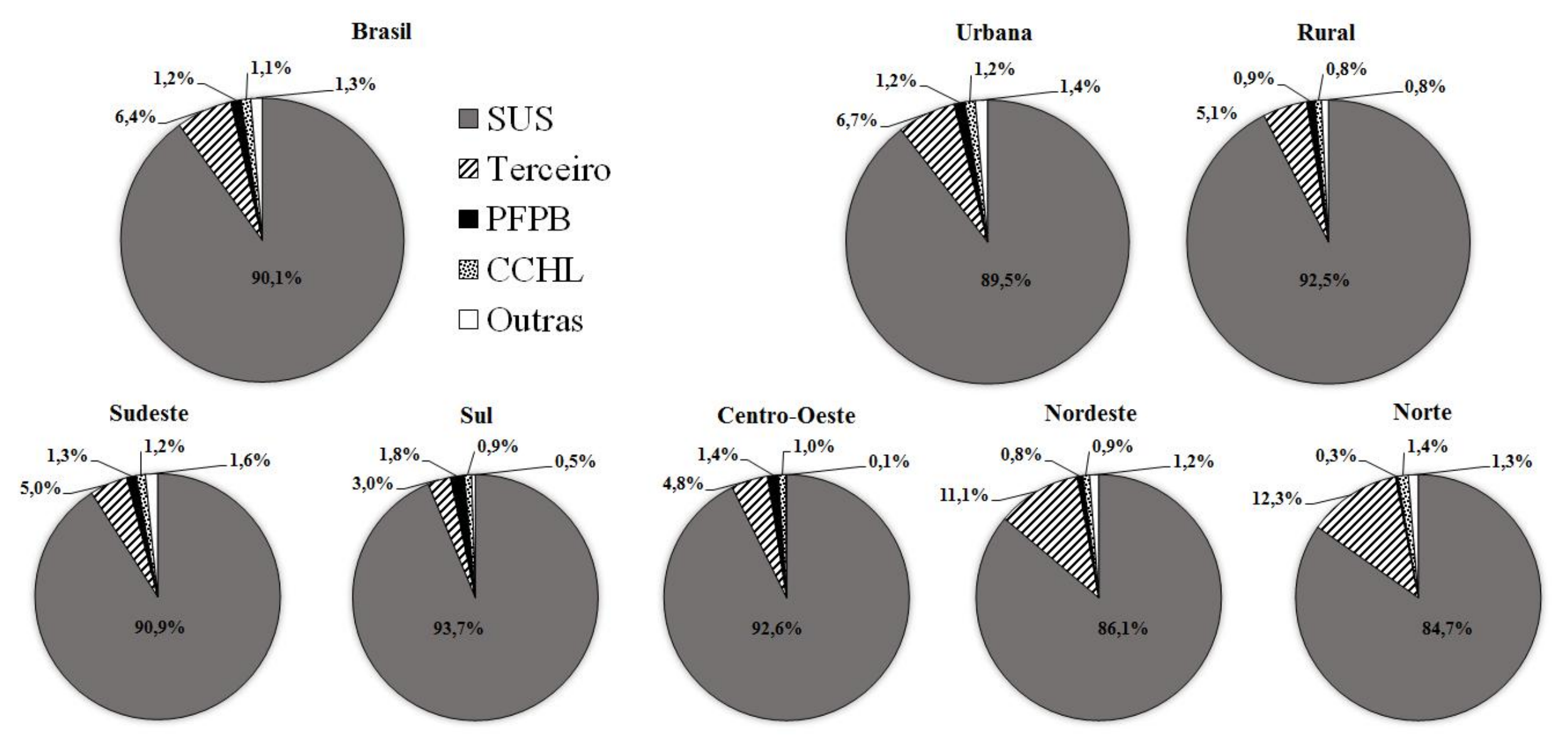

Figura 20: Local de aquisição dos medicamentos obtidos por meio de doação no Brasil, nas macrorregiões brasileiras e por região urbana e rural. PFPB=Programa Farmácia Popular do Brasil; $\mathrm{CCHL}=$ Clínica, consultório, hospital, laboratório. 
Cerca de $22 \%$ dos domicílios brasileiros que relataram aquisição de medicamentos no período de referência da pesquisa, obtiveram algum medicamento por meio do SUS, com maior percentual na área rural e na região sudeste (Figura 21). Apenas 11-13\% dos domicílios das regiões norte e centro-oeste obtiveram medicamentos do SUS.

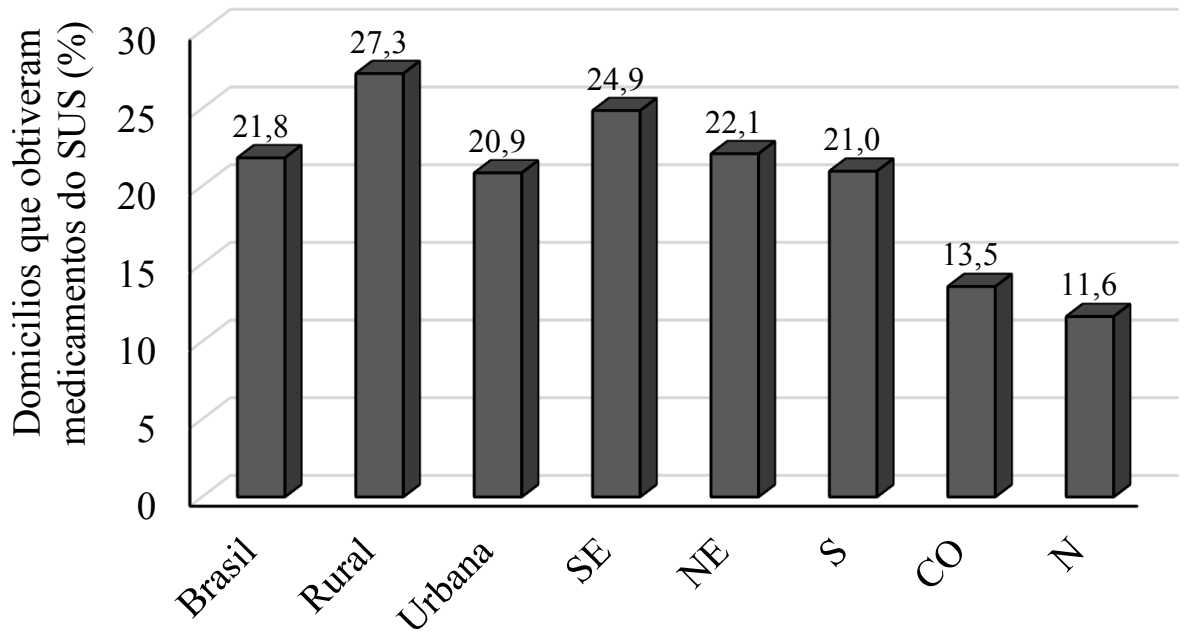

Figura 21: Percentual de domicílios que obtiveram algum medicamento por meio do SUS, no Brasil, nas regiões urbana e rural e nas macrorregiões brasileiras.

Domicílios pertencentes à classe econômica A1 não relataram ter recebido algum medicamento do SUS. Entretanto, mesmo entre as classes econômicas mais privilegiadas, como as classes A2, B1 e B2 houve domicílios que se beneficiaram do Sistema. A proporção de domicílios que receberam algum medicamento por meio do SUS é maior nas classes econômicas D e E (Figura 22). 


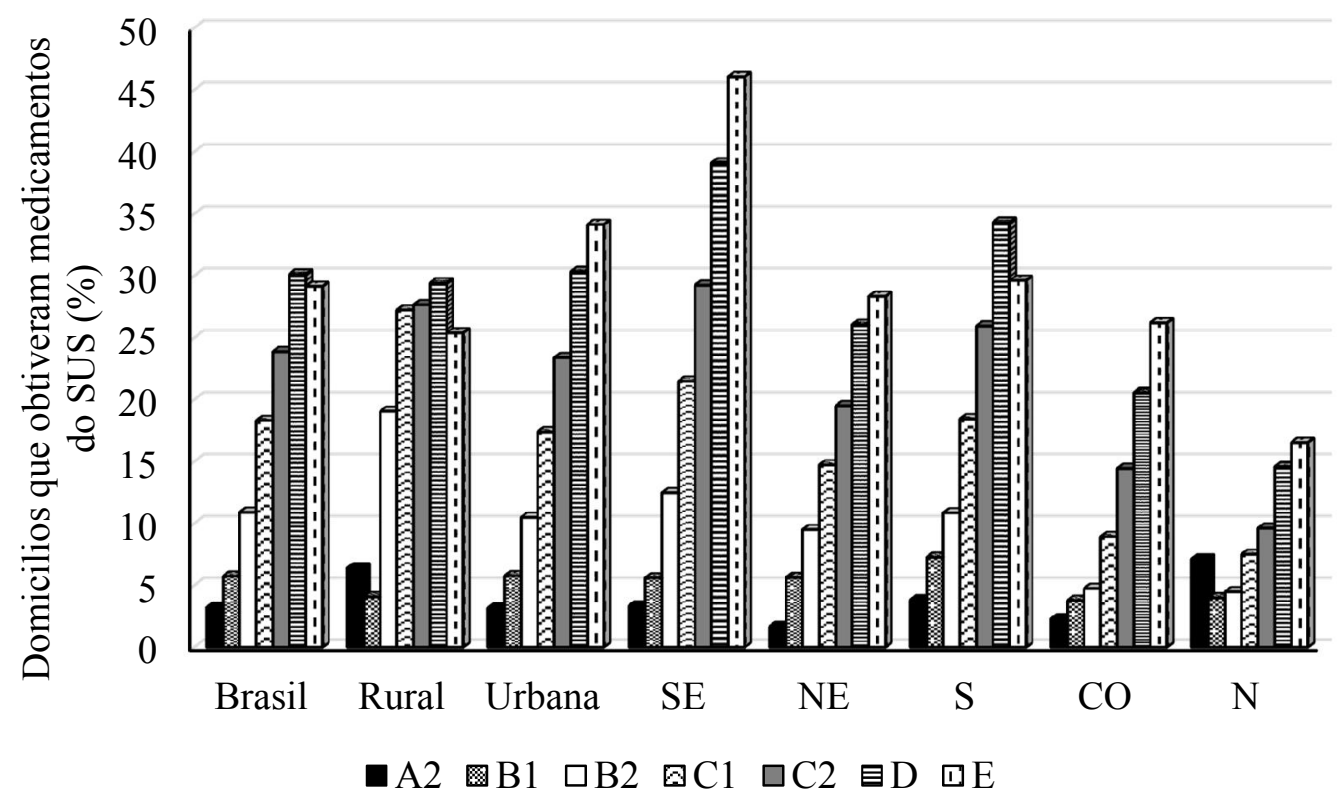

Figura 22: Percentual de domicílios dentro de cada classe econômica que receberam pelo menos um medicamento do SUS no Brasil, nas regiões urbana e rural e nas macrorregiões brasileiras.

Se considerarmos o cenário nacional, 13,9\% dos medicamentos obtidos pelos domicílios foram fornecidos pelo SUS. Em estudo recente, conduzido a partir de uma amostra representativa da população de Brasília (DF), observou-se um percentual maior (39,3\%), sendo 9,9\% dos medicamentos obtidos do Programa Farmácia Popular (GALVÃO et al., 2014). Bertoldi et al. (2009), ao estudarem os medicamentos utilizados por 2.988 indivíduos de Porto Alegre, cobertos pela Estratégia Saúde da Família mostraram que 51,0\% dos medicamentos utilizados no período recordatório de 15 dias foram fornecidos pelo SUS.

Ainda considerando todos os medicamentos adquiridos, observa-se que a proporção daqueles obtidos por meio do SUS foi maior para as classes D e E em todos as regiões pesquisadas, chegando a mais de $28 \%$ na região Sudeste (Tabela 14 ). 
Tabela 14: Proporção de medicamentos fornecidos pelo SUS em relação ao total de medicamentos obtidos por classe econômica no Brasil, nas regiões rural e urbana e nas macrorregiões brasileiras.

\begin{tabular}{ccccccccc}
\hline Classe & Brasil & Urbana & Rural & SE & S & CO & NE & N \\
\hline A2 & 1,1 & 1,0 & 4,7 & 1,0 & 1,4 & 1,8 & 0,6 & 2,7 \\
B1 & 2,8 & 2,8 & 1,3 & 2,4 & 4,4 & 1,9 & 2,5 & 2,5 \\
B2 & 6,7 & 6,4 & 12,8 & 7,5 & 7,2 & 2,5 & 5,4 & 2,3 \\
C1 & 11,2 & 10,7 & 16,9 & 13,6 & 11,5 & 5,6 & 6,8 & 3,8 \\
C2 & 16,3 & 16,1 & 17,4 & 20,3 & 17,9 & 10,6 & 11,8 & 5,3 \\
D & 20,7 & 21,3 & 18,7 & 28,1 & 24,3 & 16,1 & 16,1 & 8,5 \\
E & 20,6 & 24,2 & 18,0 & 35,7 & 27,4 & 19,5 & 18,7 & 12,6 \\
\hline
\end{tabular}

Dados do presente estudo mostram que o sistema público de saúde constitui uma importante forma de acesso a medicamentos, especialmente nas classes econômicas menos privilegiadas. Essa observação vai ao encontro do que mostrado em estudos anteriores. Bertoldi et al. (2009), ao estudarem os medicamentos utilizados por 2.988 indivíduos de Porto Alegre, cobertos pela Estratégia Saúde da Família mostraram que a proporção de medicamentos obtidos por meio do SUS foi maior entre os indivíduos mais pobres. A mesma observação foi feita por Galvão et al. (2014) em estudo populacional conduzido no Distrito Federal. Entretanto, mesmo nessas classes, é importante a proporção de medicamentos que não é obtida por meio do SUS, possivelmente devido à defíciência na assistência farmacêutica do Sistema.

O financiamento de medicamentos pelo SUS tem sido ampliado nos últimos anos (AUREA et al., 2011; VIEIRA; ZUCCHI, 2013). No entanto, a assistência farmacêutica no país ainda é subfinanciada, o gasto privado com medicamentos também tem sido ampliado e continua maior que o gasto público (OPAS, 2005; IBGE, 2012b; GARCIA et al, 2013b). Boing et al. (2013), ao analisarem os dados da Pesquisa Nacional por Amostra de Domicílios (PNAD) de 2008 observaram que $45,3 \%$ dos indivíduos que tiveram medicamentos receitados no SUS conseguiram todos os medicamentos prescritos no próprio sistema. Boing; Bertoldi e Peres (2011), por meio de um estudo de base populacional conduzido na área urbana de Florianópolis (SC), mostraram que $19,9 \%$ dos 1.720 participantes tiveram gastos com medicamentos presentes na Relação Nacional de Medicamentos Essenciais (Rename).

Cerca de um terço dos medicamentos da classe agentes antineoplásicos e imunomoduladores (L) foi fornecida pelo SUS (33,7\%; Tabela 17). Em termos percentuais essa é a classe de medicamentos que possui maior representatividade do Sistema. Destaca-se ainda que apenas $6,7 \%$ dos medicamentos adquiridos na região Norte foi fornecida pelo SUS (Tabela $15)$. 
Tabela 15: Percentual de medicamentos obtidos que foram fornecidos pelo SUS de acordo com a classificação ATC, no Brasil, nas macrorregiões brasileiras e por região urbana e rural.

\begin{tabular}{ccccccccc}
\hline Classe & Brasil & Urbana & Rural & SE & S & CO & NE & N \\
\hline L & 33,7 & 29,7 & 63,7 & 35,2 & 33,5 & 13,0 & 33,0 & 37,9 \\
C & 29,2 & 27,5 & 40,8 & 30,0 & 26,8 & 22,7 & 32,6 & 19,3 \\
B & 24,3 & 21,9 & 33,8 & 27,0 & 22,7 & 22,2 & 24,1 & 15,0 \\
P & 21,9 & 20,0 & 28,1 & 34,0 & 13,8 & 17,8 & 21,3 & 13,1 \\
J & 14,1 & 13,7 & 16,6 & 16,9 & 12,3 & 8,4 & 14,2 & 6,3 \\
A & 13,9 & 13,7 & 15,5 & 17,3 & 13,7 & 10,2 & 11,7 & 5,3 \\
G & 11,4 & 10,3 & 19,9 & 10,9 & 10,3 & 4,4 & 17,3 & 8,2 \\
N & 11,2 & 10,9 & 12,8 & 13,3 & 12,4 & 7,2 & 9,5 & 5,1 \\
M & 11,1 & 10,8 & 12,4 & 12,5 & 11,5 & 8,0 & 10,5 & 6,9 \\
R & 8,7 & 8,2 & 12,4 & 10,0 & 9,0 & 5,5 & 8,0 & 5,0 \\
H & 8,5 & 8,2 & 12,4 & 9,1 & 11,2 & 1,5 & 3,5 & 3,7 \\
D & 5,7 & 5,7 & 6,5 & 6,5 & 5,0 & 3,9 & 5,5 & 4,4 \\
S & 4,8 & 4,7 & 6,1 & 4,7 & 6,4 & 2,6 & 5,1 & 2,5 \\
V & 0,0 & 0,0 & 0,0 & 0,0 & 0,0 & 0,0 & 0,0 & 0,0 \\
TA & 1,9 & 2,0 & 1,2 & 3,6 & 0,5 & 3,7 & 1,0 & 1,1 \\
MI & 11,7 & 11,3 & 13,7 & 16,2 & 7,4 & 8,7 & 10,1 & 2,7 \\
\hline Total & $\mathbf{1 3 , 9}$ & $\mathbf{1 3 , 3}$ & $\mathbf{1 7 , 6}$ & $\mathbf{1 6 , 0}$ & $\mathbf{1 3 , 8}$ & $\mathbf{9 , 5}$ & $\mathbf{1 3 , 0}$ & $\mathbf{6 , 7}$ \\
\hline Agent
\end{tabular}

$\mathrm{L}=$ Agentes antineoplásicos e imunomoduladores; $\mathrm{C}=$ Sistema cardiovascular; $\mathrm{B}=$ Sangue e órgãos hematopoiéticos; $\mathrm{P}=$ Antiparasitários, inseticidas e repelentes; $\mathrm{J}=$ Antiinfecciosos de uso sistêmico; $\mathrm{A}=$ Aparelho digestivo e metabolismo; $\mathrm{G}=$ Sistema geniturinário e hormônios sexuais; $\mathrm{N}=$ Sistema nervoso; $\mathrm{M}=$ Sistema musculoesquelético; $\mathrm{R}=$ Sistema respiratório; $\mathrm{H}=$ Preparações hormonais sistêmicas, excluindo hormônios sexuais e insulinas; $\mathrm{D}=$ Dermatológicos; $\mathrm{S}=$ Órgãos sensoriais; $\mathrm{TA}=$ Tratamento alternativo; $\mathrm{MI}=$ Medicamento indeterminado.

No geral, a maioria dos medicamentos fornecidos pelo SUS são medicamentos genéricos. Entretanto, nas regiões Centro-Oeste e Norte mais da metade são medicamentos de marca (referência ou similares) (Tabela 16). Também foi possível observar que, em regiões rurais, $6,0 \%$ dos medicamentos fornecidos pelo SUS são manipulados, um percentual maior que em regiões urbanas.

Tabela 16: Características dos medicamentos fornecidos pelo SUS no Brasil, nas macrorregiões brasileiras e por região urbana e rural.

\begin{tabular}{lcccccccc}
\hline \multicolumn{1}{c}{ Característica } & Brasil & Urbana & Rural & SE & S & CO & NE & N \\
\hline Genérico & 54,5 & 56,0 & 47,6 & 59,0 & 47,6 & 36,9 & 54,5 & 36,2 \\
Marca (referência & 38,1 & 37,6 & 40,5 & 34,1 & 44,7 & 54,6 & 37,9 & 52,0 \\
ou similar) & 5,1 & 5,0 & 5,8 & 3,5 & 6,1 & 7,8 & 6,8 & 11,6 \\
Não sabe & 1,8 & 1,0 & 5,9 & 2,9 & 1,5 & 0,7 & 0,2 & 0,0 \\
Manipulado & 0,43 & 0,48 & 0,21 & 0,52 & 0,13 & 0,09 & 0,54 & 0,18 \\
MEPM & & &
\end{tabular}

MPEM=Medicamento a base de plantas e ervas medicinais 


\section{Classes dos medicamentos adquiridos pelos domicílios}

Considerando-se as classes dos medicamentos adquiridos, observa-se que, no primeiro nível da classificação ATC, a maior parte pertence à classe sistema nervoso $(28,8 \%$ dos medicamentos), seguida das classes sistema cardiovascular $(15,7 \%)$ e aparelho digestivo e metabolismo (14,3\%) (Tabela 17). Este resultado confirma aqueles encontrados em outros estudos conduzidos no país, que também utilizaram o sistema ATC para classificação dos medicamentos (Tabela 4).

Tabela 17: Principais classes dos medicamentos adquiridos.

\begin{tabular}{|c|c|c|}
\hline Classe Anatômica/Terapêutica ATC a & $\begin{array}{c}\text { Número de } \\
\text { medicamentos } \\
\text { adquiridos }\end{array}$ & $\%^{\mathrm{b}}$ \\
\hline Sistema Nervoso $(\mathrm{N})$ & 36.789 & 28,8 \\
\hline Analgésicos (N02) & 30.033 & 22,9 \\
\hline Psicoanalépticos (N06) & 2.569 & 2,53 \\
\hline Psicolépticos (N05) & 795 & 0,64 \\
\hline Sistema cardiovascular $(\mathrm{C})$ & 17.487 & 15,7 \\
\hline Subgrupo não identificado $(\mathrm{C} 00)^{\mathrm{c}}$ & 11.972 & 10,46 \\
\hline Agentes modificadores lipídicos (C10) & 1.710 & 1,75 \\
\hline Aparelho digestivo e metabolismo (A) & 17.874 & 14,3 \\
\hline $\begin{array}{l}\text { Medicamentos para desordens ácidas relacionadas } \\
\text { (A02) }\end{array}$ & 4.512 & 3,65 \\
\hline $\begin{array}{l}\text { Preparações antiobesidade, exceto produtos dietéticos } \\
\text { (A08) }\end{array}$ & 134 & 0,13 \\
\hline Medicamentos utilizados no diabetes (A10) & 2.655 & 2,37 \\
\hline Vitaminas (A11) & 5.973 & 4,45 \\
\hline Sistema respiratório $(\mathrm{R})$ & 15.049 & 12,1 \\
\hline Preparações para tosse e resfriado (R05) & 9.975 & 7,71 \\
\hline Anti-histamínicos de uso sistêmico (R06) & 3.818 & 3,33 \\
\hline Sistema músculo esquelético $(\mathrm{M})$ & 9.764 & 7,51 \\
\hline Anti-inflamatórios e antirreumáticos (M01) & 8.856 & 6,78 \\
\hline Sistema gênito urinário e hormônios sexuais $(\mathrm{G})$ & 8.195 & 7,33 \\
\hline $\begin{array}{l}\text { Hormônios sexuais e moduladores do sistema genital } \\
\text { (G03) }\end{array}$ & 5.775 & 5,30 \\
\hline Anti-infecciosos de uso sistêmico (J) & 5.005 & 3,89 \\
\hline Antibacterianos de uso sistêmico (J01) & 4.930 & 3,82 \\
\hline Órgãos sensoriais $(\mathrm{S})$ & 3.319 & 2,89 \\
\hline Oftalmológicos (S01) & 1.921 & 1,59 \\
\hline Dermatológicos (D) & 3.159 & 2,68 \\
\hline Antiparasitários, inseticidas e repelentes $(\mathrm{P})$ & 2.169 & 1,35 \\
\hline Anti-helmínticos (P02) & 2.090 & 1,31 \\
\hline
\end{tabular}




\begin{tabular}{lcc}
\hline Classe Anatômica/Terapêutica ATC a & $\begin{array}{c}\text { Número de } \\
\text { medicamentos } \\
\text { adquiridos }\end{array}$ & $\mathbf{\%}^{\mathrm{b}}$ \\
\hline Preparações hormonais sistêmicas, excluindo hormônios & 654 & 0,67 \\
sexuais e insulinas (H) & 406 & 0,28 \\
Sangue e órgãos formadores do sangue (B) & 96 & 0,09 \\
Antineoplásicos e agentes imunomoduladores (L) & 1 & 0,00 \\
Vários (V) & 2.260 & 1,84 \\
Tratamento alternativo (TA) & 756 & 0,56 \\
Medicamento indeterminado (MI) & & \\
a'Grupos anatômicos nível 1 e subgrupos mais importantes ou mais prevalentes (nível 2); ${ }^{\mathrm{a} O}$ \\
valor percentual é definido com base no número expandido de medicamentos; ${ }^{\mathrm{c} A p e n a s ~ a s ~}$ \\
respostas Para pressão alta (anti-hipertensivo) e Para pressão arterial.
\end{tabular}

Galvão et al. (2014), a partir de um estudo de base populacional no Distrito Federal mostraram que medicamentos das classes sistema nervoso, sistema cardiovascular e aparelho digestivo também foram os mais utilizados pelos 1.820 brasilienses de 18 a 65 anos participantes do estudo, resultado similar ao encontrado por Costa et al (2011) em Campinas e por VOSGERAU et al. (2011) em Ponta Grossa (374 indivíduos, 20-59 anos assistidos pela Estratégia Saúde da Família). Estas classes também foram as mais utilizadas por idosos de Goiânia (934 idosos, $\geq 60$ anos; SANTOS et al., 2013) e por 154 idosos de cinco instituições de longa permanência de Brasília (OLIVEIRA; NOVAES, 2012). Por fim, Bertoldi et al. (2009), por meio de estudo envolvendo 2.988 indivíduos de todas as idades, mostraram que essas três classes de medicamentos estavam entre as quatro classes de medicamentos mais utilizadas na população assistida pela Estratégia Saúde da Família de Porto Alegre.

No segundo nível da ATC, foram mais utilizados analgésicos $(22,9 \%)$, medicamentos utilizados no controle da pressão arterial (10,5\%), preparações para tosse e resfriado $(7,7 \%)$, hormônios sexuais e moduladores do sistema genital (5,3\%), vitaminas $(4,45 \%)$ e antibacterianos de uso sistêmico (3,82\%). Analgésicos, embora sejam considerados como produtos relativamente seguros são os medicamentos mais utilizados em muitos países (HARDON; HODGKIN; FRESLE, 2004). A utilização abusiva de tais medicamentos não é isenta de riscos, sendo considerada pela OMS como um dos padrões de comportamento comumente envolvidos no uso de medicamentos de forma não racional (HARDON; HODGKIN; FRESLE, 2004). A utilização de ácido acetil salicílico, por exemplo pode causar úlceras estomacais, e o uso excessivo de paracetamol pode causar a morte (HARDON; HODGKIN; FRESLE, 2004). 
Observa-se variações quanto às classes de medicamentos mais utilizadas nos estratos geográficos estudados, sendo que chama atenção o fato de que, nas regiões Norte e Nordeste, a classe sistema cardiovascular não seja a segunda classe mais adquirida (Figura 23). Tal observação pode ser explicada por fatores ligados ao estilo de vida dessas populações, bem como pela falta de acesso a medicamentos.

De acordo com a OMS, entre os fatores protetores da saúde cardiovascular estão ter uma dieta saudável, o que inclui a menor ingestão de sal e gorduras saturadas, bem como o aumento do consumo de frutas e vegetais (WHO, 2007). A ingestão de ômega-3, um ácido graxo encontrado em peixes, tem mostrado trazer benefícios ao coração; praticar atividade física; não fumar, ter moderação na ingestão de álcool e controlar o peso corporal. Além disso, alguns fatores psicossociais como estresse, ansiedade, depressão e isolamento social estão associados à ocorrência de doenças cardiovasculares (WHO, 2007). De acordo com dados da POF 20082009, as populações das regiões Norte e Nordeste são a que mais adquiriram peixes e as que menos adquiriram embutidos no país (LEVY et al., 2012). Além disso as populações dessas regiões foram as que menos adquiriram bebidas alcoólicas (LEVY et al., 2012) e, no presente, estudo (Tabela 9) foi mostrado que a aquisição de artigos de fumo foi menor em domicílios das regiões Norte, Nordeste e Centro-Oeste. Entretanto, dados referentes ao consumo individual de alimentos no Brasil, evidenciam o alto consumo de sódio em todas as regiões brasileiras (IBGE, 2011).

Considerando-se a importância do tratamento medicamentoso na prevenção de mortes por doenças cardiovasculares (WHO, 2007), a baixa taxa de aquisição de medicamentos destinados ao tratamento de doenças cardiovasculares, por 1.000 pessoas, apresentada pelas regiões Norte e Nordeste também pode indicar a falta de acesso dos doentes a esses medicamentos. Segundo SCHMIDT et al. (2011), a taxa de mortalidade por doenças cardiovasculares em 2007 - quando padronizadas por idade para a população-padrão da OMS, e corrigidas para sub-registro - foi maior na região Nordeste, seguida das regiões Norte e Centro-Oeste, enquanto as menores taxas ocorreram nas regiões Sudeste e Sul. 


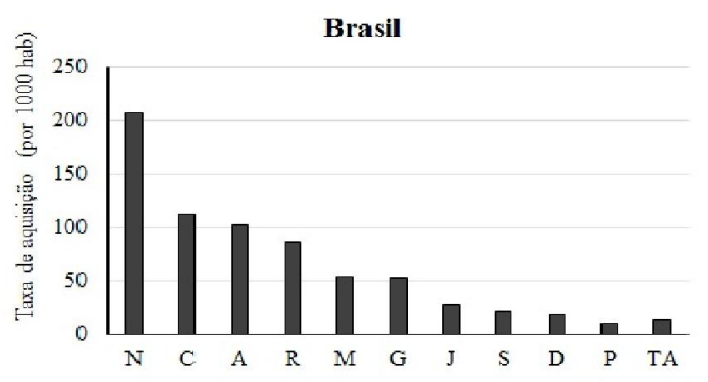

Sul
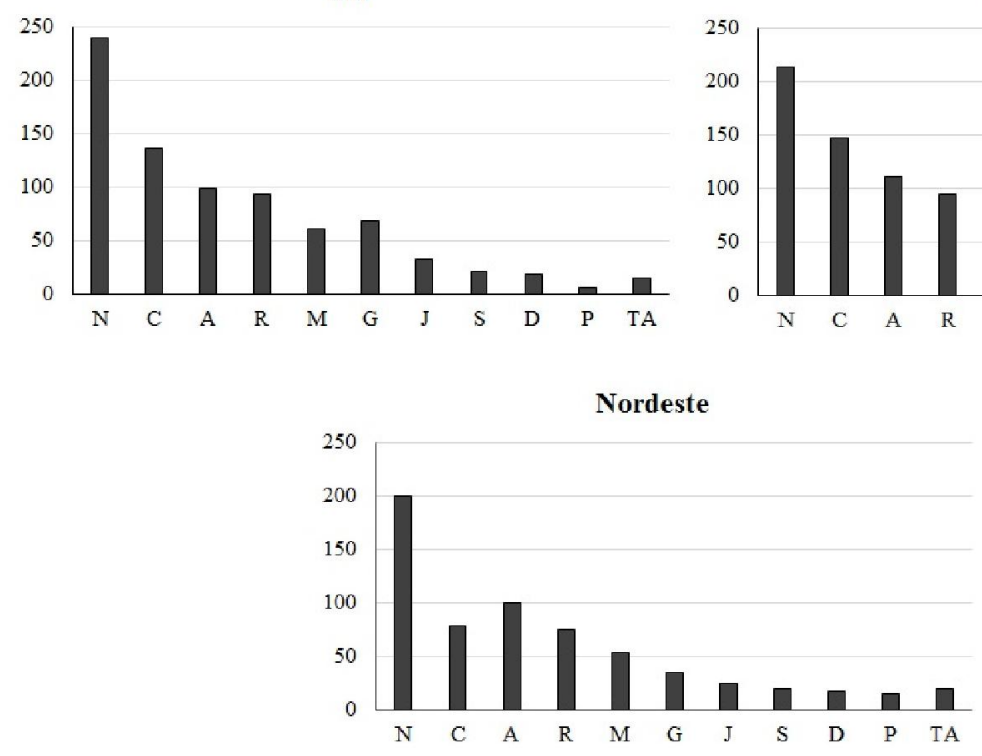

Região urbana

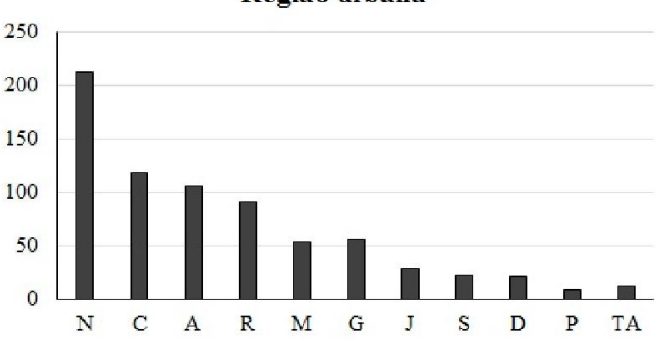

Sudeste

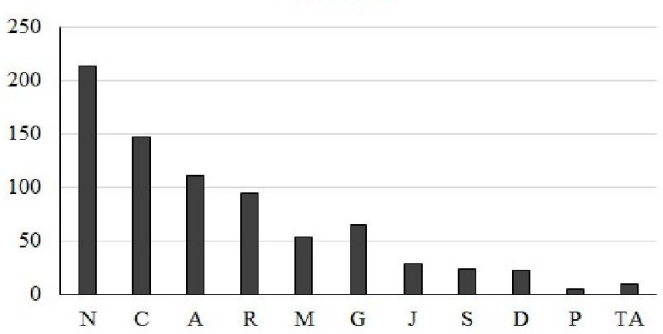

Região rural

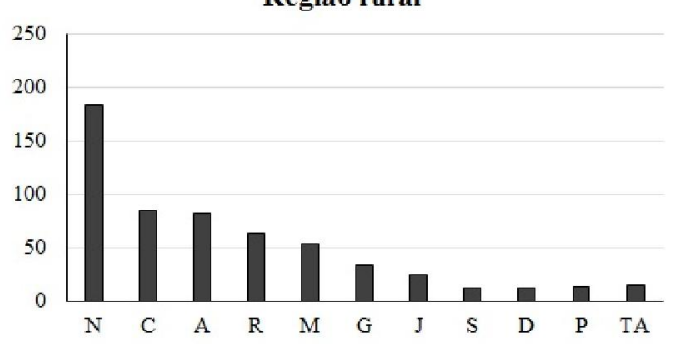

Centro-Oeste

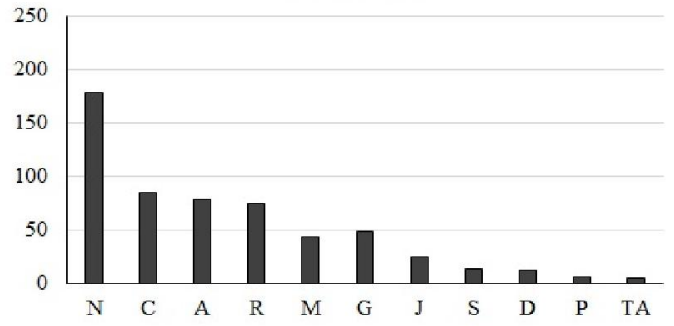

Norte

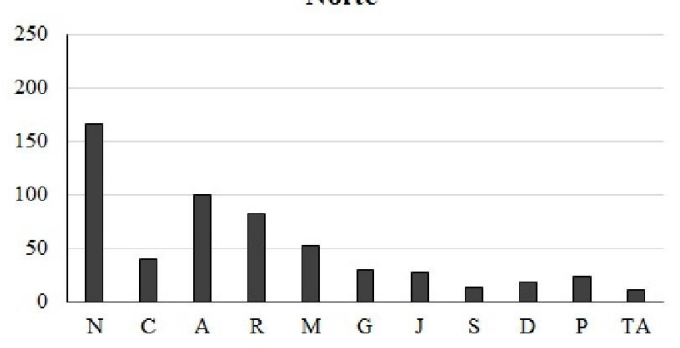

Figura 23: Aquisição de medicamentos por 1000 habitantes no Brasil, nas regiões urbana e rural e nas macrorregiões brasileiras.

$\mathrm{N}=$ Sistema nervoso; $\mathrm{C}=$ Sistema cardiovascular; $\mathrm{A}=$ Aparelho digestivo e metabolismo; $\mathrm{R}=$ Sistema respiratório; $\mathrm{M}=$ Sistema musculoesquelético; $\mathrm{G}=$ Aparelho geniturinário e hormônios sexuais; $\mathrm{J}=$ Anti-infecciosos de uso sistêmico; $\mathrm{S}=$ Orgãos sensoriais; $\mathrm{D}=$ Dermatológicos; $\mathrm{P}=\mathrm{Antiparasitários,}$ inseticidas e repelentes; $\mathrm{TA}=$ Tratamento alternativo 


\section{Disponibilidade de medicamentos no domicílio e intoxicação}

A Tabela 18 mostra a frequência de aquisição de medicamentos por 10.000 habitantes no Brasil e nas macrorregiões brasileiras, bem como as taxas de intoxicações medicamentosas por 10.000 habitantes nessas mesmas localidades. Essas taxas foram calculadas a partir das informações sobre o número de intoxicações obtidas pelo SINAN (BRASIL, 2014a) e pelo SINITOX (FIOCRUZ, 2014a) e dos dados populacionais fornecidos pela POF 2008-2009 (IBGE, 2014). No geral, em locais onde a frequência de aquisição de medicamentos é maior (regiões Sul e Sudeste), há um número maior de casos de intoxicações por medicamentos (Tabela 18).

Tabela 18: Aquisição de medicamentos por 10.000 habitantes e intoxicações por medicamentos por 10.000 habitantes registradas no SINAN e no SINITOX nos anos de 2008 e 2009, para o Brasil e para as macrorregiões brasileiras.

\begin{tabular}{lccc}
\hline & $\begin{array}{c}\text { Aquisição de } \\
\text { medicamentos por } \\
\mathbf{1 0 . 0 0 0} \text { hab. }\end{array}$ & $\begin{array}{c}\text { Intoxicações por } \\
\mathbf{1 0 . 0 0 0} \text { hab. } \\
\text { SINAN }\end{array}$ & $\begin{array}{c}\text { Intoxicações por } \\
\mathbf{1 0 . 0 0 0} \text { hab. } \\
\text { SINITOX }\end{array}$ \\
\hline Brasil & 7.192 & 1,16 & 3,16 \\
Sul & 8.134 & 2,93 & 6,02 \\
Sudeste & 7.921 & 1,19 & 4,05 \\
Nordeste & 6.417 & 0,55 & 1,19 \\
Centro-Oeste & 5.791 & 0,88 & 2,78 \\
Norte & 5.669 & 0,27 & 0,56 \\
\hline
\end{tabular}

Fonte: Ministério da Saúde/SVS - Sistema de Informação de Agravos de Notificação - SINAN Net, 2014; FIOCRUZ, 2014a; IBGE, 2014.

Medicamentos são o principal agente envolvido em intoxicações humanas no Brasil, sendo que crianças abaixo dos cinco anos representam a faixa etária mais acometida (FIOCRUZ, 2014a; BRASIL, 2010c; BORTOLETTO; BOCHNER, 1999). De acordo com os registros de intoxicações humanas do SINITOX, nos anos de 1993 a 1996, 33\% das intoxicações por medicamentos ocorreram em crianças menores de 5 anos (BORTOLETTO; BOCHNER, 1999). No mesmo período, 32\% dos casos de óbitos por medicamentos em crianças menores de um ano foram causados pela ingestão acidental desses insumos, sendo que entre crianças de um a quatro anos esse percentual é de 65\% (BORTOLETTO; BOCHNER, 1999).

Dados mais recentes do SINITOX mostram que, entre os anos de 1999 a 2011, crianças menores de 5 anos continuaram sendo a faixa etária mais acometida pelas intoxicações por 
medicamentos, sendo que dados do SINAN mostram a ingestão acidental de medicamentos como a principal circunstância de intoxicação nessa faixa etária (BRASIL, 2014a).

No presente estudo, observou-se que em 20,4\% dos domicílios que obtiveram algum medicamento havia crianças menores de cinco anos. Estes domicílios tinham, em média, 2,88 medicamentos, um número maior que a média nacional (2,38 medicamentos por domicílios). Laste et al. (2012) visitaram 473 domicílios atendidos pela Estratégia Saúde da Família de um município da região Sul e observaram que em 37,3\% dos 533 locais de guarda de medicamentos, tais insumos permaneciam expostos a crianças residentes no domicílio.

Juntas, as informações sobre circunstâncias de intoxicação de medicamentos em crianças e de armazenamento inadequado de medicamentos em domicílios reforçam a necessidade de adoção de medidas já abordadas na literatura (BORTOLETTO; BOCHNER, 1999), como execução de ações educativas de prevenção de intoxicações acidentas direcionadas às próprias crianças e também aos pais, além da necessidade de que as indústrias produtoras de medicamentos utilizem embalagens mais resistentes à manipulação das crianças.

Entre os principais medicamentos envolvidos em casos de intoxicação no Brasil estão analgésicos e antitérmicos, medicamentos utilizados em resfriados (antitussígenos, antihistamínicos e descongestionantes nasais), medicamentos utilizados na depressão e ansiedade (benzodiazepínicos), antibióticos e anticoncepcionais (BRASIL, 2010c; BORTOLETTO; BOCHNER, 1999). Estas classes de medicamentos também são as mais presentes em domicílios com menores de cinco anos participantes da POF 2008/2009 (Figura 24). A classe N02, por exemplo engloba os analgésicos e antitérmicos; a classe R05, os antitussígenos e a classe G03, os anticoncepcionais. Os medicamentos utilizados no tratamento da ansiedade e da depressão estão incluídos nos grupos N05 (psicolépticos) e N06 (psicoanalépticos) e representam $0,3 \%$ e $1,2 \%$ dos medicamentos adquiridos, respectivamente. 


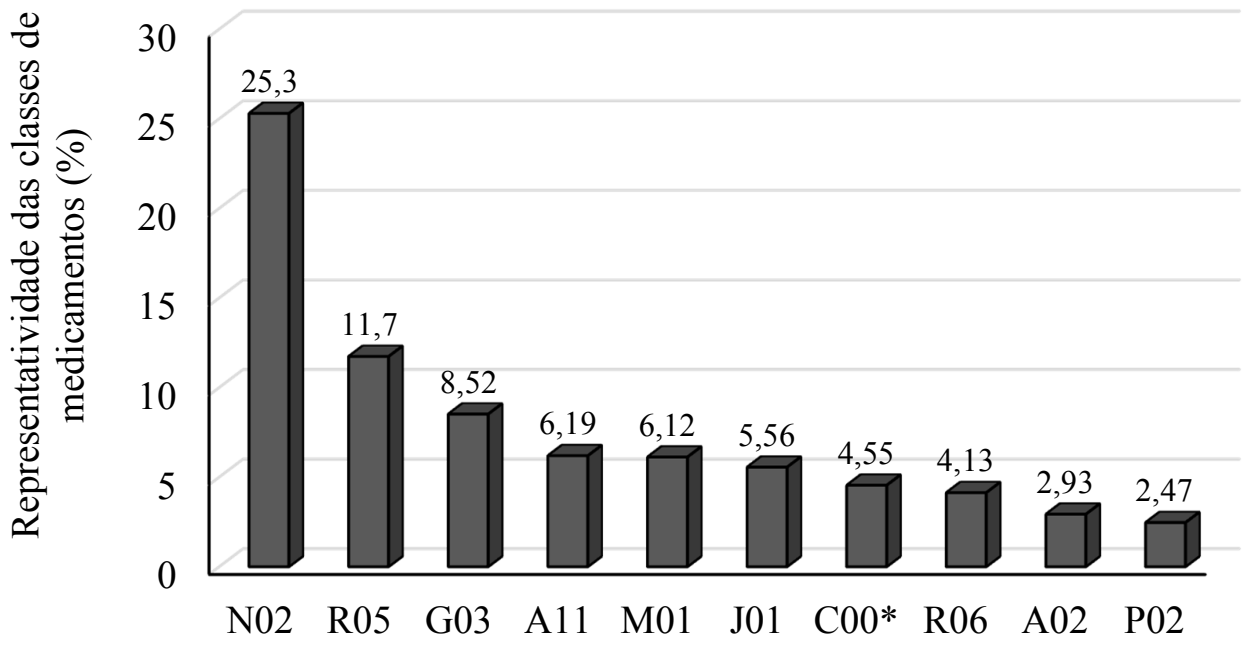

Figura 24: Principais classes de medicamentos presentes em domicílios que possuem crianças menores de cinco anos, de acordo com o segundo nível de classificação ATC.

N02=Analgésicos; R05=Preparações para tosse e resfriado; G03=Hormônios sexuais e moduladores do sistema genital; A11=Vitaminas; M01=Produtos anti-inflamatórios e antirreumáticos; J01=Antibacterianos de uso sistêmico; $\mathrm{C} 00^{*}=$ Para hipertensão ou antihipertensivo; R06=Anti-histamínicos de uso sistêmico; A02=Medicamentos para desordens ácidas relacionadas; P02=Anti-helmínticos.

\section{Classe ATC do medicamento adquirido e características dos domicílios e sua população}

\subsection{Classe socioeconômica do domicílio}

O número de medicamentos obtidos por 1000 habitantes dentro de cada classe socioeconômica, de acordo com o primeiro nível da classificação ATC é mostrado nas Figuras 25 e 26. Observa-se que a classe A1 destaca-se na obtenção de medicamentos dos grupos Aparelho digestivo e metabolismo (A), Órgãos sensoriais (S), Dermatológicos (D) e Tratamento alternativo (TA). A classe econômica A2 ressaltou-se em relação às outras classes na obtenção de medicamentos para o sistema cardiovascular (C), Sistema nervoso (N) e Preparações hormonais sistêmicas, exceto hormônios sexuais e insulinas $(\mathrm{H})$. Já a classe econômica E destacou-se na obtenção de medicamentos da classe Antiparasitários, inseticidas e repelentes $(\mathrm{P})$.

Para as classes Aparelho digestivo e metabolismo (A), Órgãos sensoriais (S) e Dermatológicos (D), o número de medicamentos obtidos por 1000 habitantes decresce na medida em que se caminha para classes econômicas menos privilegiadas, o que indica uma 
associação entre a aquisição de medicamentos desses grupos e a renda. No entanto, para a classe de medicamentos Antiparasitários, inseticidas e repelentes $(\mathrm{P})$ a relação é inversa: o número de medicamentos por 100 habitantes cresce à medida em que se caminha para classes econômicas menos privilegiadas.

Por outro lado, para a classe Sistema músculo esquelético $(\mathrm{M})$, o número de medicamentos por 1000 habitantes foi similar entre as classes econômicas não indicando qualquer relação com renda. Algo semelhante ocorre com as classes Sangue e órgãos hematopoiéticos (B) e Medicamento indeterminado (MI), que não foram especificados pelo participante. Ressalta-se que na POF 2008-2009, o questionário sobre os produtos farmacêuticos adquiridos é preenchido não necessariamente pelo usuário do medicamento.

Para as classes Sistema respiratório (R), Anti-infecciosos de uso sistêmico (J) e Preparações hormonais sistêmicas, exceto hormônios sexuais e insulinas (H); os dados indicam não haver relação entre a aquisição de medicamentos e a renda entre as classes econômicas $\mathrm{A}$ e B. Entretanto, a partir das classes B1 ou B2 o número de medicamentos por 1000 habitantes decresce na medida em que se caminha para classes econômicas menos privilegiadas, indicando que a partir dessas classes a renda passa a ter relação com a aquisição desses medicamentos e também que haja falta de acesso a medicamentos desses grupos em classes econômicas menos privilegiadas. 


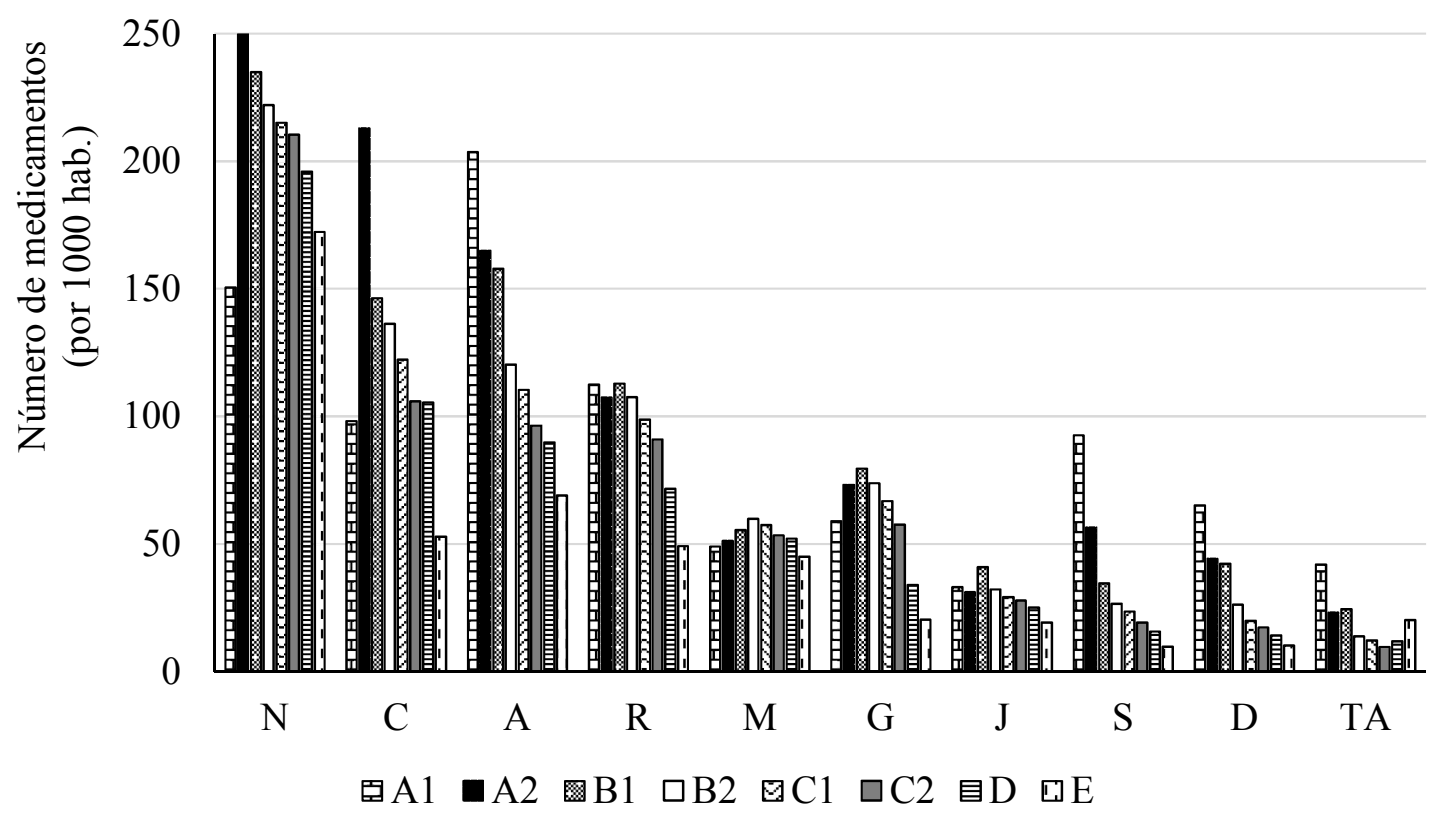

Figura 25: Número de medicamentos obtidos por 1000 habitantes dentro de cada classe social, segundo o primeiro nível da classificação ATC.

$\mathrm{N}=$ Sistema nervoso; $\mathrm{C}=$ Sistema cardiovascular; $\mathrm{A}=$ Aparelho digestivo e metabolismo; $\mathrm{R}=$ Sistema respiratório; $\mathrm{M}=$ Sistema musculoesquelético; $\mathrm{G}=$ Aparelho geniturinário e hormônios sexuais; $\mathrm{J}=\mathrm{Anti}-\mathrm{infec} \operatorname{ciosos}$ de uso sistêmico; $\mathrm{S}=$ Órgãos sensoriais; $\mathrm{D}=$ Dermatológicos; $\mathrm{TA}=$ Tratamento alternativo

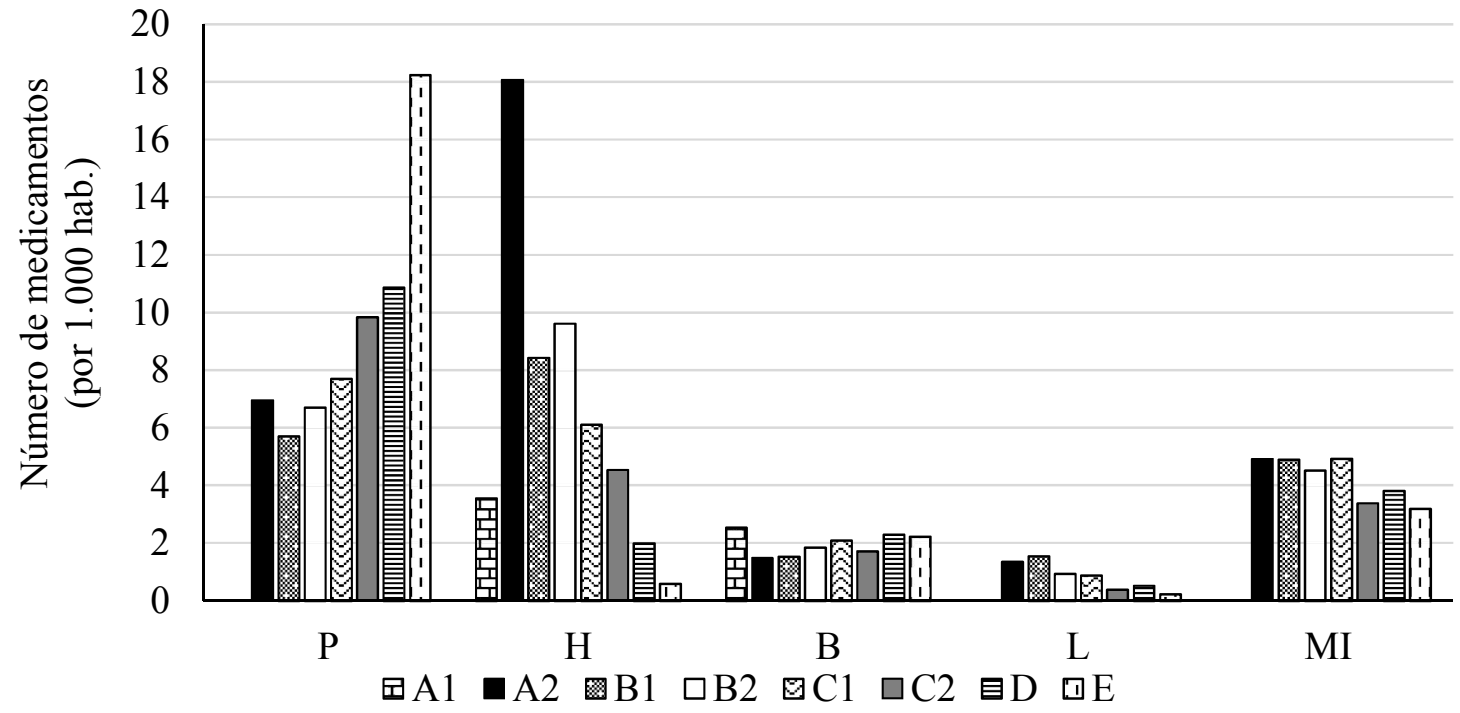

Figura 26: Número de medicamentos obtidos por 1000 habitantes dentro de cada classe social, segundo o primeiro nível da classificação ATC.

$\mathrm{P}=$ Antiparasitários, inseticidas e repelentes; $\mathrm{H}=$ Preparações hormonais sistêmicas, exceto hormônios sexuais e insulinas; $\mathrm{B}=$ Sangue e órgãos hematopoiéticos; $\mathrm{L}=$ Agentes antineoplásicos e imunomoduladores; $\mathrm{MI}=$ medicamento não identificado. 
No segundo nível da classificação ATC (Figuras 27 e 28), nota-se algo semelhante: para as classes Analgésicos (N02), Preparações para tosse e resfriado (R05), Anti-histamínicos de uso sistêmico (R06) e Antibacterianos de uso sistêmico (J01), os dados indicam não haver relação entre a aquisição de medicamentos e a renda entre as classes econômicas A e B. Entretanto, a partir das classes B1 ou B2 o número de medicamentos por 1000 habitantes decresce na medida em que se caminha para classes econômicas menos privilegiadas, indicando uma relação com renda e/ou falta de acesso a medicamentos nas classes econômicas menos privilegiadas.

Ressalta-se que para a classe econômica A1, o número de medicamentos por 1000 habitantes é menor que o da classe econômica C2 para as classes N02 (Analgésicos), G03 (Hormônios sexuais e moduladores do sistema genital), $\mathrm{C} 00^{*}$ (Para hipertensão ou antihipertensivo) e C10 (Agentes modificadores lipídicos), o que pode indicar que indivíduos da classe econômica A1 sofram menos com problemas de hipertensão e dislipidemia.

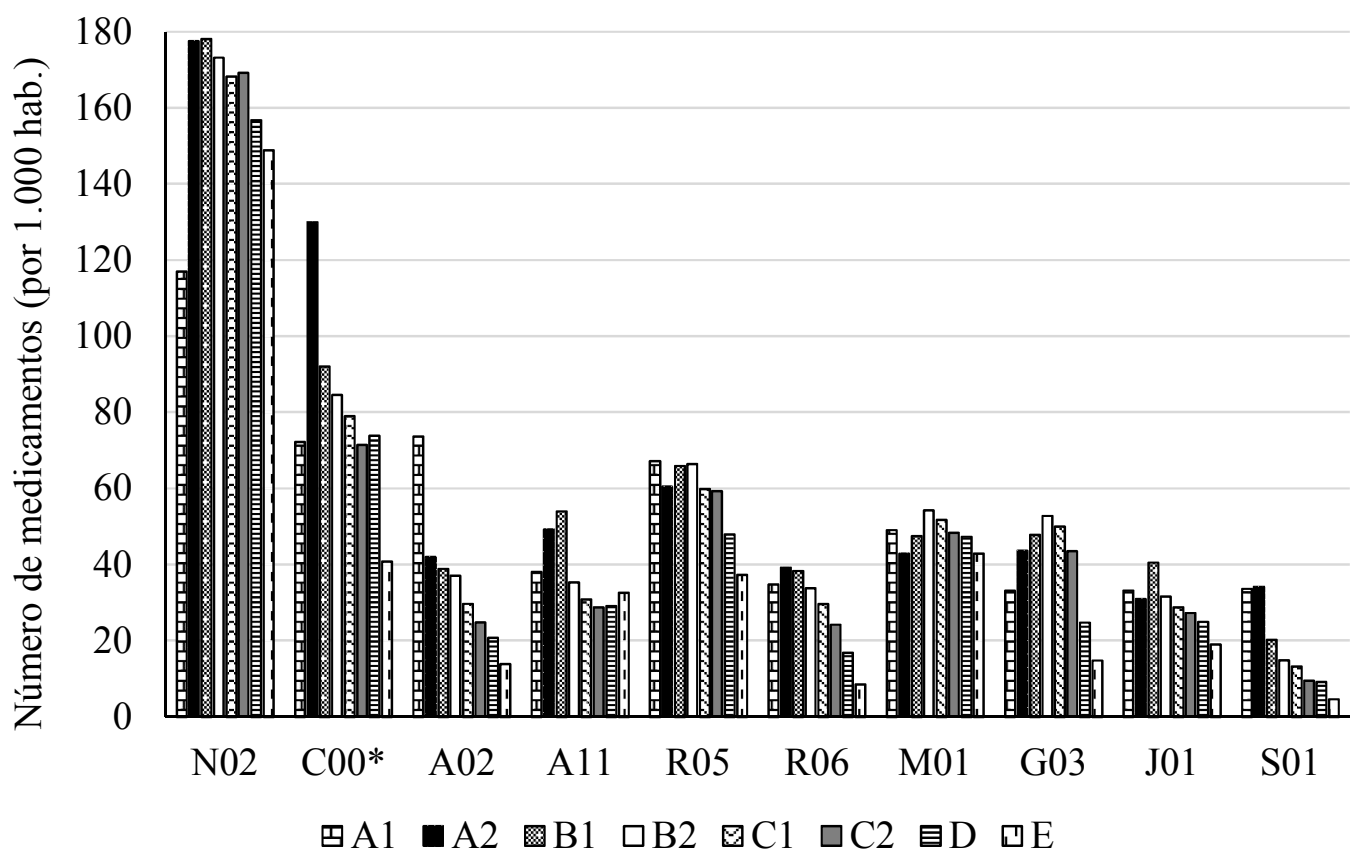

Figura 27: Número de medicamentos por 1.000 habitantes dentro de cada classe social, de acordo com o segundo nível da classificação ATC.

N02=Analgésicos; $\mathrm{C} 00^{*}=$ Para hipertensão ou anti-hipertensivo; $\mathrm{A} 02=$ Medicamentos para desordens ácidas relacionadas; A11=Vitaminas; R05=Preparações para tosse e resfriado; R06=Anti-histamínicos de uso sistêmico; M01=Produtos anti-inflamatórios e antirreumáticos; G03=Hormônios sexuais e moduladores do sistema genital; J01=Antibacterianos de uso sistêmico; S01=Oftalmológicos. 
O número de medicamentos obtidos por 1000 habitantes em domicílios de classe A1 é maior para medicamentos dos grupos Medicamentos para desordens ácidas relacionadas (A02) e Preparações antiobesidade, exceto produtos dietéticos (A08). A classe A2 destacou-se na obtenção de Medicamentos utilizados no diabetes (A10), Medicamentos para hipertensão ou anti-hipertensivos $\left(\mathrm{C} 00^{*}\right)$, Agentes modificadores lipídicos (C10) e Psicoanalépticos (N06), indicando que indivíduos dessa classe econômica possam sofrer mais de problemas cardiovasculares e de estresse. Já na classe econômica E observa-se a maior taxa de obtenção de medicamentos Antiparasitários, inseticidas e repelentes (P02), provavelmente devido as condições sanitárias mais precárias dos domicílios destas classes.

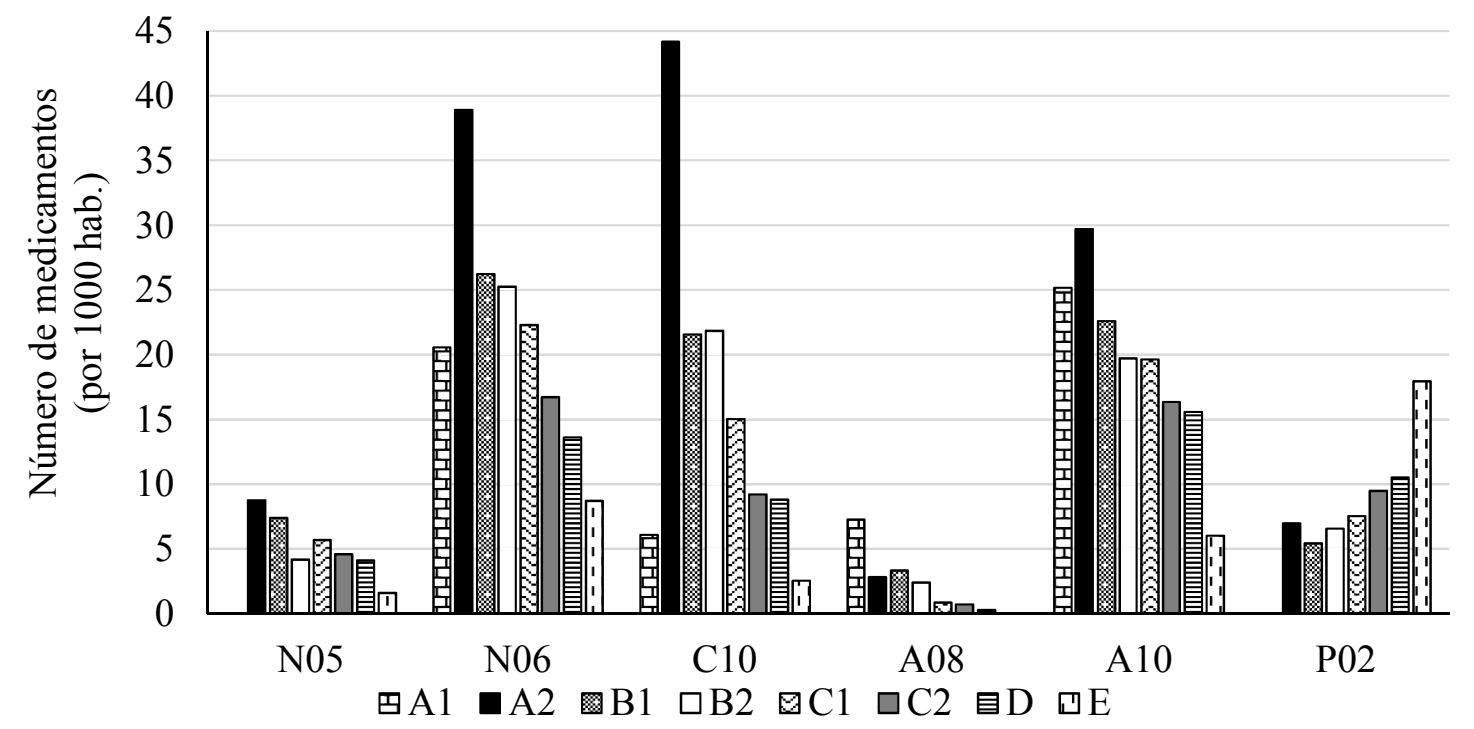

Figura 28: Número de medicamentos por 1.000 habitantes dentro de cada classe social, de acordo com o segundo nível da classificação ATC.

N05=Psicolépticos; N06=Psicoanalépticos; $\mathrm{C} 10=$ Agentes modificadores lipídicos; A08=Preparações antiobesidade, exceto produtos dietéticos; A10=Medicamentos utilizados no diabetes; A11=Vitaminas; P02=Anti-helmínticos.

Algumas observações apresentadas podem ser explicadas sob a ótica do acesso a medicamentos. Estudos anteriormente conduzidos no Brasil, por exemplo, observaram que, apesar de os fatores relacionados à obesidade serem distintos entre os sexos, prevalências mais altas de excesso de peso e obesidade, foram encontradas entre mulheres com menor renda e menor escolaridade (GIGANTE; MOURA; SARDINHA, 2009; VEDANA et al., 2008). No entanto, o número de medicamentos obtidos, por 1000 habitantes, da classe Preparações antiobesidade, exceto produtos dietéticos (A08), cresce à medida em que se caminha para classes econômicas mais privilegiadas. Tal observação vai ao encontro do mostrado por Mota 
e Silva Júnior (2012), que, a partir de dados da Pesquisa Nacional de Amostras por Domicílios do IBGE e do Sistema Nacional de Gerenciamento de Produtos Controlados (SNGPC) da ANVISA, relataram que o consumo de moduladores de apetite está positivamente relacionado

com a renda. É provável que indivíduos pertencentes a classes sociais mais privilegiadas gastem mais com medicamentos de custo mais elevado, como no caso de medicamentos destinados ao sistema respiratório (R), medicamentos dermatológicos (D) e medicamentos do grupo dos Órgãos sensoriais (S), classe que inclui colírios e soluções otológicas (BOING; BERTOLDI; PERES, 2011).

A associação positiva entre classe econômica e consumo de algumas classes de medicamentos também pode ser explicada pela ótica do acesso aos serviços de saúde, já que a falta de acesso a serviços de saúde pode promover a falta de acesso a medicamentos. Enquanto medicamentos analgésicos (N02), por exemplo, são medicamentos amplamente utilizados no contexto da automedicação (CARVALHO et al., 2005) e também estão entre os medicamentos mais prescritos em Unidades Básicas de Saúde (EV; GUIMARÃES; CASTRO, 2008; COLOMBO et al., 2004), algumas classes de medicamentos são geralmente prescritas após consultas com médicos especialistas. O trabalho de Garcia et al. (2013a), que também utilizou dados da POF 2008/2009, mostrou que enquanto nos domicílios de menor renda houve predominância de gastos com medicamentos analgésicos, antigripais e anti-inflamatórios, entre os domicílios de maior renda os gastos com medicamentos destinados ao tratamento de doenças crônicas, como diabetes e hipertensão foram mais relevantes, o que pode ter ocorrido tanto em decorrência dos preços dos medicamentos quanto em decorrência da falta de acesso a serviços médicos especializados.

\subsection{Condições sanitárias e localização do domicílio e aquisição de álcool e fumo}

As observações relativas à aquisição de medicamentos, segundo as classes econômicas dos domicílios são coerentes com as características dos domicílios que reportaram tal consumo (Tabelas 19 e 20). Nessas tabelas, o total de domicílios que adquiriram determinada classe de medicamentos foi distribuído de acordo com algumas características.

Comparando-se, por exemplo, os domicílios que obtiveram medicamentos das classes Antiparasitários, inseticidas e repelentes (P) e Anti-helmínticos (P02) com os que obtiveram outras classes de medicamentos observa-se que entre os que adquiriram P ou P02 ocorre o maior 
percentual de domicílios que não possuem água canalizada e também a menor proporção de domicílios que possuem as formas mais adequadas de escoadouro sanitário (rede coletora/ fossa séptica). Além disso, entre os domicílios que adquiriram medicamentos P02, observa-se o maior percentual de proximidade a esgoto a céu aberto ou valão (11,9\%). Tais circunstâncias contribuem para ocorrência de parasitoses intestinais (GELAW et al., 2013; KALIAPPAN et al., 2013; GARBOSSA et al., 2013; NOBRE et al., 2013; ANDRADE et al., 2011).

Observa-se também que entre os domicílios que relataram aquisição de Agentes antineoplásicos e imunomoduladores (L) ou de Órgãos sensoriais (S) ou de Oftalmológicos (S01) ou de Anti-histamínicos de uso sistêmico (R06) ocorrem os maiores percentuais de domicílios que se localizam próximos a áreas industriais (cerca de 7\%). Tal observação pode ser explicada pelo fato de que contaminantes ambientais liberados a partir de indústrias podem acarretar problemas de saúde tais como irritação ocular, alergias e até mesmo alguns tipos de câncer (CARVALHO et al., 2014; HENNING et al., 2014; RIPABELLI et al., 2013; KIM et al., 2013).

Interessante observar que, ao contrário do esperado, entre os domicílios que relataram aquisição de Agentes antineoplásicos e imunomoduladores (L) ocorre um dos menores percentuais de domicílios que adquiriram artigos de fumo (19,8\%). No entanto, entre esses domicílios é observado, o maior percentual de domicílios que adquiram bebida alcoólica $(15,1 \%)$ e a maior quantidade de álcool adquirida $(56,4 \mathrm{~mL})$. Tanto o álcool quanto o fumo são fatores de risco para o desenvolvimento de neoplasias (SCHUCKIT, 2008; BRAWLEY; KRAMER, 2008). Entretanto, como os malefícios do fumo são mais divulgados, o baixo percentual de aquisição de artigos de fumo entre os domicílios que relataram obtenção de medicamentos L pode indicar que, no contexto do diagnóstico e tratamento de câncer, as pessoas tendam a parar de fumar. 
Tabela 19: Características dos domicílios em que houve relato de obtenção de algum medicamento no período de referência de 30 dias, estratificadas de acordo com a classe de medicamento adquirido (segundo o primeiro nível da classificação ATC) e em percentual.

\begin{tabular}{|c|c|c|c|c|c|c|c|c|c|c|c|c|c|c|c|}
\hline Variável & $\mathbf{N}$ & $\mathrm{C}$ & $\mathbf{A}$ & $\mathbf{R}$ & $\mathbf{M}$ & $\mathbf{G}$ & $\mathbf{J}$ & $\mathbf{S}$ & $\mathbf{D}$ & $\mathbf{P}$ & $\mathbf{H}$ & $\mathbf{B}$ & $\mathbf{L}$ & TA & MI \\
\hline \multicolumn{16}{|c|}{ Ausência de água canalizada } \\
\hline & 6,9 & 3,9 & 6,6 & 5,5 & 7,3 & 3,6 & 6,5 & 4,3 & 4,6 & 15,7 & 1,8 & 10,2 & 3,2 & 10,1 & 5,4 \\
\hline \multicolumn{16}{|c|}{ Escoadouro sanitário } \\
\hline Rede/fossa séptica & 69,6 & 75,2 & 71,2 & 72,6 & 68,5 & 76,6 & 69,2 & 76,6 & 75,7 & 55,8 & 84,6 & 60,6 & 68,7 & 66,2 & 65,0 \\
\hline Fossa rudim./vala & 23,9 & 20,0 & 22,7 & 22,1 & 25,6 & 18,9 & 24,0 & 19,0 & 20,6 & 31,8 & 12,8 & 30,1 & 22,2 & 26,1 & 29,3 \\
\hline Direto & 2,6 & 2,6 & 2,6 & 2,6 & 2,4 & 2,4 & 3,1 & 2,1 & 1,8 & 4,4 & 1,8 & 3,9 & 5,0 & 1,5 & 3,5 \\
\hline Outra & 4,0 & 2,2 & 3,5 & 2,7 & 3,5 & 2,0 & 3,7 & 2,3 & 1,9 & 8,0 & 0,8 & 5,5 & 4,1 & 6,2 & 2,2 \\
\hline \multicolumn{16}{|c|}{ Proximidade à área industrial } \\
\hline & 5,6 & 5,4 & 5,4 & 6,1 & 5,1 & 6,6 & 5,4 & 7,0 & 6,6 & 5,8 & 6,0 & 5,4 & 6,9 & 6,4 & 6,4 \\
\hline \multicolumn{16}{|c|}{ Proximidade a lixão ou depósito de lixo } \\
\hline & 3,6 & 2,6 & 3,1 & 3,3 & 3,0 & 3,6 & 3,6 & 3,7 & 4,0 & 3,6 & 2,8 & 3,4 & 1,1 & 3,1 & 2,5 \\
\hline \multicolumn{16}{|c|}{ Proximidade a esgoto a céu aberto ou valão } \\
\hline & 9,4 & 7,7 & 9,3 & 9,7 & 9,1 & 9,0 & 10,3 & 9,1 & 9,1 & 11,8 & 4,5 & 7,7 & 2,2 & 8,6 & 9,9 \\
\hline \multicolumn{16}{|c|}{ Aquisição de bebida alcoólica } \\
\hline & 9,5 & 9,9 & 10,9 & 10,9 & 10,5 & 13,3 & 10,0 & 12,2 & 14,1 & 7,8 & 12,7 & 9,5 & 15,1 & 11,8 & 10,4 \\
\hline \multicolumn{16}{|c|}{ Quantidade média de álcool adquirida, em mL } \\
\hline & 28,0 & 30,8 & 34,8 & 34,3 & 30,7 & 43,2 & 27,2 & 47,0 & 50,5 & 22,9 & 39,3 & 27,6 & 56,4 & 37,6 & 25,5 \\
\hline \multicolumn{16}{|c|}{ Aquisição de artigos de fumo } \\
\hline & 22,0 & 20,2 & 21,5 & 21,1 & 22,8 & 21,6 & 23,5 & 19,5 & 20,6 & 24,5 & 20,4 & 27,5 & 19,8 & 22,4 & 24,2 \\
\hline
\end{tabular}

$\mathrm{N}=$ Sistema nervoso; $\mathrm{C}=$ Sistema cardiovascular; $\mathrm{A}=$ Aparelho digestivo e metabolismo; $\mathrm{R}=$ Sistema respiratório; $\mathrm{M}=$ Sistema musculoesquelético; $\mathrm{G}=$ Aparelho geniturinário e hormônios sexuais; $\mathrm{J}=$ Anti-infecciosos de uso sistêmico; $\mathrm{S}=$ Órgãos sensoriais; $\mathrm{D}=\mathrm{Dermatológicos}$; $\mathrm{P}=\mathrm{Antiparasitários}$, inseticidas e repelentes; $\mathrm{H}=$ =Preparações hormonais sistêmicas, exceto hormônios sexuais e insulinas; $\mathrm{B}=$ Sangue e órgãos hematopoiéticos; $\mathrm{L}=$ Agentes antineoplásicos e imunomoduladores; $\mathrm{TA}=$ Tratamento alternativo; $\mathrm{MI}=$ medicamento não identificado. Direto: para rio, lago ou mar. 
Tabela 20: Características dos domicílios em que houve relato de obtenção de algum medicamento no período de referência de 30 dias, estratificadas de acordo com a classe de medicamento adquirido (segundo nível da classificação ATC), em percentual.

\begin{tabular}{|c|c|c|c|c|c|c|c|c|c|c|c|c|c|c|c|c|}
\hline Variável & N02 & N05 & N06 & $\mathrm{COO}^{*}$ & $\mathrm{C10}$ & A02 & A08 & $\mathbf{A 1 0}$ & A11 & R05 & R06 & M01 & G03 & J01 & S01 & P02 \\
\hline \multicolumn{17}{|c|}{ Ausência de água canalizada } \\
\hline & 7,2 & 3,0 & 2,9 & 4,2 & 1,7 & 4,8 & 0,4 & 3,2 & 9,8 & 6,3 & 3,5 & 7,7 & 3,7 & 6,6 & 3,7 & 15,7 \\
\hline \multicolumn{17}{|c|}{ Escoadouro sanitário } \\
\hline $\mathrm{RC} / \mathrm{FS}$ & 69,1 & 73,6 & 78,3 & 74,9 & 82,5 & 75,0 & 84,5 & 77,9 & 67,6 & 71,4 & 77,9 & 67,8 & 76,6 & 69,2 & 77,5 & 55,9 \\
\hline $\mathrm{FR} / \mathrm{V}$ & 24,3 & 21,5 & 16,7 & 20,3 & 14,2 & 20,4 & 12,1 & 18,6 & 25,0 & 22,6 & 18,8 & 26,1 & 18,7 & 23,9 & 18,8 & 31,6 \\
\hline $\mathrm{D}$ & 2,5 & 2,9 & 3,4 & 2,5 & 2,4 & 2,2 & 0,7 & 2,4 & 2,4 & 2,9 & 1,9 & 2,5 & 2,7 & 3,1 & 2,2 & 4,4 \\
\hline Outra & 4,1 & 1,9 & 1,6 & 2,3 & 0,9 & 2,4 & 2,8 & 1,2 & 5,0 & 3,1 & 1,4 & 3,7 & 2,0 & 3,7 & 1,5 & 8,0 \\
\hline \multicolumn{17}{|c|}{ Proximidade à área industrial } \\
\hline & 5,4 & 6,4 & 6,0 & 5,4 & 6,0 & 5,0 & 5,2 & 6,0 & 5,4 & 5,7 & 7,4 & 5,2 & 6,5 & 5,4 & 7,3 & 5,8 \\
\hline \multicolumn{17}{|c|}{ Proximidade a lixão ou depósito de lixo } \\
\hline & 3,5 & 2,8 & 3,8 & 2,5 & 2,2 & 2,6 & 1,0 & 3,6 & 3,3 & 3,6 & 3,2 & 2,9 & 3,6 & 3,6 & 2,7 & 3,6 \\
\hline \multicolumn{17}{|c|}{ Proximidade a esgoto a céu aberto ou valão } \\
\hline & 9,6 & 9,0 & 8,8 & 7,6 & 5,8 & 8,3 & 8,3 & 8,0 & 10,1 & 9,2 & 10,7 & 9,1 & 9,3 & 10,3 & 8,0 & 11,9 \\
\hline \multicolumn{17}{|c|}{ Aquisição de bebida alcoólica } \\
\hline & 9,5 & 7,6 & 10,0 & 9,6 & 11,6 & 12,5 & 17,0 & 9,4 & 10,6 & 10,6 & 12,3 & 10,4 & 14,0 & 9,8 & 13,9 & 7,7 \\
\hline \multicolumn{17}{|c|}{ Quantidade média de álcool adquirida } \\
\hline & 27,9 & 25,7 & 28,7 & 29,6 & 32,5 & 36,8 & 29,1 & 29,2 & 40,2 & 31,4 & 40,3 & 30,4 & 45,9 & 26,8 & 51,1 & 23,1 \\
\hline \multicolumn{17}{|c|}{ Aquisição de artigos de fumo } \\
\hline & 22,2 & 23,4 & 23,5 & 20,4 & 18,5 & 23,1 & 23,1 & 20,2 & 21,5 & 21,6 & 20,4 & 23,0 & 22,4 & 23,5 & 19,8 & 24,6 \\
\hline
\end{tabular}

*N02=Analgésicos; N05=Psicolépticos; N06=Psicoanalépticos; C00*=Para hipertensão ou anti-hipertensivo; C10=Agentes modificadores lipídicos; A02=Medicamentos para desordens ácidas relacionadas; A08=Preparações antiobesidade, exceto produtos dietéticos; A10=Medicamentos utilizados no diabetes; A11=Vitaminas; R05=Preparações para tosse e resfriado; R06=Anti-histamínicos de uso sistêmico; M01=Produtos anti-inflamatórios e antirreumáticos; G03=Hormônios sexuais e moduladores do sistema genital; J01=Antibacterianos de uso

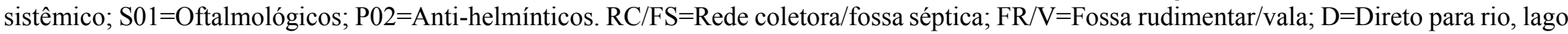
ou mar 


\subsection{Características da população residente}

As Tabelas 21 e 22 mostram algumas características da população residente em domicílios onde houve relato de aquisição de medicamentos. Observa-se, por exemplo, que percentual de idosos é maior nos domicílios em que houve relato de obtenção de medicamentos usados no diabetes (A10), medicamentos para hipertensão $\left(\mathrm{C} 00^{*}\right)$, agentes modificadores lipídicos (C10) e psicolépticos (N05). Tal observação pode ser explicada pelo fato de que as doenças cujo tratamento requer a utilização de tais medicamentos são mais prevalentes entre idosos e adultos de meia idade (CARUSO; SILLIMAN, 2008; KOTCHEN, 2008; POWERS, 2008)

Nos domicílios em que houve relato de obtenção de medicamentos utilizados no controle da obesidade (A08), há o maior percentual de pessoas que sabem ler e escrever, maior percentual de pessoas que possuem ensino superior (completo ou incompleto) e maior percentual de indivíduos que estão filiados a plano de saúde. Tais características ratificam a observação anterior de que o número de medicamentos dessa classe por 1000 habitantes é o maior entre indivíduos de classe Al e vai decrescendo na medida em que se caminha para classes econômicas menos privilegiadas.

Também é possível observar que, nos domicílios que relataram obtenção de medicamentos Antiparasitários, inseticidas e repelentes (P) e Anti-helmínticos (P02) ocorre o menor percentual de domicílios que possuem pelo menos um morador com acesso à saúde suplementar, em relação a moradores de domicílios em que houve relato de obtenção de outras classes de medicamentos (Tabelas 21 e 22). 
Tabela 21: Distribuição percentual da população residente em domicílios que relataram obtenção de algum medicamento no período de referência de 30 dias, estratificadas de acordo com a classe de medicamento adquirido (primeiro nível da classificação ATC).

\begin{tabular}{|c|c|c|c|c|c|c|c|c|c|c|c|c|c|c|c|}
\hline Variável & $\mathbf{N}$ & C & A & $\mathbf{R}$ & $\mathbf{M}$ & $\mathbf{G}$ & $\mathbf{J}$ & $\mathbf{S}$ & D & $\mathbf{P}$ & $\mathbf{H}$ & B & $\mathbf{L}$ & TA & MI \\
\hline Mulheres & 51,8 & 52,6 & 52,0 & 51,6 & 52,0 & 54,0 & 52,3 & 52,0 & 52,0 & 50,3 & 53,8 & 53,0 & 55,1 & 51,9 & 50,5 \\
\hline Homens & 48,2 & 47,4 & 48,0 & 48,4 & 48,0 & 46,0 & 47,7 & 48,0 & 48,0 & 49,7 & 46,2 & 47,0 & 44,9 & 48,1 & 49,5 \\
\hline \multicolumn{16}{|l|}{ Faixa etária } \\
\hline$<1$ & 1,3 & 0,6 & 1,7 & 1,7 & 1,1 & 1,6 & 1,8 & 1,5 & 2,4 & 1,4 & 0,8 & 2,4 & 0,1 & 1,5 & 2,7 \\
\hline $1-4$ & 5,7 & 2,9 & 5,6 & 7,5 & 5,1 & 7,5 & 7,7 & 5,3 & 5,7 & 10,1 & 3,0 & 6,2 & 1,7 & 5,2 & 7,4 \\
\hline $5-9$ & 8,6 & 4,7 & 7,2 & 9,5 & 7,2 & 8,1 & 9,7 & 6,8 & 7,2 & 12,8 & 4,6 & 7,7 & 2,3 & 7,7 & 8,3 \\
\hline $10-14$ & 9,3 & 6,5 & 7,9 & 9,1 & 8,9 & 7,3 & 9,6 & 8,4 & 8,8 & 10,9 & 6,0 & 7,5 & 4,9 & 8,8 & 8,6 \\
\hline $15-19$ & 9,4 & 7,6 & 8,7 & 8,8 & 8,7 & 8,2 & 9,0 & 8,5 & 9,2 & 8,7 & 7,2 & 8,3 & 7,3 & 9,1 & 8,7 \\
\hline $20-39$ & 31,6 & 23,6 & 30,6 & 33,4 & 29,3 & 40,5 & 33,1 & 30,3 & 32,7 & 33,1 & 26,4 & 30,3 & 20,5 & 29,9 & 31,4 \\
\hline $40-59$ & 23,2 & 28,7 & 23,1 & 21,1 & 24,0 & 19,8 & 20,9 & 23,8 & 23,7 & 17,1 & 33,2 & 20,0 & 28,9 & 24,8 & 22,3 \\
\hline $60-69$ & 6,0 & 13,2 & 8,0 & 4,8 & 8,4 & 4,4 & 4,7 & 8,1 & 5,4 & 3,4 & 9,6 & 6,7 & 14,9 & 6,8 & 5,4 \\
\hline$\geq 70$ & 4,9 & 12,3 & 7,2 & 4,1 & 7,4 & 2,7 & 3,6 & 7,2 & 4,8 & 2,4 & 9,1 & 11,0 & 19,4 & 6,1 & 5,2 \\
\hline \multicolumn{16}{|c|}{ Sabe ler e escrever (maiores de 15 anos) } \\
\hline & 89,7 & 87,5 & 89,1 & 92,1 & 88,3 & 95,1 & 91,5 & 92,2 & 93,1 & 87,1 & 95,2 & 86,7 & 91,4 & 88,7 & 89,2 \\
\hline \multicolumn{16}{|c|}{ Anos de estudo (maiores de 15 anos) } \\
\hline 0 & 8,5 & 11,3 & 9,1 & 6,6 & 10,0 & 4,1 & 7,1 & 6,9 & 5,9 & 9,7 & 5,5 & 10,8 & 10,8 & 9,2 & 8,9 \\
\hline $1-3$ & 11,7 & 14,0 & 12,1 & 10,0 & 13,3 & 8,0 & 10,6 & 10,2 & 8,6 & 14,2 & 8,6 & 15,0 & 15,2 & 12,0 & 11,2 \\
\hline $4-8$ & 35,0 & 33,3 & 32,6 & 34,2 & 33,9 & 31,6 & 34,7 & 31,0 & 30,5 & 37,7 & 32,6 & 39,1 & 28,9 & 30,0 & 33,1 \\
\hline $9-11$ & 30,8 & 25,4 & 29,7 & 33,3 & 29,0 & 36,6 & 32,2 & 30,0 & 32,4 & 28,5 & 29,2 & 25,4 & 28,1 & 28,7 & 32,5 \\
\hline $12-14$ & 5,3 & 5,9 & 5,7 & 5,7 & 5,1 & 7,0 & 5,8 & 7,7 & 7,8 & 4,1 & 9,4 & 4,1 & 5,8 & 6,7 & 5,9 \\
\hline 15 ou mais & 8,0 & 9,6 & 10,2 & 9,3 & 8,1 & 11,9 & 9,0 & 13,4 & 14,1 & 5,1 & 14,3 & 4,2 & 10,9 & 12,7 & 7,7 \\
\hline Ignorado & 0,7 & 0,5 & 0,6 & 0,7 & 0,7 & 0,7 & 0,6 & 0,7 & 0,7 & 0,8 & 0,4 & 1,4 & 0,2 & 0,7 & 0,8 \\
\hline \multicolumn{16}{|c|}{ Filiação a plano de saúde } \\
\hline & 35,4 & 44,3 & 40,3 & 38,8 & 37,8 & 44,1 & 38,3 & 48,9 & 48,5 & 28,1 & 57,7 & 37,2 & 46,6 & 42,8 & 40,9 \\
\hline \multicolumn{16}{|c|}{ Grávida ou lactante } \\
\hline & 11,3 & 6,2 & 14,2 & 13,2 & 10,3 & 10,7 & 14,4 & 11,4 & 13,8 & 14,8 & 6,5 & 22,7 & 0,4 & 12,8 & 17,1 \\
\hline
\end{tabular}

$\mathrm{N}=$ Sistema nervoso; $\mathrm{C}=$ Sistema cardiovascular; $\mathrm{A}=$ Aparelho digestivo e metabolismo; $\mathrm{R}=$ Sistema respiratório; $\mathrm{M}=$ Sistema musculoesquelético; $\mathrm{G}=$ Aparelho geniturinário e hormônios sexuais; $\mathrm{J}=$ Anti-infecciosos de uso sistêmico; $\mathrm{S}=$ Órgãos sensoriais; $\mathrm{D}=\mathrm{Dermatológicos;}$ $\mathrm{P}=$ Antiparasitários, inseticidas e repelentes; $\mathrm{H}=$ Preparações hormonais sistêmicas, exceto hormônios sexuais e insulinas; $\mathrm{B}=$ Sangue e órgãos hematopoiéticos; L=Agentes antineoplásicos e imunomoduladores; TA=Tratamento alternativo; MI=medicamento não identificado. 
Tabela 22: Distribuição percentual da população residente em domicílios em que houve relato de obtenção de algum medicamento no período de referência de 30 dias, estratificadas de acordo com a classe de medicamento adquirido (segundo nível da classificação ATC).

\begin{tabular}{|c|c|c|c|c|c|c|c|c|c|c|c|c|c|c|c|c|}
\hline Variável & N02 & N05 & N06 & $\mathrm{COO} *$ & $\mathrm{C10}$ & A02 & A08 & A10 & A11 & R05 & R06 & M01 & G03 & J01 & S01 & P02 \\
\hline Mulheres & 51,7 & 52,9 & 53,6 & 52,6 & 53,9 & 51,6 & 50,1 & 52,7 & 51,7 & 51,4 & 52,1 & 51,6 & 54,7 & 52,2 & 52,2 & 50,2 \\
\hline Homens & 48,3 & 47,1 & 46,4 & 47,4 & 46,1 & 48,4 & 49,9 & 47,3 & 48,3 & 48,6 & 47,9 & 48,4 & 45,3 & 47,8 & 47,8 & 49,8 \\
\hline \multicolumn{17}{|l|}{ Faixa etária } \\
\hline$<1$ & 1,4 & 0,8 & 0,6 & 0,6 & 0,6 & 1,3 & 0,0 & 0,6 & 2,3 & 1,9 & 1,5 & 1,1 & 1,8 & 1,8 & 1,0 & \\
\hline $1-4$ & 6,0 & 2,7 & 2,9 & 2,9 & 2,0 & 4,2 & 4,8 & 2,1 & 7,5 & 8,1 & 6,8 & 5,3 & 8,8 & 7,8 & 3,2 & 10,2 \\
\hline $5-9$ & 8,9 & 5,5 & 4,8 & 4,6 & 3,2 & 6,7 & 5,3 & 4,4 & 8,3 & 9,6 & 9,4 & 7,4 & 9,2 & 9,7 & 5,8 & 12,8 \\
\hline $10-14$ & 9,4 & 7,6 & 7,6 & 6,4 & 4,9 & 7,7 & 8,6 & 5,6 & 8,0 & 9,1 & 8,7 & 9,1 & 7,5 & 9,7 & 7,3 & 11 , \\
\hline $15-19$ & 9,5 & 9,0 & 8,4 & 7,6 & 5,7 & 9,2 & 10,8 & 7,2 & 8,2 & 8,6 & 8,8 & 8,8 & 8,2 & 8,9 & 8,4 & 8,6 \\
\hline $20-39$ & 32,4 & 23,7 & 26,2 & 23,5 & 22,2 & 30,8 & 32,9 & 22,2 & 32,6 & 33,8 & 33,4 & 29,8 & 44,3 & 33,2 & 28,2 & 33,1 \\
\hline $40-59$ & 22,7 & 27,7 & 30,5 & 28,9 & 30,0 & 25,6 & 32,8 & 27,9 & 20,0 & 20,1 & 23,2 & 23,9 & 16,5 & 20,8 & 25,5 & 17,1 \\
\hline $60-69$ & 5,5 & 10,5 & 9,8 & 13,2 & 17,4 & 8,0 & 3,5 & 15,8 & 6,5 & 4,7 & 4,3 & 7, & 2,6 & 4,7 & 10,4 & 3,4 \\
\hline$\geq 70$ & 4,2 & 12,6 & 9,1 & 12,3 & 14,0 & 6,3 & 1,2 & 14,4 & 6,6 & 3,9 & 4,0 & 6,9 & 1,2 & 3,5 & 10,1 & 2 , \\
\hline \multicolumn{17}{|c|}{ Sabe ler e escrever (maiores de 15 anos) } \\
\hline & 90,1 & 88,7 & 91,0 & 87,1 & 91,4 & 91,7 & 97,3 & 87,0 & 88,0 & 91,5 & 94,3 & 88,3 & 96,0 & 91,5 & 91,6 & 87,2 \\
\hline \multicolumn{17}{|c|}{ Anos de estudo (maiores de 15 anos) } \\
\hline 0 & 8,1 & 11,2 & 7,9 & 11,7 & 7,9 & 7,3 & 1,7 & 11,6 & 9,6 & 7,0 & 5,3 & 9,9 & 3,3 & 7,0 & 7,7 & 9 \\
\hline $1-3$ & 11,4 & 16,0 & 11,6 & 14,2 & 11,1 & 10,9 & 4,5 & 14,0 & 12,1 & 10,6 & 7,6 & 13,2 & 6,9 & 10,6 & 11,1 & 14, \\
\hline $4-8$ & 35,1 & 33,3 & 35,1 & 33,5 & 31,8 & 32,0 & 20,5 & 33,6 & 30,9 & 34,6 & 32,0 & 34,3 & 32,2 & 34,7 & 28,9 & 37, \\
\hline $5-9$ & 31,5 & 23,1 & 27,4 & 25,0 & 25,0 & 31,3 & 41,5 & 24,7 & 29,6 & 32,5 & 36,2 & 29,1 & 39,4 & 32,3 & 28,8 & 28 \\
\hline $12-14$ & 5,3 & 5,7 & 6,3 & 5,9 & 6,3 & 6,4 & 13,4 & 5,2 & 6,0 & 5,6 & 6,5 & 5,1 & 6,8 & 5,8 & 7,8 & 4 \\
\hline 15 ou $\mathrm{m}$ & 7,8 & 9,5 & 11,1 & 9,3 & 17,2 & 11,7 & 17,8 & 10,7 & 11,3 & 8,9 & 11,8 & 7,8 & 10,6 & 9,0 & 15,1 & 5 , \\
\hline Ignorado & 0,7 & 1,2 & 0,6 & 0,5 & 0,5 & 0,5 & 0,6 & 0,3 & 0,5 & 0,8 & 0,7 & 0,6 & 0,8 & 0,6 & 0,7 & 0 \\
\hline \multicolumn{17}{|c|}{ Filiação a plano de saúde } \\
\hline \multirow{2}{*}{ Grávida ou lactante } & 34,6 & 46,1 & 50,6 & 43,9 & 61,4 & 44,3 & 70,7 & 45,9 & 39,2 & 36,4 & 48,4 & 36,7 & 42,5 & 38,3 & 53,9 & 24,2 \\
\hline & 12,1 & 6,3 & 5,3 & 6,4 & 3,6 & 9,5 & 0,9 & 5,5 & 20,3 & 14,4 & 11,2 & 10,6 & 11,7 & 14,6 & 9,2 & $15,($ \\
\hline
\end{tabular}

N02=Analgésicos; N05=Psicolépticos; N06=Psicoanalépticos; $\mathrm{C} 00^{*}=$ Para hipertensão ou anti-hipertensivo; C10=Agentes modificadores lipídicos; A02=Medicamentos para desordens ácidas relacionadas; A08=Preparações antiobesidade, exceto produtos dietéticos; A10=Medicamentos utilizados no diabetes; A11=Vitaminas; R05=Preparações para tosse e resfriado; R06=Anti-histamínicos de uso sistêmico; M01=Produtos anti-inflamatórios e antirreumáticos; G03=Hormônios sexuais e moduladores do sistema genital; J01=Antibacterianos de uso sistêmico; S01=Oftalmológicos; P02=Antihelmínticos. 
Comparando-se o diagnóstico nutricional da população dos domicílios em que houve relato de obtenção de algum medicamento, de acordo com o primeiro nível da classificação ATC, nota-se que o diagnóstico nutricional dessas populações é semelhante para todas as faixas etárias avaliadas (Tabela 23). Porém, no segundo nível da classificação ATC (Tabela 24), destaca-se que para os indivíduos de 20 a 59 anos, o maior percentual de obesidade é encontrado na população residente em domicílios em que houve relato de aquisição de medicamentos contra a obesidade (A08).

Alguns estudos brasileiros apontam irracionalidades no uso de medicamentos antiobesidade (MARTINS et al., 2011; MOTA et al., 2014), sendo que, em 2011, a ANVISA, por meio da RDC 52 de 2011, determinou o cancelamento dos registros das substâncias anfepramona, femproporex e manzidol, além de fixar regras mais rígidas para o controle sanitário das vendas de sibutramina no Brasil (ANVISA, 2011d). Entretanto, em 2014, o Congresso Nacional decretou a cancelamento dessa RDC, e em setembro de 2014, a ANVISA publicou uma nova RDC sobre o tema (BRASIL, 2014e; ANVISA, 2014d).

Mota et al. (2014), a partir da análise de dados sobre aquisição de medicamentos antiobesidade obtidas do Sistema Nacional de Gerenciamento de Produtos controlados da ANVISA, e de dados sobre excesso de peso e obesidade obtidas do inquérito telefônico (Vigitel) do Ministério da Saúde, observaram um descompasso entre o consumo de inibidores de apetite e o percentual de pessoas com excesso de peso e obesidade: nos anos de 2009, 2010 e 2011, a maior quantidade desses medicamentos não foi vendida nas capitais onde havia maior percentual de adultos com sobrepeso ou obesidade, o que indicaria o uso irracional desses medicamentos. Adicionalmente, grande parte das pessoas que sofrem de sobrepeso ou obesidade podem não ter acesso a medicamentos antiobesidade. Martins et al. (2011) observaram maiores médias de Índice de Massa Corpórea (IMC) e de circunferência da cintura entre os estudantes universitários que referiram o uso de medicamentos antiobesidade. Porém, muitos dos estudantes em uso de medicamentos antiobesidade (44\%) eram eutróficos e apresentavam medida circunferência de cintura normal, não tendo, portanto, indicação para utilização desse tipo de medicamento. 
Tabela 23: Distribuição do diagnóstico Nutricional (DN) da população residente em que houve relato de obtenção de algum medicamento no período de referência de 30 dias, estratificadas de acordo com a classe de medicamento adquirido (segundo o primeiro nível da classificação ATC) e em percentual.

\begin{tabular}{|c|c|c|c|c|c|c|c|c|c|c|c|c|c|c|c|}
\hline Diagnóstico & $\mathbf{N}$ & $\mathrm{C}$ & $\mathbf{A}$ & $\mathbf{R}$ & $\mathbf{M}$ & $\mathbf{G}$ & $\mathbf{J}$ & $\mathbf{S}$ & D & $\mathbf{P}$ & $\mathbf{H}$ & B & $\mathbf{L}$ & TA & MI \\
\hline \multicolumn{16}{|c|}{ Crianças ( $<10$ anos) } \\
\hline MA & 1,5 & 1,3 & 1,6 & 1,8 & 1,6 & 1,5 & 1,5 & 1,0 & 1,2 & 1,2 & 0,5 & 0,7 & 0,0 & 1,6 & 2,6 \\
\hline $\mathrm{M}$ & 4,2 & 4,3 & 4,4 & 4,1 & 5,1 & 3,2 & 3,2 & 4,6 & 3,3 & 3,5 & 2,1 & 3,0 & 9,7 & 4,9 & 3,7 \\
\hline $\mathrm{E}$ & 60,3 & 61,4 & 60,4 & 59,8 & 61,6 & 59,7 & 63,4 & 58,0 & 62,5 & 65,4 & 64,2 & 63,0 & 49,5 & 67,0 & 63,6 \\
\hline $\mathrm{RS}$ & 7,2 & 6,5 & 8,1 & 8,0 & 7,4 & 9,3 & 7,3 & 8,7 & 8,0 & 8,3 & 8,0 & 10,0 & 0,0 & 6,3 & 9,8 \\
\hline $\mathrm{S}$ & 14,0 & 12,9 & 12,8 & 13,1 & 13,3 & 13,6 & 13,8 & 14,0 & 13,4 & 11,7 & 9,9 & 12,9 & 27,7 & 12,5 & 14,6 \\
\hline $\mathrm{O}$ & 11,0 & 10,9 & 10,6 & 11,2 & 9,1 & 10,5 & 9,3 & 11,5 & 9,1 & 9,3 & 13,5 & 10,3 & 13,1 & 7,1 & 5,1 \\
\hline $\mathrm{OG}$ & 1,8 & 2,8 & 2,1 & 1,9 & 1,9 & 2,2 & 1,5 & 2,2 & 2,5 & 0,6 & 1,7 & 0,1 & 0,0 & 0,5 & 0,6 \\
\hline \multicolumn{16}{|c|}{ Adolescentes $(\geq 10$ anos $\mathrm{e}<20$ anos $)$} \\
\hline MA & 0,4 & 0,4 & 0,4 & 0,3 & 0,6 & 0,2 & 0,4 & 0,2 & 0,1 & 0,3 & 0,0 & 0,5 & 0,0 & 0,4 & 0,1 \\
\hline $\mathrm{M}$ & 3,5 & 3,3 & 3,2 & 3,0 & 3,5 & 3,2 & 3,3 & 2,8 & 2,5 & 4,7 & 1,0 & 3,7 & 0,0 & 3,9 & 4,1 \\
\hline $\mathrm{E}$ & 76,7 & 75,0 & 75,6 & 76,2 & 76,8 & 76,5 & 78,6 & 76,9 & 76,6 & 78,3 & 68,1 & 72,5 & 78,3 & 79,0 & 78,2 \\
\hline $\mathrm{S}$ & 12,8 & 13,9 & 13,4 & 13,7 & 12,1 & 13,5 & 11,9 & 13,8 & 13,8 & 12,2 & 14,2 & 16,8 & 16,4 & 10,4 & 10,7 \\
\hline $\mathrm{O}$ & 5,5 & 6,4 & 5,7 & 5,8 & 6,2 & 6,0 & 4,8 & 5,6 & 6,0 & 3,9 & 15,9 & 2,6 & 5,3 & 5,3 & 5,6 \\
\hline $\mathrm{OG}$ & 0,3 & 0,4 & 0,3 & 0,4 & 0,2 & 0,3 & 0,6 & 0,2 & 0,3 & 0,1 & 0,0 & 0,0 & 0,0 & 0,4 & 0,5 \\
\hline Ignorado & 0,8 & 0,6 & 1,3 & 0,6 & 0,5 & 0,3 & 0,4 & 0,5 & 0,7 & 0,5 & 0,7 & 3,9 & 0,0 & 0,8 & 0,9 \\
\hline \multicolumn{16}{|c|}{ Adultos jovens ( $\geq 20$ anos $\mathrm{e}<40$ anos) } \\
\hline $\mathrm{BP}$ & 3,3 & 3,2 & 3,3 & 3,5 & 3,4 & 3,2 & 2,8 & 3,5 & 2,5 & 3,9 & 2,1 & 3,9 & 2,0 & 4,3 & 2,4 \\
\hline $\mathrm{E}$ & 55,2 & 56,7 & 53,7 & 54,1 & 55,1 & 55,4 & 54,2 & 53,7 & 55,2 & 57,8 & 59,7 & 53,4 & 58,1 & 56,7 & 58,1 \\
\hline $\mathrm{S}$ & 29,1 & 27,0 & 28,4 & 29,9 & 29,1 & 30,2 & 30,1 & 30,6 & 30,0 & 27,2 & 26,5 & 25,6 & 33,6 & 27,1 & 29,5 \\
\hline $\mathrm{O}$ & 10,4 & 11,9 & 10,9 & 10,5 & 10,8 & 10,2 & 10,9 & 10,8 & 10,4 & 9,1 & 10,9 & 10,1 & 6,3 & 10,8 & 9,2 \\
\hline I & 2,0 & 1,2 & 3,7 & 1,9 & 1,6 & 0,9 & 2,1 & 1,4 & 1,9 & 2,0 & 0,9 & 7,0 & 0,0 & 1,1 & 0,8 \\
\hline
\end{tabular}




\begin{tabular}{|c|c|c|c|c|c|c|c|c|c|c|c|c|c|c|c|}
\hline Diagnóstico & $\mathbf{N}$ & $\mathbf{C}$ & $\mathbf{A}$ & $\mathbf{R}$ & $\mathbf{M}$ & $\mathbf{G}$ & $\mathbf{J}$ & $\mathbf{S}$ & $\mathbf{D}$ & $\mathbf{P}$ & $\mathbf{H}$ & B & $\mathbf{L}$ & TA & MI \\
\hline \multicolumn{16}{|c|}{ Adultos $(\geq 40$ anos $\mathrm{e}<60$ anos $)$} \\
\hline $\mathrm{BP}$ & 1,6 & 1,1 & 1,6 & 1,5 & 1,3 & 1,2 & 1,8 & 1,4 & 1,2 & 2,0 & 0,9 & 3,5 & 0,2 & 1,3 & 2,9 \\
\hline $\mathrm{E}$ & 40,5 & 34,0 & 39,4 & 40,2 & 38,9 & 39,3 & 39,2 & 39,0 & 42,1 & 45,2 & 38,5 & 40,4 & 37,6 & 43,8 & 34,2 \\
\hline $\mathrm{S}$ & 38,9 & 40,2 & 38,2 & 39,1 & 38,5 & 40,3 & 39,9 & 40,4 & 38,5 & 39,3 & 34,0 & 41,0 & 33,9 & 36,9 & 45,3 \\
\hline $\mathrm{O}$ & 18,9 & 24,5 & 20,5 & 19,1 & 21,2 & 19,3 & 18,9 & 19,1 & 18,1 & 13,4 & 26,1 & 14,9 & 28,3 & 17,9 & 17,5 \\
\hline Ignorado & 0,1 & 0,1 & 0,3 & 0,1 & 0,1 & 0,0 & 0,2 & 0,1 & 0,0 & 0,1 & 0,4 & 0,3 & 0,0 & 0,0 & 0,1 \\
\hline \multicolumn{16}{|c|}{ Idosos $(\geq 60$ anos $)$} \\
\hline $\mathrm{BP}$ & 18,3 & 16,4 & 17,9 & 21,5 & 18,1 & 16,1 & 17,0 & 18,6 & 20,5 & 19,7 & 18,8 & 17,5 & 20,7 & 16,5 & 15,3 \\
\hline $\mathrm{E}$ & 43,6 & 41,9 & 43,4 & 43,4 & 42,5 & 45,7 & 46,3 & 46,0 & 40,7 & 44,1 & 41,7 & 40,4 & 29,8 & 44,1 & 42,8 \\
\hline S & 38,0 & 41,7 & 38,7 & 35,1 & 39,4 & 38,2 & 36,7 & 35,5 & 38,8 & 36,2 & 39,5 & 42,1 & 49,5 & 39,5 & 41,8 \\
\hline
\end{tabular}

$\mathrm{N}=$ Sistema nervoso; $\mathrm{C}=$ Sistema cardiovascular; $\mathrm{A}=$ Aparelho digestivo e metabolismo; $\mathrm{R}=$ Sistema respiratório; $\mathrm{M}=$ Sistema musculoesquelético; $\mathrm{G}=$ Aparelho geniturinário e hormônios sexuais; $\mathrm{J}=$ Anti-infecciosos de uso sistêmico; $\mathrm{S}=$ Órgãos sensoriais; $\mathrm{D}=\mathrm{Dermatológicos;}$ $\mathrm{P}=$ Antiparasitários, inseticidas e repelentes; $\mathrm{H}=$ Preparações hormonais sistêmicas, exceto hormônios sexuais e insulinas; $\mathrm{B}=$ Sangue e órgãos hematopoiéticos; L=Agentes antineoplásicos e imunomoduladores; $\mathrm{TA}=$ Tratamento alternativo; MI=medicamento não identificado. MA=Magreza acentuada; M=Magreza; BP=Baixo Peso; E=Eutrofia; RS=Risco de sobrepeso; $\mathrm{S}=$ Sobrepeso; O=Obesidade; OG=Obesidade grave. 
Tabela 24: Distribuição do diagnóstico nutricional da população residente em domicílios em que houve relato de obtenção de algum medicamento no período de referência de 30 dias, estratificadas de acordo com a classe de medicamento adquirido (segundo nível da classificação ATC), em percentual.

\begin{tabular}{|c|c|c|c|c|c|c|c|c|c|c|c|c|c|c|c|c|}
\hline Diagnóstico & N02 & N05 & N06 & C00* & $\mathbf{C 1 0}$ & A02 & A08 & A10 & A11 & R05 & R06 & M01 & G03 & J01 & S01 & P02 \\
\hline \multicolumn{17}{|c|}{ Crianças (<10 anos) } \\
\hline MA & 1,5 & 1,9 & 0,5 & 1,4 & 1,0 & 2,1 & 0,6 & 0,5 & 1,7 & 1,8 & 2,1 & 1,6 & 1,6 & 1,5 & 1,0 & 1,1 \\
\hline $\mathrm{M}$ & 4,2 & 3,5 & 2,8 & 4,2 & 5,9 & 3,3 & 1,9 & 4,8 & 4,8 & 4,4 & 3,2 & 5,2 & 3,2 & 3,2 & 4,0 & 3,6 \\
\hline $\mathrm{E}$ & 60,2 & 58,0 & 56,2 & 60,9 & 62,9 & 58,8 & 54,0 & 52,1 & 60,9 & 59,9 & 58,4 & 61,3 & 59,0 & 63,3 & 60,9 & 64,9 \\
\hline $\mathrm{RS}$ & 7,3 & 4,5 & 8,3 & 6,7 & 5,7 & 7,9 & 5,1 & 8,0 & 9,0 & 8,5 & 7,4 & 7,4 & 9,4 & 7,3 & 7,5 & 8,4 \\
\hline $\mathrm{S}$ & 14,1 & 17,0 & 14,7 & 12,9 & 10,4 & 12,6 & 19,0 & 15,5 & 13,0 & 12,6 & 14,0 & 13,4 & 14,0 & 13,8 & 12,6 & 12,0 \\
\hline $\mathrm{O}$ & 11,0 & 11,7 & 15,5 & 11,1 & 10,5 & 12,0 & 19,4 & 13,8 & 9,2 & 11,0 & 13,1 & 9,1 & 10,4 & 9,3 & 10,5 & 9,5 \\
\hline OG & 1,7 & 3,4 & 2,0 & 2,7 & 3,6 & 3,3 & 0,0 & 5,3 & 1,3 & 1,8 & 1,8 & 2,0 & 2,3 & 1,5 & 3,4 & 0,6 \\
\hline \multicolumn{17}{|c|}{ Adolescentes ( $\geq 10$ anos $\mathrm{e}<20$ anos) } \\
\hline MA & 0,5 & 0,2 & 0,3 & 0,4 & 0,4 & 0,4 & 4,1 & 0,3 & 0,4 & 0,4 & 0,1 & 0,6 & 0,2 & 0,4 & 0,0 & 0,3 \\
\hline $\mathrm{M}$ & 3,5 & 3,8 & 3,2 & 3,1 & 3,3 & 3,1 & 8,8 & 3,0 & 3,7 & 3,2 & 2,6 & 3,5 & 3,2 & 3,3 & 3,0 & 4,7 \\
\hline $\mathrm{E}$ & 76,6 & 78,5 & 75,4 & 75,2 & 71,8 & 76,0 & 61,3 & 68,7 & 76,6 & 75,9 & 75,7 & 77,0 & 76,3 & 78,6 & 76,6 & 78,3 \\
\hline S & 12,8 & 11,7 & 14,5 & 13,4 & 17,3 & 13,5 & 19,8 & 18,4 & 11,5 & 14,2 & 13,4 & 12,1 & 13,3 & 11,9 & 14,1 & 12,3 \\
\hline \multicolumn{17}{|c|}{ Adolescentes $(\geq 10$ anos $\mathrm{e}<20$ anos) continuação } \\
\hline $\mathrm{O}$ & 5,5 & 4,6 & 5,7 & 6,8 & 5,8 & 5,7 & 5,4 & 8,8 & 5,7 & 5,4 & 7,2 & 6,1 & 6,3 & 4,8 & 5,6 & 3,9 \\
\hline OG & 0,3 & 1,3 & 0,4 & 0,5 & 1,3 & 0,4 & 0,7 & 0,4 & 0,1 & 0,3 & 0,5 & 0,2 & 0,4 & 0,6 & 0,3 & 0,1 \\
\hline Ignorado & 0,9 & & 0,4 & 0,6 & 0,1 & 0,9 & 0,0 & 0,3 & 2,0 & 0,7 & 0,5 & 0,5 & 0,3 & 0,4 & 0,4 & 0,4 \\
\hline \multicolumn{17}{|c|}{ Adulto jovem ( $\geq 20$ anos e $<40$ anos) } \\
\hline BP & 3,3 & 3,2 & 2,9 & 3,0 & 4,0 & 3,5 & 1,0 & 2,6 & 3,6 & 3,5 & 4,0 & 3,5 & 3,1 & 2,8 & 3,4 & 3,9 \\
\hline $\mathrm{E}$ & 55,2 & 55,7 & 54,3 & 57,0 & 54,9 & 53,4 & 29,8 & 52,7 & 54,9 & 54,2 & 52,9 & 54,8 & 55,9 & 54,1 & 55,8 & 57,5 \\
\hline $\mathrm{S}$ & 29,1 & 28,8 & 30,0 & 26,7 & 29,5 & 30,3 & 31,9 & 29,4 & 26,3 & 30,1 & 30,2 & 29,3 & 30,4 & 30,2 & 28,0 & 27,5 \\
\hline $\mathrm{O}$ & 10,3 & 11,0 & 11,7 & 12,1 & 11,3 & 11,1 & 37,2 & 14,4 & 8,9 & 10,4 & 11,3 & 10,9 & 10,0 & 10,8 & 11,7 & 9,1 \\
\hline Ignorado & 2,0 & 1,2 & 1,0 & 1,2 & 0,3 & 1,7 & & 1,0 & 6,2 & 1,9 & 1,6 & 1,5 & 0,6 & 2,1 & 1,1 & 2,0 \\
\hline
\end{tabular}




\begin{tabular}{ccccccccccccccccc}
\hline Diagnóstico & $\mathbf{N 0 2}$ & $\mathbf{N 0 5}$ & $\mathbf{N 0 6}$ & $\mathbf{C 0 0}$ & $\mathbf{C 1 0}$ & $\mathbf{A 0 2}$ & $\mathbf{A 0 8}$ & $\mathbf{A 1 0}$ & $\mathbf{A 1 1}$ & $\mathbf{R 0 5}$ & $\mathbf{R 0 6}$ & M01 & G03 & J01 & S01 & P02 \\
\hline Adulto ( $\geq \mathbf{4 0}$ anos & $\mathbf{2}<\mathbf{6 0}$ anos) & & & & & & & & & & & & & \\
BP & 1,6 & 2,2 & 1,3 & 1,1 & 0,6 & 1,0 & & 1,1 & 2,4 & 1,5 & 1,2 & 1,4 & 1,3 & 1,7 & 1,4 & 2,0 \\
E & 40,4 & 40,0 & 37,6 & 33,7 & 30,9 & 38,2 & 30,6 & 29,0 & 43,3 & 40,4 & 40,5 & 38,6 & 38,3 & 39,1 & 38,0 & 45,1 \\
S & 39,2 & 38,8 & 40,1 & 40,0 & 43,3 & 38,4 & 35,2 & 40,2 & 37,4 & 38,3 & 40,3 & 38,6 & 40,2 & 39,9 & 41,0 & 39,6 \\
O & 18,7 & 19,1 & 20,9 & 25,0 & 25,2 & 22,1 & 34,0 & 29,7 & 16,4 & 19,6 & 17,9 & 21,3 & 20,2 & 19,1 & 19,7 & 13,2 \\
Ignorado & 0,1 & & 0,1 & 0,2 & & 0,2 & 0,3 & & 0,6 & 0,1 & 0,2 & 0,1 & & 0,2 & & 0,1 \\
Idoso ( $\geq \mathbf{6 0}$ anos) & & & & & & & & & & & & & & & \\
BP & 18,3 & 18,5 & 18,4 & 16,0 & 14,4 & 16,9 & 13,4 & 13,2 & 23,6 & 21,7 & 19,4 & 17,9 & 17,5 & 17,1 & 18,4 & 18,8 \\
E & 43,6 & 41,4 & 45,2 & 41,0 & 45,2 & 42,3 & 53,6 & 40,0 & 44,6 & 43,6 & 45,1 & 42,2 & 41,9 & 46,3 & 44,6 & 44,9 \\
S & 38,1 & 40,1 & 36,4 & 42,9 & 40,5 & 40,9 & 33,1 & 46,9 & 31,8 & 34,7 & 35,5 & 39,9 & 40,6 & 36,5 & 36,9 & 36,2 \\
\hline
\end{tabular}

N02=Analgésicos; N05=Psicolépticos; N06=Psicoanalépticos; C00*=Para hipertensão ou anti-hipertensivo; C10=Agentes modificadores lipídicos; A02=Medicamentos para desordens ácidas relacionadas; A08=Preparações antiobesidade, exceto produtos dietéticos; A10=Medicamentos utilizados no diabetes; A11=Vitaminas; R05=Preparações para tosse e resfriado; R06=Anti-histamínicos de uso sistêmico; M01=Produtos antiinflamatórios e antirreumáticos; G03=Hormônios sexuais e moduladores do sistema genital; J01=Antibacterianos de uso sistêmico; S01=Oftalmológicos; P02=Anti-helmínticos. MA=Magreza acentuada; M=Magreza; BP=Baixo Peso; E=Eutrofia; RS=Risco de sobrepeso; $\mathrm{S}=$ Sobrepeso; $\mathrm{O}=$ Obesidade; $\mathrm{OG}=$ Obesidade grave. 


\section{CONCLUSÃO}

O presente estudo fornece informações importantes para descrever a distribuição regional e socioeconômica da aquisição de medicamentos pela população brasileira. Esta é uma prática comum na população brasileira, com mais de $80 \%$ dos domicílios relatando ter obtido algum medicamento no período recordatório de 30 dias. De maneira geral, as características dos domicílios que relataram aquisição desses insumos refletem as características de toda a população da Pesquisa, e da população brasileira, mostrando um perfil socioeconômico menos privilegiado em domicílios das regiões Norte e Nordeste e áreas rurais em relação aos domicílios das regiões Sudeste e Sul e áreas urbanas.

Observa-se que o percentual de domicílios que adquiriram medicamentos é menor nas classes econômicas menos privilegiadas e o mesmo ocorre em relação ao número de medicamentos por habitante. Entre as classes A1 e A2 parece não haver relação entre renda e aquisição de medicamentos.

A maior parte dos medicamentos adquiridos foi de marca (referência ou similar), obtida por meio de recursos próprios e em farmácias ou drogarias. Quanto menos privilegiada a posição econômica do domicílio, maior a proporção de medicamentos obtidos por doação.

O Sistema Único de Saúde tem um papel importante no fornecimento de medicamentos no Brasil, sendo o principal provedor dos medicamentos obtidos por doação nos domicílios. Entretanto, nas regiões Norte e Nordeste mais de 10\% dos medicamentos doados foram fornecidos por terceiros. A falta de acesso a medicamentos devido a questões financeiras foi indicada por mais de um quinto dos domicílios brasileiros, sendo maior nas regiões Norte e Nordeste e em áreas rurais. Esses resultados indicam a necessidade de ações específicas para a melhoria da assistência farmacêutica do SUS nessas regiões.

No geral, nas regiões em que houve maior aquisição de medicamentos, houve maior registro de intoxicações medicamentosas reportadas ao SINAN e ao SINITOX. Os medicamentos mais adquiridos foram os pertencentes às classes ATC sistema nervoso, sistema cardiovascular e aparelho digestivo e metabolismo, similar ao reportado por outros estudos conduzidos no Brasil. Para a maioria das classes de medicamentos, o número de medicamentos é menor nos domicílios com situação econômica menos privilegiada. Por outro lado, esses domicílios adquirem mais medicamentos antiparasitários, inseticidas, repelentes e anti- 
helmínticos, provavelmente devido à ausência de água canalizada e à proximidade a esgoto a céu aberto ou valão, que são comuns nas regiões onde estes domicílios se encontram.

Em geral, o percentual de adultos obesos é maior nos domicílios que mais adquiriram medicamentos antiobesidade, e o percentual de idosos é maior em domicílios que relataram obtenção de medicamentos para diabetes, hipertensão e dislipidemias. Entre os domicílios que adquiriram medicamentos antineoplásicos está o menor percentual de domicílios que adquiriram artigos de fumo, mas também o maior percentual de domicílios que adquiriram bebidas alcóolicas e o maior volume de álcool adquirido. Este resultado pode indicar que diante de um diagnóstico de câncer, os indivíduos e seus familiares parem de fumar, já que o nexo causal entre fumo e câncer já está bem estabelecido.

Algumas limitações deste estudo devem ser ressaltadas. Utilizou-se uma base de dados secundária, na qual os medicamentos obtidos pelos domicílios foram descritos de acordo com a finalidade da utilização (por exemplo, para dor e febre, para problemas cardíacos e circulatórios). Dessa forma, a classificação ATC baseada somente nesta informação, sem o nome do medicamento, pode não refletir o que realmente foi adquirido pelo domicílio. Outra limitação se deve ao fato de não ser possível determinar para qual morador ou para quais moradores do domicílio o medicamento adquirido foi destinado (ou se os medicamentos destinaram-se a não residentes), o que impossibilita a relação entre a aquisição de medicamentos e o perfil individual. Também não é possível determinar se os medicamentos adquiridos foram utilizados. Além disso, os dados da POF não permitem determinar a quantidade de medicamento adquirida. Por fim, as informações sobre medicamentos da POF são obtidas pelos próprios respondentes da POF, que podem incorrer em erros, decorrentes principalmente de desvio de memória, o que pode ter sido agravado pela a utilização de um período recordatório de 30 dias.

Apesar das limitações, os resultados do presente estudo demonstram a magnitude potencial de informações que podem ser produzidas pela POF. Tais informações podem ser utilizadas em diferentes níveis decisórios do Sistema Único de Saúde, objetivando a utilização racional de medicamentos, bem como a melhoria do acesso a esses insumos no país. Acreditase que os resultados apresentados neste estudo também podem contribuir para o aprimoramento do questionário referente à aquisição de produtos farmacêuticos da POF. Seria importante, por exemplo, agregar no questionário a informação do nome do medicamento e da quantidade adquirida. 


\section{REFERÊNCIAS BIBLIOGRÁFICAS}

AGÊNCIA NACIONAL DE VIGILÂNCIA SANITÁRIA - ANVISA. Instrução Normativa n. 7, de 16 de dezembro de 2011. Dispõe sobre cronograma e procedimentos para credenciamento de farmácias e drogarias privadas referentes à escrituração dos medicamentos e substâncias contendo antimicrobianos no Sistema Nacional de Gerenciamento de Produtos Controlados (SNGPC). Diário Oficial da União, $n^{0}$. 242, Seção 1, p. 704, 2011c.

AGÊNCIA NACIONAL DE VIGILÂNCIA SANITÁRIA - ANVISA. Mercado de Genéricos no Brasil. Evolução dos medicamentos genéricos - 2000 a 2007 (mês a mês). Disponível em

$<$ http://portal.anvisa.gov.br/wps/portal/anvisa/anvisa/posuso/regulacaodemercado/!ut/p/c4/ 04_SB8K8xLLM9MSSzPy8xBz9CP0os3hnd0cPE3MfAwN_Dz8DA09_c19vrwAXA4M

AM_2CbEdFAGk6puA!/?1dmy\&urile=wcm\%3Apath\%3A/anvisa+portal/anvisa/pos++ comercializacao +-+ pos +-

+ uso/regulacao + de + marcado/publicacao + regulacao + economica/mercado + de + genericos $+n$ o+brasil >. Acesso em: 19 ago. 2014c.

AGÊNCIA NACIONAL DE VIGILÂNCIA SANITÁRIA - ANVISA. Resolução-RDC n. 20, de 5 de maio de 2011. Dispõe sobre o controle de medicamentos à base de substâncias classificadas como antimicrobianos, de uso sob prescrição, isoladas ou em associação. Diário Oficial da União, $\mathrm{n}^{0}$. 87, Seção 1, p. 39-41, 2011 b.

AGÊNCIA NACIONAL DE VIGILÂNCIA SANITÁRIA - ANVISA. Resolução-RDC n. 44, de 26 de outubro de 2010. Dispõe sobre o controle de medicamentos à base de substâncias classificadas como antimicrobianos, de uso sob prescrição médica, isoladas ou em associação e dá outras providências. Diário Oficial da União, n. 207, Seção 1, p. 76-77, 2010a.

AGÊNCIA NACIONAL DE VIGILÂNCIA SANITÁRIA - ANVISA. Resolução-RDC n. 61, de 17 de dezembro de 2010. Altera o anexo da RDC n ${ }^{\circ} 44$, de 26 de outubro de 2010, que dispõe sobre o controle de medicamentos à base de substâncias classificadas como antimicrobianos, de uso sob prescrição médica, isoladas ou em associação, e dá outras providências. Diário Oficial da União, n. 244, Seção 1, p. 94, 2010 b.

AGÊNCIA NACIONAL DE VIGILÂNCIA SANITÁRIA - ANVISA. Resolução-RDC n. 17, de 15 de abril de 2011. Altera a RDC $n^{0} .44$ de 26 de outubro de 2010, que dispõe sobre o controle de medicamentos à base de substâncias classificadas como antimicrobianos, de uso sob prescrição médica, isoladas ou em associação e dá outras providências. Diário Oficial da União, n. 74, Seção 1, p. 65, 2011 a.

AGÊNCIA NACIONAL DE VIGILÂNCIA SANITÁRIA - ANVISA. Resolução-RDC n. 52, de 6 de outubro de 2011. Dispõe sobre a proibição do uso das substâncias anfepramona, femproporex e mazindol, seus sais e isômeros, bem como intermediários e medidas de controle da prescrição e dispensação de medicamentos que contenham a substância sibutramina, seus sais e isômeros, bem como intermediários e dá outras providências. Diário Oficial da União, n. 56, Seção 1, p. 55-56, $2011 \mathrm{~d}$.

AGÊNCIA NACIONAL DE VIGILÂNCIA SANITÁRIA - ANVISA. Resolução-RDC n. 50, de 25 de setembro de 2014. Dispõe sobre as medidas de controle de comercialização, prescrição e dispensação de medicamentos que contenham as substâncias anfepramona, femproporex, mazindol e sibutramina, seus sais e isômeros, bem como intermediários e dá outras providências. Diário Oficial da União, n. 186, Seção 1, p. 66-67, 2014d. 
AGÊNCIA NACIONAL DE VIGILÂNCIA SANITÁRIA - ANVISA. Sistema Nacional de Notificações para a Vigilância Sanitária - NOTIVISA. Apresentação. Disponível em: $<$ http://www.anvisa.gov.br/hotsite/notivisa/apresenta.htm>. Acesso em: 30 jun. 2014a.

AGÊNCIA NACIONAL DE VIGILÂNCIA SANITÁRIA - ANVISA. Sistema nacional de notificações para a Vigilância Sanitária - NOTIVISA. Quantitativo de notificações de 2006 a 2013.2 Disponível em: $<$ http://www.anvisa.gov.br/hotsite/notivisa/relatorios/index.htm $>$ Acesso em: 30 jun. 2014 b.

ALANIS, A. J. Resistance to antibiotics: Are we in the post-antibiotic era? Archives of Medical Research, v. 36, n. 6, p. 697-705, 2005.

ALMEIDA, M. R.; CASTRO, L. L. C.; CALDAS, E. D. Conhecimentos, práticas e percepção de risco do uso de medicamentos no Distrito Federal. Revista de Ciências Farmacêuticas Básica e Aplicada, v. 32, n. 1, p. 225-232, 2011.

ANDRADE, E. C.; LEITE, I. C. G. ; VIEIRA, M. T. ; ABRAMO, C. TIBIRIÇA, S. H. C.; SILVA, P. L. Prevalence of Parasitic Intestinal Diseases in a Quilombola Community, in the Municipality of Bias Fortes, State of Minas Gerais, Brazil, 2008. Epidemiologia e Serviços de Saúde, v. 20, n. 3, p. 337-344, 2011.

ARRAIS, P. S. D.; LUTESCIA, H. L.; BATISTA, M. C. D. S.; CARVALHO, M. L.; RIGHI, R. E.; ARNAU, J. M. Perfil da automedicação no Brasil. Revista de Saúde Pública, v. 31, n. 1, p. 71-77, 1997.

ASSOCIAÇÃO BRASILEIRA DE EMPRESAS DE PESQUISA - ABEP. Critério de Classificação Econômica Brasil, 2008. Disponível em: $<$ http://www.abep.org/new/criterioBrasil.aspx>. Acesso em: 26 abril 2014.

ASSOCIAÇÃO BRASILEIRA DE EMPRESAS DE PESQUISA - ABEP. Critério de Classificação Econômica $\quad$ Brasil, $2009 . \quad$ Disponível em: $<$ http://www.abep.org/new/criterioBrasil.aspx>. Acesso em: 26 abril 2014.

AUREA, A. P. ; MAGAlHAES, L. C. G.; GARCIA, L. P. ; SANTOS, C. F. ; ALMEIDA, R. F. Programas de assistência farmacêutica do governo federal: estrutura atual, evolução dos gastos com medicamentos e primeiras evidências de sua eficiência, 2005-2008. Brasília: Ipea, 2011. Texto para Discussão.

BERTOLDI, A. D.; BARROS, A. J. D.; HALLAL, P. C. Generic drugs in Brazil: known by many, used by few. Cadernos de Saúde Pública, v. 21, n. 6, p. 1808-1815, 2005.

BERTOLDI, A. D.; BARROS, A. J. D.; WAGNER, A.; ROSS-DEGNAN, D.; HALLAL, P. C. Medicine access and utilization in a population covered by primary health care in Brazil. Health Policy, v. 89, n. 3. p. 295-302, 2009.

Bertoldi, A. D.; CAMARGO, A. L.; SIlveIRA, M. P. T.; MENEZES, A. M. B.; ASSUNÇAO, M. C. F.; GONÇALVES, H.; HALLAL, P. C. Self-Medication among Adolescents Aged 18 Years: The 1993 Pelotas (Brazil) Birth Cohort Study. Journal of Adolescent Health, v. 55, p. 175-181, 2014.

BERTOLDI, A. D.; SILVEIRA, M. P. T.; MENEZES, A. M. B.; ASSUNÇAO, M. C. F.; GONÇALVES, H. HALLAL, P. C. Tracking of Medicine Use and Self-Medication From Infancy to Adolescence: 1993 Pelotas (Brazil) Birth Cohort Study. Journal of Adolescent Health, v. 51, p. S11-S15, 2012.

BLATT, C. R.; TRAUTHMAN, S. C.; SCHMIDT, E. H.; MARCHESAN, S.; SILVA, L. M.; MARTINS, J. L. General awareness and use of generic medication among citizens of 
Tubarão, state of Santa Catarina, Brazil. Ciência \& Saúde Coletiva, v. 17, n.1, p. 79-87, 2012.

BOING, A. C.; BERTOLDI, A. D.; BOING, A. F.; BASTOS, J. L.; PERES, K. G. Access to medicines in the public sector: analysis of users of the Brazilian Unified National Health System. Cadernos de Saúde Pública, v. 29, n. 4 p. 691-701, 2013.

BOING, A. C.; BERTOLDI, A. D.; PERES, K. G. Socioeconomic inequalities in expenditures and income committed to the purchase of medicines in Southern Brazil. Revista de Saúde Pública, v. 45, n. 5, p. 897-905, 2011.

BORTOLETTO, M. E.; BOCHNER, R. Drug impact on human poisoning in Brazil. Cadernos de Saúde Pública, v. 15, n. 4, p. 859-869, 1999.

BRADLEY, M. C.; MOTTERLINI, N.; PADMANABHAN, S.; CAHIR, C.; WILLIAMS, T.; FAHEY, T.; HUGHES, C. M. Potentially inappropriate prescribing among older people in the United Kingdom. Geriatrics, v. 14, n. 72, p. 2-9, 2014.

BRASIL. Conselho Nacional de Secretários de Saúde. Assistência Farmacêutica no SUS. 1. ed. Brasília: CONASS, 2011. 172 p. Coleção Para Entender a Gestão do SUS, 2011a.

BRASIL. Constituição da República Federativa do Brasil: Texto constitucional promulgado em 5 de outubro de 1988, com as alterações adotadas pelas Emendas Constitucionais n. 1/92 a 64/2010 e pelas Emendas Constitucionais de Revisão n. 1 a 6/94. Brasília: Senado Federal, Subsecretaria de Edições Técnicas, 2010a.

BRASIL. Decreto Legislativo n. 273 de 2014. Susta a Resolução - RDC n ${ }^{\circ}$ 52, de 6 de outubro de 2011, da Agência Nacional de Vigilância Sanitária - ANVISA, que dispõe sobre a proibição do uso das substâncias anfepramona, femproporex e mazindol, seus sais e isômeros, bem como intermediários e medidas de controle da prescrição e dispensação de medicamentos que contenham a substância sibutramina, seus sais e isômeros, bem como intermediários. Diário Oficial da União, n. 171, Seção 1, p. 1, 2014e.

BRASIL. Decreto n. 6.871, de 4 de junho de 2009. Regulamenta a Lei n. 8918, de 14 de julho de 1994, que dispões sobre a padronização, a classificação, o registro, a inspeção, a produção e a fiscalização de bebidas. Diário Oficial da União, n. 106, Seção 1, p. 20-29, 2009.

BRASIL. Decreto n. 99.066, de 8 de março de 1990. Regulamenta a Lei n. 7678, de 8 de novembro de 1988, que dispõe sobre a produção, circulação e comercialização do vinho e derivados do vinho e da uva. Disponível em: $<$ http://www.planalto.gov.br/ccivil_03/decreto/1990-1994/D99066.htm> Acesso em: 12 nov. 2013.

BRASIL. Lei n. 10.970 de 12 de novembro de 2004. Altera dispositivos da Lei 7.678, de 8 de novembro de 1988, que dispõe sobre a produção, circulação e comercialização do vinho e derivados da uva e do vinho, e dá outras providências. Diário Oficial da União, n. 219, Seção 1, p. 1-2, 2004 b.

BRASIL. Lei n. 12.320 de 06 de setembro de 2010. Dá nova redação ao caput do art. 15 da Lei $\mathrm{n}^{\mathrm{o}} 7.678$, de 8 de novembro de 1988, que dispõe sobre a produção, circulação e comercialização do vinho e derivados da uva e do vinho, na forma que especifica. Diário Oficial da União, n. 172, Seção 1, p. 1, 2010 b.

BRASIL. Lei n. 8.080, de 19 de setembro de 1990. Dispõe sobre as condições para a promoção, proteção e recuperação da saúde, a organização e o funcionamento dos serviços correspondentes e dá outras providências. Diário Oficial da União, n. 182, seção 1, p. 18055-18059, $1990 . \quad$ Disponível em: http://www.planalto.gov.br/ccivil_03/leis/18080.htm>. Acesso em 28 out. 2014. 
BRASIL. Ministério da Saúde, Organização Pan-Americana de Saúde, Organização Mundial da Saúde. Avaliação da assistência farmacêutica no Brasil: estrutura, processo e resultados. Brasília: Organização Pan-Americana da Saúde; BRASIL. Ministério da Saúde, 2005. $260 \mathrm{p}$.

BRASIL. Ministério da Saúde. Conselho Nacional de Saúde. Resolução n. 338, de 6 de maio de 2004. Aprova a Política Nacional de Assistência Farmacêutica. Diário Oficial da União, n. 96, Seção 1, p. 52, 2004a.

BRASIL. Ministério da Saúde. Farmácia Popular do Brasil. Disponível em: $<$ http://portalsaude.saude.gov.br/index.php/o-

ministerio/principal/secretarias/sctie/farmacia-popular>. Acesso em: 25 set. 2014d.

BRASIL. Ministério da Saúde. Fundação Nacional de Saúde. Portaria n. ${ }^{\circ}$ 73, de 9 de março de 1998. Constitui comissão para desenvolver os instrumentos, definir fluxos e no novo software do SINAN. Boletim de Serviço da Funasa, Brasília, 20 mar. 1998.

BRASIL. Ministério da Saúde. Grupo Hospitalar Conceição. Manual de toxicologia básica para agentes comunitários de saúde. Porto alegre: GHC/ANVISA, 2010c. 50 p.

BRASIL. Ministério da Saúde. Portaria $n^{0}$. 1.272, de 6 de junho de 2014. Define a Lista Nacional de Notificação Compulsória de doenças, agravos e eventos de saúde pública nos serviços de saúde públicos e privados em todo o território nacional, nos termos do anexo, e dá outras providências. Diário Oficial da União, n. 108, Seção 1, p. 67-69, 2014c.

BRASIL. Ministério da Saúde. Secretaria de Atenção à Saúde. Departamento de Atenção Básica. Orientações para coleta e análise de dados antropométricos em serviços de saúde: Norma Técnica do Sistema de Vigilância Alimentar e Nutricional - SISVAN. Brasília: Ministério da Saúde, 2011b. 76 p.

BRASIL. Ministério da Saúde. Secretaria de Políticas de Saúde. Departamento de Atenção Básica. Política nacional de medicamentos. Brasília: Ministério da Saúde, 2001. 40 p.

BRASIL. Ministério da Saúde. Secretaria de Vigilância em Saúde. Departamento de Vigilância Epidemiológica. Sistema de Informação de Agravos de Notificação - SINAN: normas e rotinas. 2. ed. Brasília: Editora do Ministério da Saúde, 2007. 68 p.

BRASIL. Ministério da Saúde. Sistema de Informação de Agravos de Notificação - SINAN. Tabulação de Dados. Disponível em: $<$ http://dtr2004.saude.gov.br/sinanweb/tabnet/dh?sinannet/iexogena/bases/Intoxbrnet.def $>$. Acesso em: 14 abril 2014a.

BRASIL. Ministério da Saúde. Sistema de Informação de Agravos de Notificação - SINAN. O que é o SINAN? Disponível em: <http://dtr2004.saude.gov.br/sinanweb/>. Acesso em: 14 abril 2014b.

BRASIL. Portaria do Ministério da Saúde n. 100 de 07 de fevereiro de 2013. Aprova o Protocolo Clínico e Diretrizes terapêuticas do Lúpus Eritematoso Sistêmico. Diário Oficial da União, n. 28, Seção 1, p. 70-75, 2013.

BRASIL. Portaria n. 399 de 22 de fevereiro de 2006. Divulga o Pacto pela Saúde 2006 Consolidação do SUS e aprova as Diretrizes Operacionais do Referido Pacto. Diário Oficial da União, n. 39, 23 fev. 2006, Seção 1, p. 49-51.

BRAWLEY, O. W.; KRAMER, B. S. Prevenção e detecção precoce do câncer. In: FAUCI A. S. et al. (Ed.). Harrison medicina interna. 17. ed. Rio de Janeiro: McGraw-Hill Interamericana do Brasil, 2008. 2754 p. 
CAHIR, C.; FAHEY, T.; TEELING, M.; TELJEUR, C.; FEELY, J.; BENNETT, K. Potentially inappropriate prescribing and cost outcomes for older people: a national population study. British Journal of Clinical Pharmacology, v. 69, n. 5, p. 543-552, 2010.

CARUSO, L. B.; SILliMAN, R. A. Medicina geriátrica. In: FAUCI, A. S. et al. (Ed.). Harrison medicina interna. 17. ed. Rio de Janeiro: McGraw-Hill Interamericana do Brasil, 2008. 2754 p.

CARVALHO, D. F. P.; GUIMARAES, M. T.; RIBEIRO, T. S.; CAMPINA, N. N.; LOBARINHAS, M. R.; LOPES, A. L. J.; CUNHA, M. G.; SOUZA, I. B.; OLIVEIRA, V. L. F.; BRAGA E BRAGA, L.; MARTINS, L. C.; GOMES, A.; PEREIRA, L. A. A.; BRAGA, A. L. F. Prevalence of liver diseases as referred by people living in the Santos and São Vicente Estuary. Environmental Science and Pollution Research, (no prelo), 2014.

CARVALHO, M. F. C.; ROMANO-LIEBER, N. S.; BERGSTEN-MENDES, G.; SECOLI, S. R.; RIBEIRO, E.; LEBRAO, M. L.; DUARTE, Y. A. O. Polypharmacy among the elderly in the city of São Paulo, Brazil - SABE Study. Revista Brasileira de Epidemiologia, v. 15, n. 4, p. 817-827, 2012.

CARVALHO, M. F.; PASCOM, A. R. P.; SOUZA-JUNIOR, P. R. B.; DAMACENA, G. N.; SZWARCWALD, C. L. Utilization of medicines by the Brazilian population, 2003. Cadernos de Saúde Pública, v. 21, p. S100-S108, 2005. Suplemento.

CHILE. Centro Nacional de Farmacoecomomia - CENAFAR. Subdepartamento de Estudios y ETESA. Departamento de Asuntos Científicos. Instituto de Salud Pública de Chile. Medicamentos em Chile: Revision de la evidencia del mercado nacional de fármacos. Chile, 2013. 40 p.

COlOMBO, D.; HelenA, E. T. S.; AGOSTINHO, A. C. M. G.; DIDJURGEIT, J. S. M. A. Padrão de Prescrição de Medicamentos nas Unidades de Programa de Saúde da Família de Blumenau. Revista Brasileira de Ciências Farmacêuticas, v. 40, n. 4, p. 549-558, 2004.

CONSELHO NACIONAL DE SECRETÁRIOS DE SAÚDE - CONASS. Relatório do Seminário Internacional de Assistência Farmacêutica do CONASS, realizado em 15 e 16 de junho de 2009, em Brasília/DF. Brasília: CONASS, 2010. Disponível em: $<$ http://www.conass.org.br/conassdocumenta/cd_20.pdf $>$. Acesso em 17 jul. 2014.

COSTA, K. S.; BARROS, M. B. A.; FRANCISCO, P. M. S. B.; CESAR, C. L. G.; GOLDBAUM, M.; CARANDINA, L. Utilização de medicamentos e fatores associados: um estudo de base populacional no Município de Campinas, São Paulo, Brasil. Cadernos de Saúde Pública, v. 27, n. 4, p. 649-658, 2011.

DIEHL, E. E.; GRASSI, F. Use of medicines in a Guaraní Indian village on the coast of Santa Catarina State, Brazil. Cadernos de SaúdePública, v. 26, n. 8, p. 1.549-1.560, 2010.

DUKES, M. N. G (Ed.). Drug Utilization Studies: Methods and Uses. WHO Regional Publications, European Series n. 45, 1993. 218 p.

ESTADOS UNIDOS. U. S. Department of Health and Human Services. Centers for Disease Control and Prevention. With Special Feature on Prescription Drugs. U.S. Government Printing Office, 2013. 497 p.

EUROPEAN CENTRE FOR DISEASE PREVENTION AND CONTROL (ECDC); EUROPEAN MEDICINES AGENCY (EMEA). ECDC/EMEA joint technical report. The bacterial challenge: time to react. A call to narrow the gap between multidrug-resistant bacteria in the EU and the development of new antibacterial agents. Stockholm: European Centre for Disease Prevention and Control, 2009. 54 p. 
EV, L. S.; GUIMARÃES, A. G.; CASTRO, V. S. Avaliação das Prescrições Dispensadas em uma Unidade Básica de Saúde do Município de Ouro Preto, Minas Gerais, Brasil. Acta Farmacêutica Bonaerense, v. 27, n. 4, p. 543-547, 2008.

FERREIRA, L. A.; IBIAPINA, C. C.; MACHADO, M. G. P.; FAGUNDES, E. D. T. A alta prevalência de prescrições de medicamentos off-label e não licenciados em unidade de terapia intensive pediátrica brasileira. Revista da Associação Médica Brasileira, v. 58, $\mathrm{n}$. 1, p. 82-87, 2012.

FIELD, A. P.; HOLE, G. J. How to disign and report experiments. Londres: Sage, 2003. 384 p.

FUNDAÇÃO OSWALDO CRUZ - FIOCRUZ. Sistema Nacional de Informações Tóxico Farmacológicas. Sobre o SINITOX. Centros de Informação. Disponível em: $<$ http://www.fiocruz.br/sinitox_novo/cgi/cgilua.exe/sys/start.htm?sid=6>. Acesso em: 18 abril 2014b.

FUNDAÇÃO OSWALDO CRUZ - FIOCRUZ. Sistema Nacional de Informações Tóxico Farmacológicas. Dados nacionais. Disponível em: $<$ http://www.fiocruz.br/sinitox/cgi/cgilua.exe/sys/start.htm?sid=8> Acesso em: 21 abril 2014a.

GALLAGHER, P.; LANG, P. O.; CHERUBINI, A.; TOPINKIVA, E.; CRUZ-JENTOFT, A.; ERRASQUIN, B. M.; MADLOVA, P.; GASPERINI, B.; BAEYENS, H.; BAEYENS, J.; MICHEL, J.; O'MAHONY, D. Prevalence of potentially inappropriate prescribing in an acutely ill population of older patients admitted to six European hospitals. European Journal of Clinical Pharmacology, v. 67, n. 11, p. 1175-1188, 2011.

GALVÃO, T. F.; SILVA, M. T.; GROSS, R.; PEREIRA, M. G. Medication use in adults living in Brasilia, Brazil: a cross-sectional, population-based study. Pharmacoepidemiology and Drug Safety, v. 23, n. 5, p. 507-514, 2014.

GARBOSSA, G. Social and environmental health determinants and their relationship with parasitic diseases in asymptomatic children from a shantytown in Buenos Aires, Argentina. Pathogens and Global Health, v. 107, n. 3, p. 141-152, 2013.

GARCIA, L. P.; MAGALHAES, L. C. G.; SANT'ANNA, A. C.; FREITAS, L. R. S.; AUREA, A. P. Dimensões do acesso a medicamentos no Brasil: perfil e desigualdades dos gastos das famílias, segundo as Pesquisas de Orçamentos Familiares 2002-2003 e 2008-2009. Rio de Janeiro: Ipea, 2013b. 50 p. Textos para Discussão.

GARCIA, L. P.; SANT’ANNA, A. C.; MAGALHAES, L. C. G.; FREITAS, L. R. S.; AUREA, A. P. Brazilian family spending on medicines: an analysis of data from the Family Budget Surveys, 2002-2003 and 2008-2009. Cadernos de Saúde Pública, v. 29, n. 8, p. 1605-1616, $2013 \mathrm{a}$.

GELAW, A.; ANAGAW, B.; NIGUSSIE, B.; SILESH, B.; YIRGA, A.; ALEM, M.; ENDRIS, M.; GELAW, B. Prevalence of intestinal parasitic infections and risk factors among schoolchildren at the University of Gondar Community School, Northwest Ethiopia: a cross sectional study. BMC Public Health, v. 13, n. 304. Disponível em: < http://www.biomedcentral.com/1471-2458/13/304>. Acesso em 14 jul. 2014.

GIGANTE, D. P.; MOURA, E. C.; SARDINHA, L. M. V. Prevalence of overweight and obesity and associated factors, Brazil, 2009. Revista de Saúde Pública, v. 43, p. 83-89. Suplemento 2.

HARDON, A.; HODGKIN, C.; FRESLE, D. How to investigate the use of medicines by consumers. Geneva: World Health Organization / University of Amsterdam, 2004. 89 p. 
HENNING, F.; FUKS, K.; MOEBUS, S.; WEINMAYR, G.; MEMMESHEIMER, M.; JAKOBS, H.; BROCKER-PREUSS, M.; FUHRER-SAKEL, D.; MOHLENKAMP, S.; ERBEL, R.; JOCKEL, K.; HOFFMANN, B. Association between Source-Specific Particulate Matter Air Pollution and hs-CRP: Local Traffic and Industrial Emissions. Environmental Health Perspectives, v. 122, n. 7, p. 703-710, 2014.

HOLlOWAY, K.; VAN DIJK, L. Rational Use of Medicines. In: The World Medicines Situation Report. 3. ed. Geneva: World Health Organization, 2011.

IMS INSTITUTE FOR HEALTHCARE INFORMATICS. Advancing the responsible use of medicines: Applying levers for change. United States of America: IMS Health Incorporated and its affiliates, 2012. 215 p. Disponível em: < http://www.imshealth.com/ims/Global/Content/Insights/IMS $\% 20$ Institute $\% 20$ for $\% 20$ Healt hcare $\% 20$ Informatics/Responsible\%20Use $\% 20$ of $\% 20$ Medicines/IHII_Advancing_Respons ible_Use_of_Meds_Report.pdf>. Acesso em: 10 mar. 2014.

INGLATERRA. Prescribing and Primary Care. Health and Social Care Information Centre. Prescriptions Dispensed in the Community England 2003-13. Health and Social Care Information Centre, 2014. $110 \mathrm{p}$.

INSTITUTO BRASILEIRO DE GEOGRAFIA E ESTATÍSTICA - IBGE. Coordenação de Trabalho e Rendimento. Pesquisa de orçamentos familiares 2008-2009: análise do consumo alimentar pessoal no Brasil. Rio de Janeiro: IBGE, 2011. 150 p. Disponível em: < http://www.ibge.gov.br/home/estatistica/populacao/condicaodevida/pof/2008_2009_analis e_consumo/pofanalise_2008_2009.pdf $>$. Acesso em 18 ago. 2013.

INSTITUTO BRASILEIRO DE GEOGRAFIA E ESTATÍSTICA - IBGE. Diretoria de Pesquisas. Coordenação de Contas Nacionais. Contas Nacionais número 37. Conta-Satélite de Saúde Brasil 2007-2009. Rio de Janeiro: IBGE, 2012b. Disponível em: < http://www.ibge.gov.br/home/estatistica/economia/economia_saude/css_2007_2009/econo mia_saude.pdf $>$ Acesso em: 12 jun. 2014.

INSTITUTO BRASILEIRO DE GEOGRAFIA E ESTATÍSTICA - IBGE. Diretoria de Pesquisas. Coordenação de Trabalho e Rendimento. Pesquisa de Orçamentos Familiares 2008-2009: Perfil das despesas no Brasil - Indicadores selecionados. Rio de Janeiro: IBGE, $2012 \mathrm{a}$. Disponível em:

$\mathrm{ftp} / / / \mathrm{ftp}$. ibge.gov.br/Orcamentos Familiares/Pesquisa de Orcamentos Familiares 20082 009/Perfil_das_Despesas_no_Brasil/POF2008_2009_perfil.pdf $>$. Acesso em 18 ago. 2013.

INSTITUTO BRASILEIRO DE GEOGRAFIA E ESTATÍSTICA - IBGE. Diretoria de Pesquisas. Coordenação de Trabalho e Rendimento. Pesquisa de Orçamentos Familiares 2008-2009: Despesas, Rendimentos e Condições de Vida. Rio de Janeiro: IBGE, 2010. Disponível em: http://www.ibge.gov.br/home/estatistica/populacao/condicaodevida/pof/2008_2009/POFpu blicacao.pdf $>$. Acesso em: 18 ago. 2013.

INSTITUTO BRASILEIRO DE GEOGRAFIA E ESTATÍSTICA - IBGE. Diretoria de Pesquisas. Coordenação de Trabalho e Rendimento. Pesquisa de Orçamentos Familiares 2008-2009: Manual do Agente de Pesquisa. Rio de Janeiro: IBGE, 2008. Disponível em:< http://biblioteca.ibge.gov.br/visualizacao/instrumentos_de_coleta/doc2625.pdf $>$. Acesso em: 18 ago. 2013.

INSTITUTO BRASILEIRO DE GEOGRAFIA E ESTATÍSTICA - IBGE. Diretoria de Pesquisas. Coordenação de Métodos e Qualidade. Amostra Mestra para o Sistema Integrado de Pesquisas Domiciliares. Rio de Janeiro: IBGE, 2007. 67p. 
INSTITUTO BRASILEIRO DE GEOGRAFIA E ESTATÍSTICA - IBGE. Pesquisa de Orçamentos Familiares 2008/2009, Microdados. Disponível em: $<$ http://www.ibge.gov.br/home/estatistica/populacao/condicaodevida/pof/2008_2009_aquis icao/microdados.shtm>. Acesso em: 18 abril 2014.

INSTITUTO BRASILEIRO DE GEOGRAFIA E ESTATÍSTICA - IBGEINSTITUTO BRASILEIRO DE GEOGRAFIA E ESTATÍSTICA. Atlas do censo demográfico 2010. Rio de Janeiro: IBGE, 2013. 156p. Disponível em: $<$ http://biblioteca.ibge.gov.br/index.php/biblioteca-catalogo?view=detalhes\&id=264529>. Acesso em: 03 set. 2014.

KALIAPPAN, S. P.; GEORGE, S.; FRANCIS, M. R.; KATTULA, D.; SARKAR, R.; MINZ, S.; MOHAN, V. R.; GEORGE, K.; ROY, S.; AJJAMPUR, S. S. R.; MULIYIL, J.; KANG, G. Prevalence and clustering of soil-transmitted helminth infections in a tribal area in southern India. Tropical Medicine \& International Health, v. 18, n.12, p. 1452-1462, 2013.

KAPLAN, W.; WIRTZ, V. J.; MANTEL-TEEUWISSE, A.; STOLK, P.; DUTHEY, B.; LAING, R. Priority Medicines for Europe and the World 2013 Update. Geneva: World Health Organization, 2013. 227 p. Disponível em: $<$ http://www.who.int/medicines/areas/priority_medicines/MasterDocJune28_FINAL_Web. pdf?ua=1>. Acesso em: 20 abril 2014.

KIM, H. H.; LEE, C. S.; JEON, J. M.; YU, S. D.; LEE, C. W.; PARK, J. H.; SHIN, D. C.; LIM, Y. W. Analysis of the association between air pollution and allergic diseases exposure from nearby sources of ambient air pollution within elementary school zones in four Korean cities. Environmental Science and Pollution Research, v. 20, p. 4831-4846, 2013.

KOTCHEN, T. A. Doença vascular hipertensiva. In: FAUCI A. S. et al. (Ed.). Harrison medicina interna. 17. ed. Rio de Janeiro: McGraw-Hill Interamericana do Brasil, 2008. $2754 \mathrm{p}$.

KOVACEVIC, S. V.; SIMISIC, M. ; RUDINSKI, S. S.; CULAFIC, M.; VUCICEVIC, K.; PROSTRAN, M.; MILJKOVIC, B. Potentially Inappropriate Prescribing in Older Primary Care Patients. Plos One, v. 9, n. 4, 2014.

LASTE, G. The role of the community health agent in control of the in-house stock of medication in communities served by the family health strategy. Ciência \& Saúde Coletiva, v. 17, n. 5, p. 1.305-1.312, 2012.

LEE, D; BERGMAN, U. Studies of Drug Utilization. In: Strom BL, Kimmel SE, Hennessy S, editors. Pharmacoepidemiology. 5 ed. Oxford, UK: Wiley-Blackwell, 2012. p. 379-401.

LEITE, S. N.; VIEIRA, M.; VEBER, A. P. Drug utilization studies: a synthesis of articles published in Brazil and Latin America. Ciência \& Saúde Coletiva, v. 13, p. 793-802, 2008. Suplemento.

LEVY, R. B; CLARO, R. M.; MONDINI, L.; SICHIERI, R.; MONTEIRO, C. A. Distribuição regional e socioeconômica da disponibilidade domiciliar de alimentos no Brasil em 20082009. Revista de Saúde Pública, n.46, v. 1, p. 6-15, 2012.

LIU, C.; PENG, L.; CHEN, Y.; LIN, M.; LIU, L.; CHEN, L. Potentially inappropriate prescribing (IP) for elderly medical inpatients in Taiwan: A hospital-based study. Archives of Gerontology and Geriatrics, v. 55, p. 148-151.

LUZ, T. C. B.; LUIZA, V. L.; AVELAR, F. G.; HOKERBERG, Y. H. M.; PASSOS, S. R. L. Consumo de medicamentos por trabalhadores de hospital. Ciência \& Saúde Coletiva, v. 17, n. 2, p. 499-509, 2012. 
MARTINS, M. C. C.; SOUZA FILHO, M. D.; MOURA, F. S.; CARVALHO, J. S. R.; MULlER, M. C.; NEVES, R. V.; MOUSINHO, P. C.; LIMA, I. P. Uso de drogas antiobesidade entre estudantes universitários. Revista da Associação Médica Brasileira, v. 57, n. 5, p. 570-576, 2011.

MASTROIANNI, P. C.; LUCCHETTA, R. C.; SARRA, J. R.; GALDUROZ, J. C. F. Estoque doméstico e uso de medicamentos em uma população cadastrada na estratégia saúde da família no Brasil. Revista Panamericana de Salud Pública, v. 29, n. 5, p. 358-364, 2011.

MEDEIROS-SOUZA et al. Diagnosis and control of polypharmacy in the elderly. Revista de Saúde Pública, v. 41, n. 6, p. 1049-1053, 2007.

MORAES, A. C. F.; DELAPORTE, T. R. M.; MOLENA FERNANDES, C. A.; FALCAO, M. C. Factors associated with medicine use and self medication are different in adolescents. Clinics, v. 66, n. 7, p. 1.149-1.155, 2011.

MOTA, D. M.; OLIVEIRA, M. G.; BOVI, R. F.; SILVA, S. F.; CUNHA, J. A. F.; DIVINO, J. A. Are there irrationalities in the consumption of anti-obesity drugs in Brazil? A pharmacoeconometric analysis of panel datasets. Ciência \& Saúde Coletiva, v. 19, v. 5, n. 13891400, 2014.

MOTA, D. M.; SILVA-JÚNIOR, G. G. Evidências advindas do consumo de medicamentos moduladores do apetite no Brasil: um estudo farmacoeconométrico. Revista da Associação Médica Brasileira, v. 58, n. 1, p. 88-94, 2012.

NOBRE, L. N.; SILVA, R. V.; MACEDO, M. S.; TEIXEIRA, R. A.; LAMOUNIER, J. A.; FRANCESCHINI, S. C. C. Risk factors for intestinal parasitic infections in preschoolers in a low socio-economic area, Diamantina, Brazil. Pathogens and Global Health, v. 107, n. 2, p. 103-107, 2013.

OLIVEIRA, E. A.; BERTOLDI, A. D.; DOMINGUES, M. R.; SANTOS, I. S.; BARROS, A. J. D. Medicine use from birth to age two years: the 2004 Pelotas (Brazil) Birth Cohort Study. Revista de Saúde Pública, v. 44, n. 4, p. 591-600, 2010.

OLIVEIRA, E. A.; BERTOLDI, A. D.; DOMINGUES, M. R.; SANTOS, INA. S. BARROS, A. J. D. Factors associated to medicine use among children from the 2004 Pelotas Birth Cohort (Brazil). Revista de Saúde Pública, v. 46, n. 3, p. 487-496, 2012.

OLIVEIRA, M. P. F.; NOVAES, M. R. C. G. Drug use by elderly residents in long-stay institutions, Brasília-DF, Brazil. Revista Brasileira de Enfermagem, v. 65, n. 5, p. 737 744, 2012.

ORGANIZAÇÃO PAN-AMERICANA DA SAÚDE - OPAS. Ministério da Saúde. Avaliação da assistência farmacêutica no Brasil: estrutura, processo e resultados. Brasília: Organização Pan-Americana da Saúde/Organização Mundial da Saúde; Ministério da Saúde, 2005. $260 \mathrm{p}$.

PANIZ, V. M. V.; FASSA, A. G.; FACCHINI, L. A.; BERTOLDI, A. D.; PICCINI, R. X.; TOMASI, E.; THUME, E.; SILVEIRA, D. S.; SIQUEIRA, F. V.; RODRIGUES, M. A. Access to continuous-use medication among adults and the elderly in South and Northeast Brazil. Cadernos de Saúde Pública, v. 24, n. 2, p. 267-280, 2008.

PEREIRA, F. S. V. T.; BUCARETCHI, F.; STEPHAN, C.; CORDEIRO, R. Self-medication in children and adolescents. Jornal de Pediatria, v. 83, n. 5, p. 453-458, 2007.

POWERS, A. C. Diabetes melito. In: FAUCI A. S. et al. (Ed.). Harrison medicina interna. 17. ed. Rio de Janeiro: McGraw-Hill Interamericana do Brasil, 2008. 2754 p.

RICKWOOD, S.; KLEINROCK, M.; NUÑEZ-GAVIRIA, M. The Global Use of Medicines: Outlook through 2017. IMS Institute for Healthcare Informatics, 2013. 38 p. Disponível em: 
$<$ http://www.imshealth.com/cds/imshealth/Global/Content/Corporate/IMS\%20Health\%20I nstitute/Reports/Global_Use_of_Meds_Outlook_2017/IIHI_Global_Use_of_Meds_Report 2013.pdf $>$ Acesso em: 21 abril 2014.

RIPABELLI, G.; TAMBURRO, M.; SAMMARCO, M. L.; LAURENTIIS, G.; BIANCO, A. Asthma prevalence and risk factors among children and adolescents living around na industrial area: a cross-sectional study. BMC Public Health, v. 13, p. 1038-1047, 2013.

ROZENFELD, S.; VALENTE, J. Estudos de utilização de medicamentos - considerações técnicas sobre coleta e análise de dados. Epidemiologia e Serviços de Saúde, v. 13, n. 2, p. 115-123, 2004.

SAKSHAUG, S.; STROM, H.; BERG, C.; BLIX, H. S.; LITLESKARE, I.; GRANUM, T. Drug Consumption in Norway 2009-2013. Nasjonalt folkehelseinstitutt, 2014. 98 p.

SANTOS, T. R. A.; LIMA, D. M.; NAKATANI, A. Y. K.; PEREIRA, L. V.; LEAL, G. S.; AMARAL, R. G. Medicine use by the elderly in Goiania, Midwestern Brazil. Revista de Saúde Pública, v. 47, n. 1, p. 94-103, 2013.

SCHMIDT, M. I.; DUNCAN, B. B.; SILVA, G. A.; MENEZES, A. M.; MONTEIRO, C. A.; BARRETO, S. M.; CHOR, D.; MENEZES, P. R. Doenças crônicas não transmissíveis no Brasil: carga e desafios atuais. The Lancet, p. 61-74, 2011. Série Saúde no Brasil.

SCHUCKIT, M. A. Álcool e alcoolismo. In: FAUCI A. S. et al. (Ed.). Harrison medicina interna. 17. ed. Rio de Janeiro: McGraw-Hill Interamericana do Brasil, 2008. 2754 p.

SILVA, C. A.; GIUGLIANI, E. R. J. Consumption of medicines among adolescents students: a concern. Jornal de Pediatria, v. 80, n. 4, 2004.

SILVEIRA, F. G.; OSORIO, R. G.; PIOLA, S. F. Os gastos das famílias com saúde. Ciência \& Saúde Coletiva, v. 7, n. 4, p. 719-731, 2002.

TOBAR, F. Economía de los medicamentos genéricos en América Latina. Revista Panamericana de Salud Pública/ Pan American Journal of Public Health, v. 23, n.1, p. 59-67, 2008.

TOSKES, P. P.; GREENBERGER, N. J. Abordagem ao paciente com doença pancreática. In: FAUCI A. S. et al. (Ed.). Harrison medicina interna. 17. ed. Rio de Janeiro: McGraw-Hill Interamericana do Brasil, 2008. 2754 p.

VEDANA, E. H. B.; PERES, M. A.; NEVES, J.; ROCHA, G. C.; LONGO, G. Z. Prevalência de Obesidade e Fatores Potencialmente Causais em Adultos em Região do Sul do Brasil. Arquivos Brasileiros de Endocrinologia \& Metabologia, v. 52, n. 7, p. 1156-1162, 2008.

VIEIRA, F. S.; ZUCCHI, P. Financing of Pharmaceutical Services in Brazilian Public Health System. Saúde e Sociedade, v. 22, n. 1, p. 73-84, 2013.

VIEIRA, F. S.; ZUCCHI, P. Price differences between generic and innovator medicines in Brazil. Revista de Saúde Pública, v. 40, n. 3, p. 444-449, 2006.

VOLPATO, D. E.; SOUZA, B. V.; ROSA, L. G. D.; MELO, L. H.; DAUDT, C. A. S.; DEBONI, L. Use of Antibiotics without Medical Prescription. The Brazilian Journal of Infectious Diseases, v. 9, n. 3, p. 288-291, 2005.

VOSGERAU, M. Z. S.; SOARES, D. A.; SOUXA, R. K. T.; MATSUO, T.; CARVALHO, G. S. Consumption of medicines by adults within an area covered by a family health unit. Ciência \& Saúde Coletiva, v. 16, p. 1629-1638, 2011. Suplemento.

WELLER, T. M. A.; JAMIESON, C. E. The expanding role of the antibiotic pharmacist. Journal of Antimicrobial Chemotherapy, v. 54, n. 2, p. 295-298, 2004. 
WIRTZ, V. J.; DRESER, A.; GONZALES, R. Trends in antibiotic utilization in eight Latin American countries, 1997-2007. Revista Panamericana de Salud Pública, v. 27, n.3, 2010.

WORLD HEALTH ORGANIZATION - WHO. Health statistics and information systems. WHO World Health Survey. Disponível em: $<$ http://www.who.int/healthinfo/survey/en/>. Acesso em: 13 jul. 2014.

WORLD HEALTH ORGANIZATION - WHO. Medicines use in primary care in developing and transitional countries: Fact Book summarizing results from studies reported between 1990 and 2006. Geneva, 2009. 150 p. Disponível em: $<$ http://apps.who.int/medicinedocs/documents/s16073e/s16073e.pdf $>$ Acesso em: 20 abril 2014.

WORLD HEALTH ORGANIZATION - WHO. Prevention of cardiovascular disease: guidelines for assessment and management of total cardiovascular risk. Geneva: World Health Organization, 2007. $86 \mathrm{p}$.

WORLD HEALTH ORGANIZATION - WHO. The Pursuit of Responsible Use of Medicines: Sharing and learning from Country Experiences. Technical Report prepared for the Ministers Summit on The benefits of responsible use of medicines: Setting policies for better and cost effective health care. Geneva: World Health Organization, 2012. 64 p.

WORLD HEALTH ORGANIZATION - WHO. The World Drug Situation. Geneva: World Health Organization, $1988 . \quad 58 \quad$ p. $\quad$ Disponível em: $<$ http://apps.who.int/medicinedocs/documents/s16222e/s16222e.pdf $>$. Acesso em: 20 jun. 2014.

WORLD HEAlth ORGANIZATION - WHO. The World Medicines Situation Report, 2011. 3. ed. Geneva: World Health Organization, 2011. 360 p.

WORLD HEALTH ORGANIZATION - WHO. WHO Collaborating Centre for Drug Statistics Methodology. Guidelines for ATC classification and DDD assignment 2014. 17 ed. Oslo: WHO Collaboration Centre for Drug Statistics Methodology, 2013. 286 p. Disponível em: $<$ http://www.whocc.no/filearchive/publications/2014_guidelines.pdf $>$ Acesso em: 24 fev. 2014.

WORLD HEALTH ORGANIZATION - WHO. WHO International Working Group for Drug Statistics Methodology, WHO Collaborating Centre for Drug Statistics Methodology, WHO Collaborating Centre for Drug Utilization Research and Clinical Pharmacological Services. Introduction to drug utilization research. Geneva: World Health Organization, 2003. 48 p. 


\section{APÊNDICE}

APÊNDICE A: Teor alcoólico de bebidas

Tabela 1: Teor alcoólico das bebidas listadas na POF 2008-2009

\begin{tabular}{|c|c|c|c|c|}
\hline Bebida & $\begin{array}{r}\text { Faixa de } \\
(\% \mathrm{v} / \\
\text { legisla }\end{array}$ & $\begin{array}{l}\text { alcoólico } \\
\text { ista na } \\
\text { isileira }\end{array}$ & $\begin{array}{l}\text { Grau alcoólico } \\
\text { médio (\% v/v) }\end{array}$ & Referência \\
\hline $\begin{array}{ll}\text { Aguardente } & \text { de } \\
\text { alcachofra } & \end{array}$ & 38,00 & 54,00 & 46,00 & BRASIL, 2009 \\
\hline $\begin{array}{ll}\text { Aguardente } & \text { de } \\
\text { alcachofra orgânica } & \end{array}$ & 38,00 & 54,00 & 46,00 & BRASIL, 2009 \\
\hline Aguardente de arroz & 38,00 & 54,00 & 46,00 & BRASIL, 2009 \\
\hline $\begin{array}{l}\text { Aguardente de arroz } \\
\text { orgânica }\end{array}$ & 38,00 & 54,00 & 46,00 & BRASIL, 2009 \\
\hline Aguardente de banana & 36,00 & 54,00 & 45,00 & BRASIL, 2009 \\
\hline $\begin{array}{l}\text { Aguardente de banana } \\
\text { orgânica }\end{array}$ & 36,00 & 54,00 & 45,00 & BRASIL, 2009 \\
\hline Aguardente de cana & 38,00 & 54,00 & 46,00 & BRASIL, 2009 \\
\hline $\begin{array}{l}\text { Aguardente de cana de } \\
\text { açúcar }\end{array}$ & 38,00 & 54,00 & 46,00 & BRASIL, 2009 \\
\hline $\begin{array}{l}\text { Aguardente de cana de } \\
\text { açúcar orgânica }\end{array}$ & 38,00 & 54,00 & 46,00 & BRASIL, 2009 \\
\hline $\begin{array}{l}\text { Aguardente de cana } \\
\text { orgânica }\end{array}$ & 38,00 & 54,00 & 46,00 & BRASIL, 2009 \\
\hline Aguardente de catuaba & 38,00 & 54,00 & 46,00 & BRASIL, 2009 \\
\hline $\begin{array}{l}\text { Aguardente de catuaba } \\
\text { orgânica }\end{array}$ & 38,00 & 54,00 & 46,00 & BRASIL, 2009 \\
\hline Aguardente de jalapa & 38,00 & 54,00 & 46,00 & BRASIL, 2009 \\
\hline $\begin{array}{l}\text { Aguardente de } \\
\text { mandioca }\end{array}$ & 36,00 & 54,00 & 45,00 & BRASIL, 2009 \\
\hline Aguardente de uva & 36,00 & 54,00 & 45,00 & BRASIL, 2009 \\
\hline
\end{tabular}




\begin{tabular}{|c|c|c|c|c|}
\hline Bebida & $\begin{array}{r}\text { Faixa de } \\
(\% \mathrm{v} / \\
\text { legisla }\end{array}$ & $\begin{array}{l}\text { alcoólico } \\
\text { ista na } \\
\text { asileira }\end{array}$ & $\begin{array}{l}\text { Grau alcoólico } \\
\text { médio (\% v/v) }\end{array}$ & Referência \\
\hline $\begin{array}{l}\text { Aguardente de uva } \\
\text { orgânica }\end{array}$ & 36,00 & 54,00 & 45,00 & BRASIL, 2009 \\
\hline Bagaceira & 35,00 & 54,00 & 44,50 & BRASIL, 2004b \\
\hline Bagaceira orgânica & 35,00 & 54,00 & 44,50 & BRASIL, 2004b \\
\hline Batida de coco & 15,00 & 36,00 & 25,50 & BRASIL, 2009 \\
\hline $\begin{array}{l}\text { Batida de qualquer } \\
\text { sabor }\end{array}$ & 15,00 & 36,00 & 25,50 & BRASIL, 2009 \\
\hline $\begin{array}{l}\text { Bebida alcoólica não- } \\
\text { especificada }\end{array}$ & & & 25,85 & \\
\hline Bitter & 0,51 & 54,00 & 27,26 & BRASIL, 2009 \\
\hline Cachaça & 38,00 & 48,00 & 43,00 & BRASIL, 2009 \\
\hline Cachaça orgânica & 38,00 & 48,00 & 43,00 & BRASIL, 2009 \\
\hline Caipirinha & 15,00 & 36,00 & 25,50 & BRASIL, 2009 \\
\hline Cajuína (vinho) & 14,00 & 20,00 & 17,00 & BRASIL, 2010 \\
\hline Cajuína orgânica & 14,00 & 20,00 & 17,00 & BRASIL, 2010 \\
\hline Campari & 0,51 & 54,00 & 27,26 & BRASIL, 2009 \\
\hline Catuaba & 14,00 & 20,00 & 17,00 & BRASIL, 2010 \\
\hline Catuaba orgânica & 14,00 & 20,00 & 17,00 & BRASIL, 2010 \\
\hline $\begin{array}{l}\text { Caxiri (aguardente de } \\
\text { mandioca) }\end{array}$ & 36,00 & 54,00 & 45,00 & BRASIL, 2009 \\
\hline Cervejas e Chopes & 4,61 & & 4,61 & \\
\hline Champanhe & 10,00 & 13,00 & 11,50 & BRASIL, 2004b \\
\hline Cinzano & 14,00 & 20,00 & 17,00 & BRASIL, 2010b \\
\hline Conhaque & 36,00 & 54,00 & 45,00 & BRASIL, 2004b \\
\hline Coquetel de frutas & 0,51 & 54,00 & 27,26 & BRASIL, 2009 \\
\hline Drink Dreher & 36,00 & 54,00 & 45,00 & BRASIL, 2004b \\
\hline $\begin{array}{l}\text { Duelo de cana com } \\
\text { sabor de fruta }\end{array}$ & 38,00 & 54,00 & 46,00 & BRASIL, 2009 \\
\hline
\end{tabular}




\begin{tabular}{|c|c|c|c|c|}
\hline Bebida & $\begin{array}{r}\text { Faixa de } \\
(\% \text { v/ } \\
\text { legisla }\end{array}$ & $\begin{array}{l}\text { alcoólico } \\
\text { ista na } \\
\text { asileira }\end{array}$ & $\begin{array}{l}\text { Grau alcoólico } \\
\text { médio }(\% \mathrm{v} / \mathrm{v})\end{array}$ & Referência \\
\hline $\begin{array}{l}\text { Duelo de cana com } \\
\text { sabor de fruta orgânico }\end{array}$ & 38,00 & 54,00 & 46,00 & BRASIL, 2009 \\
\hline Fernet & 0,51 & 54,00 & 27,26 & BRASIL, 2009 \\
\hline Genebra & 35,00 & 54,00 & 44,50 & BRASIL, 2009 \\
\hline Gin & 35,00 & 54,00 & 44,50 & BRASIL, 2009 \\
\hline Graspa & 35,00 & 54,00 & 44,50 & BRASIL, 2004b \\
\hline Graspa orgânica & 35,00 & 54,00 & 44,50 & BRASIL, 2004b \\
\hline Jurubeba vinho & 14,00 & 20,00 & 17,00 & BRASIL, 2010b \\
\hline $\begin{array}{ll}\text { Jurubeba } & \text { vinho } \\
\text { orgânica } & \end{array}$ & 14,00 & 20,00 & 17,00 & BRASIL, 2010b \\
\hline Keep Cooler & 3,00 & 7,00 & 5,00 & BRASIL, 1990 \\
\hline Leite de onça & 0,51 & 54,00 & 27,26 & BRASIL, 2009 \\
\hline Licor de qualquer sabor & 15,00 & 54,00 & 34,50 & BRASIL, 2009 \\
\hline Martini & 14,00 & 20,00 & 17,00 & BRASIL, 2010b \\
\hline Pinga & 38,00 & 54,00 & 46,00 & BRASIL, 2009 \\
\hline Quentão & 0,51 & 54,00 & 27,26 & BRASIL, 2009 \\
\hline Rum & 35,00 & 54,00 & 44,50 & BRASIL, 2009 \\
\hline San Rafael & 14,00 & 20,00 & 17,00 & BRASIL, 2010b \\
\hline Saque & 14,00 & 26,00 & 20,00 & BRASIL, 2009 \\
\hline Saque orgânico & 14,00 & 26,00 & 20,00 & BRASIL, 2009 \\
\hline Sherry & 15,00 & 54,00 & 34,50 & BRASIL, 2009 \\
\hline Sidra champanhe & 4,00 & 8,00 & 6,00 & BRASIL, 2009 \\
\hline St. Remy & 0,51 & 54,00 & 27,26 & BRASIL, 2009 \\
\hline Steinharger & 35,00 & 54,00 & 44,50 & BRASIL, 2009 \\
\hline Tequila & 36,00 & 54,00 & 45,00 & BRASIL, 2009 \\
\hline Uisque & 38,00 & 54,00 & 46,00 & BRASIL, 2009 \\
\hline Underberg & 0,51 & 54,00 & 27,26 & BRASIL, 2009 \\
\hline Vermute & 14,00 & 20,00 & 17,00 & BRASIL, 2010b \\
\hline Vinho & 8,60 & 14,00 & 11,30 & BRASIL, 2004b \\
\hline
\end{tabular}




\begin{tabular}{|c|c|c|c|c|}
\hline Bebida & $\begin{array}{r}\text { Faixa de } \\
(\% \mathrm{v} / \\
\text { legisla }\end{array}$ & $\begin{array}{l}\text { alcoólico } \\
\text { ista na } \\
\text { ısileira }\end{array}$ & $\begin{array}{l}\text { Grau alcoólico } \\
\text { médio (\% v/v) }\end{array}$ & Referência \\
\hline Vinho branco & 8,60 & 14,00 & 11,30 & BRASIL, 2004b \\
\hline Vinho branco orgânico & 8,60 & 14,00 & 11,30 & BRASIL, 2004b \\
\hline Vinho de catuaba & 14,00 & 20,00 & 17,00 & BRASIL, 2010b \\
\hline $\begin{array}{l}\text { Vinho de catuaba } \\
\text { orgânico }\end{array}$ & 14,00 & 20,00 & 17,00 & BRASIL, 2010b \\
\hline Vinho de jurubeba & 14,00 & 20,00 & 17,00 & BRASIL, 2010b \\
\hline $\begin{array}{l}\text { Vinho de jurubeba } \\
\text { orgânico }\end{array}$ & 14,00 & 20,00 & 17,00 & BRASIL, 2010b \\
\hline Vinho de uva & 8,60 & 14,00 & 11,30 & BRASIL, 2004b \\
\hline Vinho de uva e outros & 14,00 & 20,00 & 17,00 & BRASIL, 2004b \\
\hline $\begin{array}{l}\text { Vinho de uva e outros } \\
\text { orgânico }\end{array}$ & 14,00 & 20,00 & 17,00 & BRASIL, 2004b \\
\hline Vinho de uva orgânico & 8,60 & 14,00 & 11,30 & BRASIL, 2004b \\
\hline Vinho licoroso & 14,00 & 18,00 & 16,00 & BRASIL, 2004b \\
\hline $\begin{array}{ll}\text { Vinho } & \text { licoroso } \\
\text { orgânico } & \end{array}$ & 14,00 & 18,00 & 16,00 & BRASIL, 2004b \\
\hline Vinho moscatel & 7,00 & 10,00 & 8,50 & BRASIL, 2004b \\
\hline $\begin{array}{l}\text { Vinho moscatel } \\
\text { orgânico }\end{array}$ & 7,00 & 10,00 & 8,50 & BRASIL, 2004b \\
\hline Vinho orgânico & 8,60 & 14,00 & 11,30 & BRASIL, 2004b \\
\hline Vinho quinado & 14,00 & 20,00 & 17,00 & BRASIL, 2010b \\
\hline $\begin{array}{ll}\text { Vinho } & \text { quinado } \\
\text { orgânico } & \end{array}$ & 14,00 & 20,00 & 17,00 & BRASIL, 2010b \\
\hline Vinho rose & 8,60 & 14,00 & 11,30 & BRASIL, 2004b \\
\hline Vinho rose orgânico & 8,60 & 14,00 & 11,30 & BRASIL, 2004b \\
\hline Vinho seco & 8,60 & 14,00 & 11,30 & BRASIL, 2004b \\
\hline Vinho seco orgânico & 8,60 & 14,00 & 11,30 & BRASIL, 2004b \\
\hline Vinho suave & 8,60 & 14,00 & 11,30 & BRASIL, 2004b \\
\hline Vinho suave orgânico & 8,60 & 14,00 & 11,30 & BRASIL, 2004b \\
\hline
\end{tabular}




\begin{tabular}{|l|c|c|c|l|}
\hline \multicolumn{1}{|c|}{ Bebida } & \multicolumn{2}{|c|}{$\begin{array}{r}\text { Faixa de Grau alcoólico } \\
\text { (\% v/v) prevista na } \\
\text { legislação brasileira }\end{array}$} & $\begin{array}{c}\text { Grau alcoólico } \\
\text { médio (\% v/v) }\end{array}$ & \multicolumn{1}{|c|}{ Referência } \\
\hline Vinho tinto & 8,60 & 14,00 & 11,30 & BRASIL, 2004b \\
\hline Vinho tinto orgânico & 8,60 & 14,00 & 11,30 & BRASIL, 2004b \\
\hline Vinho verde & 8,60 & 14,00 & 11,30 & BRASIL, 2004b \\
\hline Vinho verde orgânico & 8,60 & 14,00 & 11,30 & BRASIL, 2004b \\
\hline Vodka & 36,00 & 54,00 & 45,00 & BRASIL, 2009 \\
\hline Whisky & 38,00 & 54,00 & 46,00 & BRASIL, 2009 \\
\hline
\end{tabular}


APÊNDICE B: Classificação das respostas relativas a medicamentos

Quadro 1: Classificação ATC das respostas relativas a medicamentos, relatadas na POF 2008-2009

\begin{tabular}{|c|c|}
\hline \multicolumn{2}{|c|}{ Aparelho digestivo e metabolismo (A) } \\
\hline Subgrupo & Resposta \\
\hline Preparações estomatológicas (A01) & $\begin{array}{l}\text { - Creme dental medicinal } \\
\text { - Medicamento para gengiva de bebê } \\
\text { - Para afta } \\
\text { - Violeta genciana }\end{array}$ \\
\hline $\begin{array}{l}\text { Medicamentos para desordens ácidas } \\
\text { relacionadas (A02) }\end{array}$ & $\begin{array}{l}\text { - Antiácido } \\
\text { - Antirrefluxo gástrico } \\
\text { - Para azia (antiácido) } \\
\text { - Para estômago } \\
\text { - Para gastrite } \\
\text { - Para problemas no estômago } \\
\text { - Para refluxo gástrico }\end{array}$ \\
\hline $\begin{array}{l}\text { Medicamentos para desordens } \\
\text { gastrintestinais funcionais }(\mathrm{A03})\end{array}$ & $\begin{array}{l}\text { - Anticólica } \\
\text { - Antiespasmódico } \\
\text { - Para gases e cólica }\end{array}$ \\
\hline Antieméticos e antinauseantes (A04) & $\begin{array}{l}\text { - Para enjoo } \\
\text { - Para enjoo e vômito (antiemético) } \\
\text { - Para vômito }\end{array}$ \\
\hline Terapia do fígado e da bile (A05) & $\begin{array}{l}\text { - Hepático (para o fígado) } \\
\text { - Para fígado (hepático) } \\
\text { - Para fígado, pâncreas e vias biliares } \\
\text { - Para hepatite } \\
\text { - Para vesícula }\end{array}$ \\
\hline Medicamentos para constipação (A06) & $\begin{array}{l}\text { - Laxante } \\
\text { - Laxante e purgativo } \\
\text { - Óleo (laxativo) } \\
\text { - Para prisão de ventre (laxante) } \\
\text { - Purgativo }\end{array}$ \\
\hline $\begin{array}{l}\text { Agentes antidiarreicos, anti- } \\
\text { inflamatórios } \\
\text { intestinais (A07) }\end{array}$ & $\begin{array}{l}\text { - Antidiarreico } \\
\text { - Intestinal } \\
\text { - Para diarreia } \\
\text { - Para intestino } \\
\text { - Repositor eletrolítico (cloreto de potássio, } \\
\text { sódio, etc) } \\
\text { - Soluções hidratantes } \\
\text { - Soro fisiológico hidratante }\end{array}$ \\
\hline $\begin{array}{l}\text { Preparações antiobesidade, exceto } \\
\text { produtos dietéticos (A08) }\end{array}$ & $\begin{array}{l}\text { - Controlador de apetite } \\
\text { - Emagrecedor } \\
\text { - Moderador de apetite } \\
\text { - Para emagrecer }\end{array}$ \\
\hline
\end{tabular}




\begin{tabular}{|c|c|}
\hline Digestivos, incluindo enzimas (A09) & - Digestivo \\
\hline $\begin{array}{l}\text { Medicamentos usados no diabetes } \\
\text { (A10) }\end{array}$ & - Para diabete \\
\hline Vitaminas (A11) & $\begin{array}{l}\text { - Complexo B } \\
\text { - Complexo vitamínico } \\
\text { - Vitamina B12 } \\
\text { - Vitamina C } \\
\text { - Vitaminas }\end{array}$ \\
\hline Suplementos minerais (A12) & $\begin{array}{l}\text { - Cálcio (calcificante ósseo) } \\
\text { - Cálcio para osteoporose }\end{array}$ \\
\hline Tônicos (A13) & $\begin{array}{l}\text { - Fortificante } \\
\text { - Fortificantes e estimulantes do apetite } \\
\text { - Óleo fortificante }\end{array}$ \\
\hline Estimulantes do apetite (A15) & - Estimulante do apetite \\
\hline \multicolumn{2}{|c|}{ Sangue e órgãos hematopoiéticos (B) } \\
\hline Subgrupo & Resposta \\
\hline Subgrupo não identificado (B00) & $\begin{array}{l}\text { - Para derrame cerebral } \\
\text { - Para problemas de coagulação }\end{array}$ \\
\hline Agentes antitrombóticos (B01) & - Anticoagulante \\
\hline Agentes anti-hemorrágicos (B02) & $\begin{array}{l}\text { - Anti-hemorrágico } \\
\text { - Coagulante }\end{array}$ \\
\hline Preparações antianêmicas (B03) & $\begin{array}{l}\text { - Antianêmico } \\
\text { - Para anemia }\end{array}$ \\
\hline \multicolumn{2}{|c|}{ Sistema Cardiovascular $(\mathbf{C})$} \\
\hline Subgrupo & Resposta \\
\hline Subgrupo não identificado (C00) & $\begin{array}{l}\text { - Para circulação } \\
\text { - Para pressão alta (anti-hipertensivo) } \\
\text { - Para pressão arterial } \\
\text { - Para problemas cardíacos e circulatórios }\end{array}$ \\
\hline Terapia cardíaca $(\mathrm{CO1})$ & $\begin{array}{l}\text { - Para insuficiência cardiovascular } \\
\text { - Para o coração (insuficiência cardiovascular) } \\
\text { - Vasodilatador/pressão arterial }\end{array}$ \\
\hline Diuréticos (C03) & -Diurético \\
\hline Vasoprotetores (C05) & $\begin{array}{l}\text { - Para hemorroidas } \\
\text { - Para varizes } \\
\text { - Remédio para varizes }\end{array}$ \\
\hline Agentes modificadores lipídicos (C10) & $\begin{array}{l}\text { - Para colesterol } \\
\text { - Para triglicerídeo } \\
\text { - Redutor de colesterol } \\
\text { - Redutor de colesterol ou triglicerídeos } \\
\text { - Redutor de triglicerídeos }\end{array}$ \\
\hline \multicolumn{2}{|c|}{ Dermatológicos (D) } \\
\hline Subgrupo & Resposta \\
\hline $\begin{array}{l}\text { Antifúngicos de uso dermatológico } \\
\text { (D01) }\end{array}$ & $\begin{array}{l}\text { - Antimicótico } \\
\text { - Creme antimicótico } \\
\text { - Para micose (dermatológico) }\end{array}$ \\
\hline
\end{tabular}




\begin{tabular}{|c|c|}
\hline Emolientes e protetores (D02) & $\begin{array}{l}\text { - Óleo dermatológico } \\
\text { - Óleo para assadura } \\
\text { - Vaselina }\end{array}$ \\
\hline $\begin{array}{l}\text { Preparações para o tratamento de } \\
\text { feridas e úlceras (D03) }\end{array}$ & $\begin{array}{l}\text { - Cicatrizante } \\
\text { - Creme cicatrizante }\end{array}$ \\
\hline $\begin{array}{l}\text { Antibióticos e quimioterápicos para uso } \\
\text { dermatológico (D06) }\end{array}$ & - Para herpes \\
\hline Antissépticos e desinfetantes (D08) & $\begin{array}{l}\text { - Água oxigenada } \\
\text { - Álcool (para desinfecção) } \\
\text { - Álcool iodado } \\
\text { - Antisséptico } \\
\text { - Antissépticos e desinfetantes tópicos } \\
\text { - Desinfetante farmacêutico } \\
\text { - Mercúrio cromo } \\
\text { - Merthiolate }\end{array}$ \\
\hline $\begin{array}{l}\text { Outras preparações dermatológicas } \\
\text { (D11) }\end{array}$ & $\begin{array}{l}\text { - Anti-caspa } \\
\text { - Creme antialérgico } \\
\text { - Creme dermatológico } \\
\text { - Creme para assadura } \\
\text { - Creme para queimaduras } \\
\text { - Dermatológico } \\
\text { - Loção dermatológica } \\
\text { - Para assadura } \\
\text { - Para problemas de pele } \\
\text { - Remédio para cabelos (shampu e outros) } \\
\text { - Remédio para queda de cabelos (shampu, } \\
\text { creme e outros) } \\
\text { - Sabonete antialérgico } \\
\text { - Sabonete e shampu medicinal } \\
\text { - Sabonete medicinal } \\
\text { - Shampu medicinal }\end{array}$ \\
\hline \multicolumn{2}{|c|}{ Sistema geniturinário e hormônios sexuais (G) } \\
\hline Subgrupo & Resposta \\
\hline Subgrupo não identificado (G00) & $\begin{array}{l}\text { - Creme vaginal } \\
\text { - Hormônio } \\
\text { - Para problemas ginecológicos } \\
\text { - Pomada vaginal } \\
\text { - Remédio ginecológico }\end{array}$ \\
\hline $\begin{array}{l}\text { Hormônios sexuais e modeladores do } \\
\text { sistema genital (G03) }\end{array}$ & $\begin{array}{l}\text { - Adesivos intradérmicos (menopausa) } \\
\text { - Antiabortivo } \\
\text { - Anticoncepcional } \\
\text { - Fito-hormônios } \\
\text { - Para menopausa }\end{array}$ \\
\hline Urológicos (G04) & $\begin{array}{l}\text { - Estimulante sexual } \\
\text { - Para os rins } \\
\text { - Para próstata }\end{array}$ \\
\hline
\end{tabular}




\begin{tabular}{|c|c|}
\hline & $\begin{array}{l}\text { - Para próstata e vias urinárias } \\
\text { - Renal (para os rins) } \\
\text { - Urológico }\end{array}$ \\
\hline \multicolumn{2}{|c|}{ Preparações hormonais sistêmicas, exceto hormônios sexuais e insulina (H) } \\
\hline Subgrupo & Resposta \\
\hline $\begin{array}{l}\text { Corticosteroides para uso sistêmico } \\
\text { (H02) }\end{array}$ & $\begin{array}{l}\text { - Corticóide } \\
\text { - Para lúpus }\end{array}$ \\
\hline Terapia da tireóide (H03) & $\begin{array}{l}\text { - Antitireoidismo } \\
\text { - Para tireóide } \\
\text { - Para tiróide }\end{array}$ \\
\hline \multicolumn{2}{|c|}{ Anti-infecciosos de uso sistêmico (J) } \\
\hline Subgrupo & Resposta \\
\hline Antibacterianos de uso sistêmico (J01) & $\begin{array}{l}\text { - Antibacteriano } \\
\text { - Antibiótico } \\
\text { - Anti-infeccioso } \\
\text { - Anti-infeccioso e anti-inflamatório } \\
\text { - Para infecção } \\
\text { - Para infecções da boca e garganta }\end{array}$ \\
\hline Antimicóticos de uso sistêmico (J02) & - Antifúngico \\
\hline Antimicobactérias (J04) & $\begin{array}{l}\text { - Anti-hanseníase } \\
\text { - Para tuberculose }\end{array}$ \\
\hline Antivirais de uso sistêmico (J05) & $\begin{array}{l}\text { - Antivirótico } \\
\text { - Para Aids } \\
\text { - Tratamento da Aids }\end{array}$ \\
\hline \multicolumn{2}{|c|}{ Antineoplásicos e agentes imunomoduladores (L) } \\
\hline Subgrupo & Resposta \\
\hline Agentes antineoplásios (L01) & $\begin{array}{l}\text { - Antineoplásico (tratamento de câncer) } \\
\text { - Para câncer } \\
\text { - Para quimioterapia } \\
\text { - Quimioterápico }\end{array}$ \\
\hline \multicolumn{2}{|c|}{ Sistema musculoesquelético $(\mathbf{M})$} \\
\hline $\begin{array}{l}\text { Anti-inflamatórios e antirreumáticos } \\
\text { (M01) }\end{array}$ & $\begin{array}{l}\text { - Analgésico e anti-inflamatório } \\
\text { - Anti-inflamatório } \\
\text { - Anti-inflamatório e antirreumático } \\
\text { - Antirreumático } \\
\text { - Para coluna } \\
\text { - Para dores musculares } \\
\text { - Para inflamação e reumatismo (anti- } \\
\text { inflamatório e antirreumático) } \\
\text { - Para problemas musculares } \\
\text { - Para reumatismo }\end{array}$ \\
\hline Relaxantes musculares (M03) & - Relaxante muscular \\
\hline $\begin{array}{l}\text { Medicamentos para tratamento de } \\
\text { doenças ósseas (M05) }\end{array}$ & $\begin{array}{l}\text { - Anti-osteopenia } \\
\text { - Anti-osteoporose } \\
\text { - Para as articulações } \\
\text { - Para os ossos }\end{array}$ \\
\hline
\end{tabular}




\begin{tabular}{|c|c|}
\hline & $\begin{array}{l}\text { - Para os ossos e articulações } \\
\text { - Para osteoporose } \\
\text { - Vacina para osteoporose }\end{array}$ \\
\hline \multicolumn{2}{|c|}{ Sistema Nervoso (N) } \\
\hline Subgrupo & Resposta \\
\hline Subgrupo não identificado (N00) & $\begin{array}{l}\text { - Neurológico } \\
\text { - Para memória } \\
\text { - Para o sistema nervoso } \\
\text { - Para sistema nervoso }\end{array}$ \\
\hline Anestésicos (N01) & - Anestésico \\
\hline Analgésicos (N02) & $\begin{array}{l}\text { - Analgésico } \\
\text { - Analgésico e antitérmico } \\
\text { - Antitérmico } \\
\text { - Pancreático } \\
\text { - Para contusão (analgésico) } \\
\text { - Para dor e febre (analgésico e antitérmico) } \\
\text { - Para enxaqueca } \\
\text { - Para o pâncreas } \\
\text { - Sedativo (morfina) }\end{array}$ \\
\hline Antiepiléticos (N03) & $\begin{array}{l}\text { - Anticonvulsivo } \\
\text { - Antiepiléptico } \\
\text { - Antiepilético } \\
\text { - Para convulsão } \\
\text { - Para epilepsia } \\
\end{array}$ \\
\hline $\begin{array}{l}\text { Medicamentos antiparkinsonianos } \\
\text { (N04) }\end{array}$ & $\begin{array}{l}\text { - Antiparksoniano } \\
\text { - Para o Mal de Parkinson }\end{array}$ \\
\hline Psicolépticos (N05) & $\begin{array}{l}\text { - Ansiolítico } \\
\text { - Antipsicótico } \\
\text { - Calmante } \\
\text { - Para estresse } \\
\text { - Para psicose } \\
\text { - Para stress } \\
\text { - Sonífero }\end{array}$ \\
\hline Psicoanalépticos (N06) & $\begin{array}{l}\text { - Antidepressivo } \\
\text { - Para Alzheimer } \\
\text { - Para depressão (antidepressivo) }\end{array}$ \\
\hline $\begin{array}{l}\text { Outros medicamentos para o sistema } \\
\text { nervoso (N07) }\end{array}$ & $\begin{array}{l}\text { - Adesivos antitabagismo } \\
\text { - Antitabagismo } \\
\text { - Combate ao alcoolismo e tabagismo } \\
\text { - Para labirintite (anti-inflamatório) } \\
\text { - Para tontura } \\
\text { - Para tratamento do alcoolismo } \\
\text { - Para vertigem }\end{array}$ \\
\hline \multicolumn{2}{|c|}{ Antiparasitários, inseticidas e repelentes (P) } \\
\hline Subgrupo & Resposta \\
\hline Antiprotozoários (P01) & - Para Doença de Chagas \\
\hline
\end{tabular}




\begin{tabular}{|c|c|}
\hline & $\begin{array}{l}\text { - Para doenças infecciosas e endêmicas } \\
\text { - Para malária } \\
\text { - Para protozoários }\end{array}$ \\
\hline Anti-helmínticos (P02) & $\begin{array}{l}\text { - Anti-helmíntico } \\
\text { - Anti-helmíntico (vermífugo) } \\
\text { - Para vermes } \\
\text { - Para vermes (vermífugo) } \\
\text { - Vermífugo }\end{array}$ \\
\hline $\begin{array}{l}\text { Ectoparasiticidas, } \\
\text { escabicidas, inseticidas e repelentes } \\
\text { (P03) }\end{array}$ & $\begin{array}{l}\text { - Ectoparasitose (sarna, piolho, etc) } \\
\text { - Para piolho } \\
\text { - Para sarna } \\
\text { - Remédio para piolho (sabonete) } \\
\text { - Sabonete anti-piolho }\end{array}$ \\
\hline \multicolumn{2}{|c|}{ Sistema respiratório $(\mathbf{R})$} \\
\hline Subgrupo & Resposta \\
\hline Subgrupo não identificado (R00) & • Para o pulmão \\
\hline Preparações nasais (R01) & - Descongestionante nasal \\
\hline $\begin{array}{l}\text { Medicamentos para doenças } \\
\text { obstrutivas das vias respiratórias (R03) }\end{array}$ & $\begin{array}{l}\text { - Para asma e bronquite } \\
\text { - Para asma } \\
\text { - Para bronquite } \\
\text { - Para nebulização } \\
\text { - Broncodilatadores }\end{array}$ \\
\hline $\begin{array}{l}\text { Anti-histamínicos para uso sistêmico } \\
\text { (R06) }\end{array}$ & $\begin{array}{l}\text { - Antialérgico } \\
\text { - Para alergia (antialérgico) }\end{array}$ \\
\hline $\begin{array}{l}\text { Outros medicamentos para o sistema } \\
\text { respiratório }\end{array}$ & - Para sinusite (anti-inflamatório) \\
\hline \multicolumn{2}{|c|}{ Órgãos sensoriais (S) } \\
\hline Subgrupo & Resposta \\
\hline Subgrupo não identificado (S00) & $\begin{array}{l}\text { - Para problemas de boca, ouvido, nariz e } \\
\text { garganta }\end{array}$ \\
\hline Oftalmológicos (S01) & $\begin{array}{l}\text { - Para problemas oculares (oftalmológicos) } \\
\text { - Colírios } \\
\text { - Solução oftálmica (para a vista) }\end{array}$ \\
\hline Otológicos (S02) & - Otológicos \\
\hline \multicolumn{2}{|l|}{ Vários (V) } \\
\hline Subgrupo & Resposta \\
\hline Meios de contraste (V08) & - Líquido para contraste (exame) \\
\hline \multicolumn{2}{|c|}{ Tratamento Alternativo (TA) } \\
\hline Subgrupo & Resposta \\
\hline Tratamento alternativo (TA00) & $\begin{array}{l}\text { - Água medicinal } \\
\text { - Antialérgico homeopático } \\
\text { - Antigripal homeopático } \\
\text { - Calmante natural } \\
\text { - Cânfora } \\
\text { - Chá de qualquer tipo } \\
\text { - Chás e remédios alternativos }\end{array}$ \\
\hline
\end{tabular}




\begin{tabular}{|c|c|}
\hline & $\begin{array}{l}\text { - Depurador do sangue } \\
\text { - Depurador sanguíneo } \\
\text { - Depurativo do sangue } \\
\text { - Depurativo sanguíneo } \\
\text { - Descongestionante nasal homeopático } \\
\text { - Extratos de qualquer tipo } \\
\text { - Florais } \\
\text { - Garrafada de qualquer tipo } \\
\text { - Garrafada de qualquer tratamento } \\
\text { - Mel medicinal (qualquer tipo) } \\
\text { - Óleo doce (para gases) } \\
\text { - Remédio homeopático indeterminado } \\
\text { - Remédio ortomolecular } \\
\text { - Tintura de Romã }\end{array}$ \\
\hline \multicolumn{2}{|c|}{ Medicamento Indeterminado } \\
\hline Subgrupo & Resposta \\
\hline Medicamento Indeterminado (MI00) & $\begin{array}{l}\text { - Pomada indeterminada } \\
\text { - Remédio indeterminado } \\
\text { - Remédio manipulado indeterminado } \\
\text { - Injeção ampola (não determinada) }\end{array}$ \\
\hline
\end{tabular}

